DENIS MASSUCATTO DOS SANTOS

\begin{abstract}
AVALIAÇÃO DA INFLUÊNCIA DO EFEITO DE ULTRASSOM NA LIXIVIAÇÃO DE METAIS DE PLACAS DE CIRCUITO IMPRESSO OBSOLETAS
\end{abstract}

São Paulo 
DENIS MASSUCATTO DOS SANTOS

\section{AVALIAÇÃO DA INFLUÊNCIA DO EFEITO DE ULTRASSOM NA LIXIVIAÇÃO DE METAIS DE PLACAS DE CIRCUITO IMPRESSO OBSOLETAS}

Tese apresentada à Escola Politécnica da Universidade de São Paulo como requisito parcial para obtenção do título de Doutor em Ciências, Programa de Engenharia Química

São Paulo 
DENIS MASSUCATTO DOS SANTOS

\title{
AVALIAÇÃO DA INFLUÊNCIA DO EFEITO DE ULTRASSOM NA LIXIVIAÇÃO DE METAIS DE PLACAS DE CIRCUITO IMPRESSO OBSOLETAS
}

\author{
Tese apresentada à Escola Politécnica da \\ Universidade de São Paulo como \\ requisito parcial para obtenção do título \\ de Doutor em Ciências. \\ Área de Concentração: \\ Engenharia Química \\ Orientador: \\ Prof. Dr. Denise Crocce Romano \\ Espinosa
}

São Paulo 
Dedico este trabalho à minha amada mãe 


\section{AGRADECIMENTOS}

Agradeço à Prof. Dr. Denise C. R. Espinosa, pela orientação neste trabalho.

Agradeço ao Prof. Dr. Jorge A. S. Tenório, por me aceitar no Laboratório de Reciclagem, Tratamento de Resíduos e Metalurgia Extrativa.

Agradeço à Dr. Daniella C. Buzzi, pela ajuda com as análises químicas.

Agradeço ao mestrando Franco L. Ramunno, pelas discussões sobre cinética química.

Agradeço à Prof. Ticiane pelo uso do equipamento de ultrassom.

Agradeço aos colegas do LAREX: Eduardo, Victor, Flávia, Viviane, Jorge, Mônica, Tatiana, Solange, Hugo, Felipe, Carlos, Marcos, Thiago, Ariane, Luciana, Girley, Joner e Sérgio, pela companhia e pelos momentos de descontração.

Aos colegas de república, André, Juliano, Daniel e Pedro.

Agradeço aos técnicos dos laboratórios: Ana Carolina, Rubens, Danilo, Lívio e Rafael.

Agradeço aos funcionários da secretaria: Ivo, Patrícia, Vera, Cristina e Suellen.

Agradeço a minha família, pelo apoio e pela compaixão.

Agradeço à CAPES, pela bolsa de estudos concedida.

Agradeço à FAPESP, pelo auxílio regular à pesquisa, Projeto $\mathrm{n}^{\circ}$ 2011/51544-5. 


\section{RESUMO}

Os equipamentos elétricos e eletrônicos (EEE) possuem uma grande importância na sociedade contemporânea, e estão presentes no cotidiano das pessoas de forma ubíqua. Com o aumento no consumo de EEE juntamente com a obsolescência precoce, surge um novo tipo de resíduo, chamado de Resíduos de Equipamentos Elétricos e Eletrônicos (REEE). Os REEE não devem ser descartados em aterros, pelo risco de contaminação e pelo desperdício de material. Assim, a reciclagem se faz necessária. As placas de circuito impresso $(\mathrm{PCl})$ estão presentes na grande maioria do REEE e contem a maior variedade de metais, incluindo metais valiosos como $\mathrm{Au}, \mathrm{Ag}$, Pt e $\mathrm{Cu}$. A complexidade torna a reciclagem destas placas muito difícil. Rotas hidrometalúrgicas tem surgido como uma alternativa mais limpa para o tratamento de $\mathrm{PCl}$, em detrimento aos processos pirometalúrgicos. Nas rotas hidrometalúrgicas, os metais são extraídos pela lixiviação realizada por ácidos ou bases. $O$ efeito ultrassônico tem sido empregado na síntese de novas substâncias e também em alguns casos no tratamento de resíduos. O processo central no uso de ultrassom é a cavitação acústica, capaz de produzir microbolhas na solução com temperatura da ordem de $5000 \mathrm{~K}$ e pressão de $500 \mathrm{~atm}$ localmente. Além disto, a implosão das bolhas de cavitação em meio heterogêneo causa um jato de solução na superfície, que pode alcançar velocidade de $100 \mathrm{~m} \cdot \mathrm{s}^{-1}$. Assim, esta tese tem como objetivo a investigação do efeito do ultrassom sobre $\mathrm{PCl}$ obsoletas. Dois efeitos foram investigados: o efeito da cominuição das $\mathrm{PCI}$ promovido pela cavitação e a influência da cavitação na lixiviação com ácido sulfúrico de $\mathrm{Fe}$, Al e $\mathrm{Ni}$. Os parâmetros investigados na cominuição foram: tipo de placa, granulometria da placa moída e potência de ultrassom. Os parâmetros de lixiviação avaliados foram: razão sólido-líquido (S/L), concentração de ácido e potência de ultrassom. Também foram realizados ensaios de lixiviação sonicados com meio oxidante. Foi feita a análise cinética para se determinar qual é o controle da reação de lixiviação.

Palavras chave: lixiviação; ultrassom; resíduos sólidos; sucata eletrônica. 


\section{ABSTRACT}

Electric and Electronic Equipment (EEE) have a large importance on modern society, and are present in daily life in a ubiquitous manner. With the increase in consumption of EEE associated with planned obsolescence, a new type of waste arises: Waste of Electrical and electronic Equipment. WEEE shall not be disposed in landfills due to contamination risk and loss of valueable material. In this way, recycling is necessary. Printed Circuit Boards (PCB) are present in most of WEEE and contains the largest variety of metals, including the valuable ones, like $\mathrm{Au}, \mathrm{Ag}, \mathrm{Pt}$ and $\mathrm{Cu}$. Complexity of PCB makes recycling difficult. Hydrometallurgical routes have emerged as cleaner alternative for PCB treatment, instead of pyrometallurgical ones. In hydrometallurgical routes, metals are extracted by leaching performed by acids or bases. Ultrasonic effect has been employed in synthesis of new substances and also in some cases in waste treatment. Acoustic cavitation is the central phenomenon in ultrasound processing, and it is capable in producing microbubbles with temperature of $5000 \mathrm{~K}$ and pressures of $500 \mathrm{~atm}$ locally. Furthermore, bubbles imploding near a surface cause a jet streaming, and it can reach velocity of $100 \mathrm{~m} . \mathrm{s}^{-1}$. So, this thesis aims to investigate the effect of ultrasound on obsolete PCB. Two distinct effets were investigated: the effect of comminution of PCB promoted by cavitation and the influence of ultrasound in sulphuric acid leaching on metals $\mathrm{Fe}, \mathrm{Al}$ and $\mathrm{Ni}$. In comminution, the following parameters were investigated: type of board, initial particle size of boards and ultrasound power. Leaching experiments were conducted to evaluate influence of solid-liquid $(S / L)$ ratio, acid concentration and power ultrasound. Ultrasonic leaching of metals in presence of oxidizing agent was also conducted. Kinetic analysis was performed in order to determine what kind of control affects the leaching reaction.

Keywords: leaching; ultrasound; solid waste; electronic waste. 


\section{LISTA DE FIGURAS}

Figura 1. Fotografia do primeiro transístor, de 1947, que veio substituir a válvula termiônica (6).

Figura 2. Exemplo de montagem de duas PCl: em (a) Rádio Motorola VT-71, do ano de 1948, com montagem de componentes tipo ponto-a-ponto (27) e (b) Raspberry $\mathrm{Pi}$, um computador de dimensões reduzidas de 2011 (28) .....12

Figura 3. Estrutura dos agentes retardantes de chama (a) bifenila polibromada e (b) éter difenílico polibromado. Os valores de $\mathrm{x}$ e y podem variar de 1 a $5 \mathrm{em}$ ambos os casos.

Figura 4. Exemplos de PCl quanto às suas camadas: (a) dual-layer e (b) multi-layer, adaptada de (35).

Figura 5. Exemplo de componente fixado por tecnologia PTH. (34) 16

Figura 6. Diferença entre os métodos de montagem: (a) PTH e (b) SMT, adaptada de (34). 16

Figura 7. Diagrama esquemático de um moinho a martelos oscilantes, adaptada de (58). 20

Figura 8. Fotografia de um moinho tipo shredder, utilizado para cominuição mais grosseira (59).

Figura 9. Perfil de concentração do reagente $A$ em relação à partícula $B$ a ser lixiviada (adaptada de (86 p. 577)).

Figura 10. Concentração do reagente $A$ em função do raio da partícula $B$, considerando-se o controle por reação química (adaptada de (86 p. 576)).

Figura 11. Exemplo dos ciclos de compressão e descompressão sofridos por uma bolha de cavitação, causando o crescimento e a implosão com o tempo, adaptada de (91).

Figura 12. Representação esquemática da implosão da bolha, evidenciando o jato de líquido, adaptada de (91). 
Figura 13. Mecanismo de ativação por alongamento em metais alcalinos, adaptada de (3).

Figura 14. Ativação de níquel pelo desprendimento da camada de óxido, adaptada de (3).

Figura 15. Microscopia eletrônica de varredura de duas partículas de zinco, parcialmente fundidas pela colisão à alta velocidade, promovida pelo efeito do ultrassom (96).

Figura 16. Placas utilizadas nos experimentos: ML (a) e DL (b). .48

Figura 17. Fluxograma dos ensaios realizados com a placa DL. 50

Figura 18. Esquema do aparato experimental utilizado: (a) fonte de energia, (b) transdutor de ultrassom, (c) frasco encamisado de fundo cônico, (d) elevador tipo Jack para laboratório, (e) entrada de água, (f) saída de água e (g) banho termostático.

Figura 19. Esquema de ensaios realizados para averiguar a cominuição de $\mathrm{PCl}$ promovidas por ultrassom.

Figura 20. Configuração do experimento utilizando-se ácido sulfúrico em meio oxidante.

Figura 21. Placas ML previamente ao tratamento. .65

Figura 22. $\mathrm{PCl} \mathrm{DL}$ de desktop antes da cominuição (a); itens removidos manualmente (b) e $\mathrm{PCl}$ cortada em pedaços (c).

Figura 23. Distribuição granulométrica da amostra DL cominuída em grelha de $2 \mathrm{~mm}$. Percentual retido em cada peneira.

Figura 24. Material passante acumulado: ML moída em grelha de $6 \mathrm{~mm}$ em tempos distintos de exposição ao ultrassom, com potência de $700 \mathrm{~W}$.

Figura 25. Material passante acumulado: ML moída em grelha de $6 \mathrm{~mm}$ em tempos distintos de exposição ao ultrassom, com potência de 500W. 71

Figura 26. Material passante acumulado: DL moída em grelha de $6 \mathrm{~mm}$ em tempos distintos de exposição ao ultrassom, com potência de $700 \mathrm{~W}$.

Figura 27. Redução do tamanho médio de partícula: ML $6 \mathrm{~mm}$ em diferentes potências de ultrassom. 
Figura 28. Redução do tamanho médio de partícula: ML $4 \mathrm{~mm}$ em diferentes potências de ultrassom.

Figura 29. Redução do tamanho médio de partícula: ML $2 \mathrm{~mm}$ em diferentes potências de ultrassom.

Figura 30. Redução do tamanho médio de partícula: comparação de diferentes tamanhos iniciais de placa ML em potência de $700 \mathrm{~W}$. .75

Figura 31. Redução do tamanho médio de partícula: comparação de diferentes tamanhos iniciais de placa ML em potência de $500 \mathrm{~W}$. 76

Figura 32. Redução do tamanho médio de partícula: comparação de diferentes tamanhos iniciais de placa DL em potência de $700 \mathrm{~W}$. .77

Figura 33. Redução relativa do tamanho médio de partícula em função do tempo de exposição ao ultrassom. .78

Figura 34. Influência da razão S/L no ensaio silencioso, com concentração de ácido de $0,5 \mathrm{~mol} . \mathrm{L}^{-1}$ 80

Figura 35. Influência da razão $S / L$ no ensaio sonicado com 700 W, com concentração de ácido de $0,5 \mathrm{~mol} . \mathrm{L}^{-1}$

Figura 36. Influência da concentração de ácido no ensaio silencioso, com razão S/L de 1:20.

Figura 37. Influência da concentração de ácido no ensaio sonicado com potência de 700W, com razão S/L de 1:20.

Figura 38. Influência da potência de ultrassom, com razão $S / L$ de 1:20 e concentração de ácido de $0,5 \mathrm{~mol} . \mathrm{L}^{-1}$.

Figura 39. Influência da razão S/L no ensaio silencioso, com concentração de ácido de $0,1 \mathrm{~mol} \cdot \mathrm{L}^{-1}$ .85

Figura 40. Influência da razão $S / L$ no ensaio sonicado com potência de $700 \mathrm{~W}$, com concentração de ácido de $0,1 \mathrm{~mol} . \mathrm{L}^{-1}$.

Figura 41. Influência da concentração de ácido no ensaio silencioso, com razão S/L de 1:20.

Figura 42. Influência da concentração de ácido no ensaio sonicado com potência de 700W, com razão S/L de 1:20. 
Figura 43. Influência da potência de ultrassom, com razão $S / L$ de 1:20 e concentração de ácido sulfúrico de $0,5 \mathrm{~mol} \cdot \mathrm{L}^{-1}$.

Figura 44. Influência da razão $S / L$ no ensaio silencioso, com concentração de ácido de $0,5 \mathrm{~mol} . \mathrm{L}^{-1}$ .90

Figura 45. Influência da razão S/L no ensaio sonicado com potência de $700 \mathrm{~W}$, com concentração de ácido de $0,5 \mathrm{~mol} . \mathrm{L}^{-1}$.

Figura 46. Influência da concentração de ácido no ensaio silencioso, com razão S/L de 1:20.

Figura 47. Influência da concentração de ácido no ensaio sonicado com potência de $700 \mathrm{~W}$, com razão S/L de 1:20.

Figura 48. Influência da potência de ultrassom na lixiviação de níquel, com razão S/L de 1:20 e concentração de ácido de $0,5 \mathrm{~mol} . \mathrm{L}^{-1}$.

Figura 49. Extração de ferro em meio oxidante em diferentes potências de ultrassom. Condições: Razão S/L 1:40, concentração de ácido sulfúrico $0,5 \mathrm{~mol} . \mathrm{L}^{-1}$ e oxigênio borbulhado a $100 \mathrm{~mL} \cdot \mathrm{min}^{-1}$ .95

Figura 50. Extração de alumínio em meio oxidante em diferentes potências de ultrassom. Condições: Razão S/L 1:40, concentração de ácido sulfúrico $0,5 \mathrm{~mol} . \mathrm{L}^{-1}$ e oxigênio borbulhado a $100 \mathrm{~mL} \cdot \mathrm{min}^{-1}$ .96

Figura 51. Extração de níquel em meio oxidante em diferentes potências de ultrassom. Condições: Razão S/L 1:40, concentração de ácido sulfúrico $0,5 \mathrm{~mol} . \mathrm{L}^{-1}$ e oxigênio borbulhado a $100 \mathrm{~mL} \cdot \mathrm{min}^{-1}$

Figura 52. Extração de ferro com ácido sulfúrico e ácido sulfúrico em meio oxidante, no ensaio silencioso. Condições: concentração de ácido: $0,5 \mathrm{~mol} \cdot \mathrm{L}^{-1} \mathrm{e}$ razão S/L 1:40. 98

Figura 53. Extração de alumínio com ácido sulfúrico e ácido sulfúrico em meio oxidante, no ensaio silencioso. Condições: concentração de ácido: 0,5 mol.L $L^{-1}$ e razão S/L 1:40. 99

Figura 54. Extração de níquel com ácido sulfúrico e ácido sulfúrico em meio oxidante, no ensaio silencioso. Condições: concentração de ácido: 0,5 mol. $L^{-1}$ e razão $S / L$ 1:40. 
Figura 55. Extração de cobre com ácido sulfúrico e ácido sulfúrico em meio oxidante, no ensaio silencioso. Condições: concentração de ácido: $0,5 \mathrm{~mol} . \mathrm{L}^{-1} \mathrm{e}$ razão S/L 1:40.

Figura 56. Ajuste da lixiviação por controle por difusão do ensaio silencioso e sonicado com potência de $700 \mathrm{~W}$. 103

Figura 57. Ajuste da lixiviação por controle por reação química do ensaio silencioso e sonicado com potência de $700 \mathrm{~W}$. 104

Figura 58. Fração reagida de ferro em função do tempo reduzido para o ensaio silencioso na ausência de oxidante e com razão S/L 1:40 e concentração de ácido 0,5 mol. $\mathrm{L}^{-1}$ 105

Figura 59. Fração reagida de ferro em função do tempo reduzido para o ensaio sonicado com potência de $700 \mathrm{~W}$ (na ausência de oxidante) e com razão $\mathrm{S} / \mathrm{L}$ 1:40 e concentração de ácido $0,5 \mathrm{~mol} . \mathrm{L}^{-1}$. 106

Figura 60. Fração reagida de ferro em função do tempo reduzido para o ensaio silencioso na presença de oxidante e com razão S/L 1:40 e concentração de ácido $0,5 \mathrm{~mol} \cdot \mathrm{L}^{-1}$. 107

Figura 61. Fração reagida de níquel em função do tempo reduzido para o ensaio silencioso na presença de oxidante e com razão S/L 1:40 e concentração de ácido $0,5 \mathrm{~mol} \cdot \mathrm{L}^{-1}$. 108

Figura 62. Fração reagida de cobre em função do tempo reduzido para o ensaio silencioso na presença de oxidante e com razão S/L 1:40 e concentração de ácido $0,5 \mathrm{~mol} \cdot \mathrm{L}^{-1}$. 109

Figura 63. Aplicação do método do tempo reduzido adotando-se $X^{*}=0,5$ 110

Figura 64. Aplicação do método do tempo reduzido adotando-se $X^{*}=0,15$ 110 


\section{LISTA DE TABELAS}

Tabela 1. Evolução da venda de computadores e celulares no Brasil (em mil

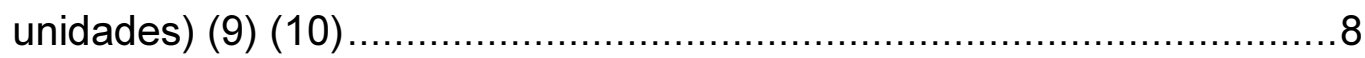

Tabela 2. Categorias de placas mais usadas (adaptada de (29)) .........................13

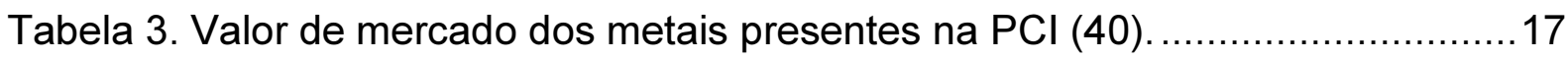

Tabela 4. Composição dos metais mais significativos presentes em placas de circuito impresso, (valores expressos em percentual em massa). ...................18

Tabela 5. Revisão dos métodos de separação mecânica de REEE. ………............22

Tabela 6. Sumário dos métodos de recuperação de metais por lixiviação.................27

Tabela 7. Escala de dureza de alguns metais e seus respectivos óxidos (adaptada de (3)).

Tabela 8. Relação de peneiras utilizadas na caracterização da distribuição granulométrica das amostras DL...................................................51

Tabela 9. Conjuntos de peneiras utilizadas para as diferentes amostras no ensaio granulométrico.

Tabela 10. Relação de amostras de placa ML analisadas nas diferentes potências de ultrassom

56

Tabela 11. Condições utilizadas para investigação da influência dos parâmetros na lixiviação, para os ensaios silencioso e sonicado a 700W.

Tabela 12. Condições utilizadas para investigação da influência dos parâmetros na lixiviação.

Tabela 13. Balanço de massa da cominuição em moinho de martelos da amostra $\mathrm{ML}$.

Tabela 14. Balanço de massa da etapa de cominuição em moinho de martelos......68

Tabela 15. Resultados da caracterização das placas DL........................................69

Tabela 16. Distribuição granulométrica da amostra DL........................................69

Tabela 17. Percentual de cominuição de $\mathrm{PCl}$ em ultrassom com potência de $700 \mathrm{~W}$ em 4 horas, em função do tipo de placa: DL e ML. 


\section{LISTA DE ABREVIATURAS E SIGLAS}

\begin{tabular}{ll} 
BMO & $\begin{array}{l}\text { Base Metals Operation } \\
\text { Cedir-USP }\end{array}$ \\
Centro de Descarte e Reuso de Resíduos de Informática da \\
Universidade de São Paulo \\
EEE & Dual-layer \\
EPA & Envipamento Elétrico e Eletrônico \\
FR & Flame Retardant (retardante de chama) \\
ITO & Indium tin oxide (óxido de índio e estanho) \\
LCD & Liquid Crystal Display (tela de cristal líquido) \\
LED & Light Emitting Diode \\
LME & London Market Exchange \\
ML & Multi-layer \\
PCI & Placa de Circuito Impresso \\
PMO & Precious Metal Operation \\
PNRS & Política Nacional de Resíduos Sólidos \\
PTH & Pin-through hole \\
REEE & Resíduo de Equipamento Elétrico e Eletrônico Ambiental) \\
RoHS & Restriction of Certain Hazardous Substances \\
SMT & Tecnologia de Montagem Superficial \\
SPLP & Synthetic precipitation leaching procedure \\
TCLP & Toxicity characteristic leaching procedure \\
UE & União Européia \\
WEEE & Waste of Electric and Electronic Equipment \\
\hline
\end{tabular}


Sumário

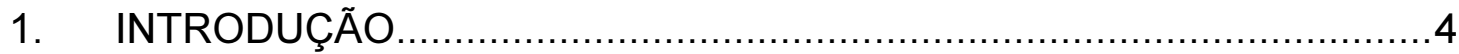

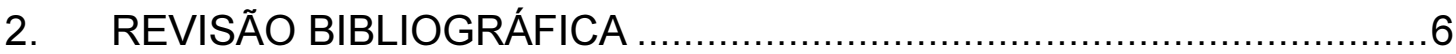

2.1. Equipamentos elétricos e eletrônicos .......................................6

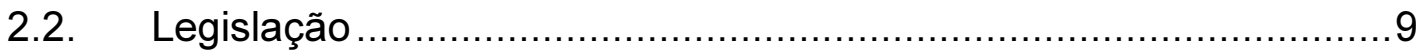

2.3. Composição ................................................................. 10

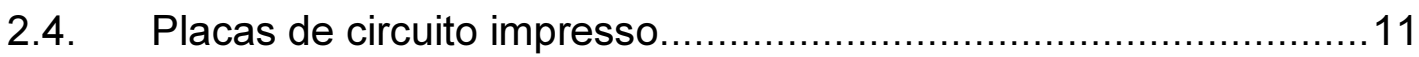

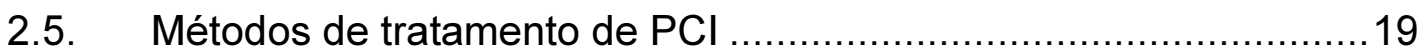

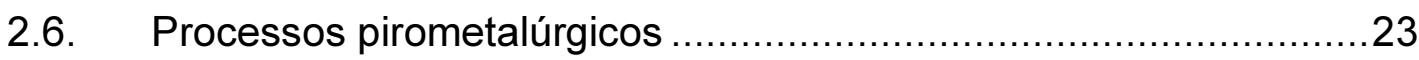

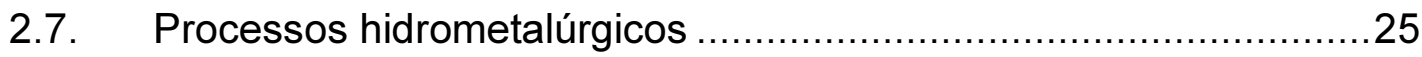

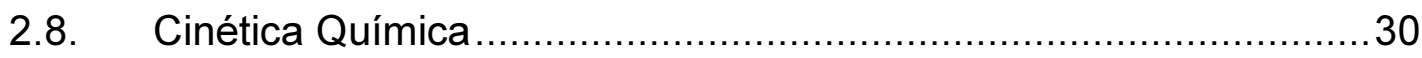

2.8.1. Reação controlada por difusão ........................................ 32

2.8.2. Controle por reação química ........................................... 35

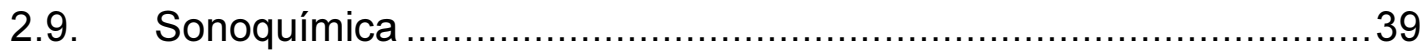

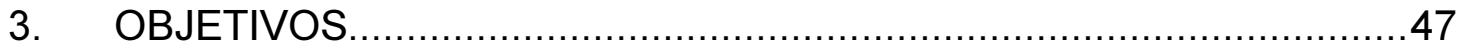

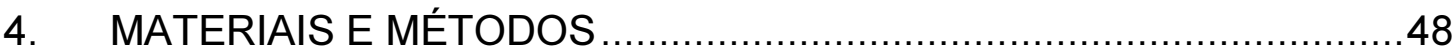

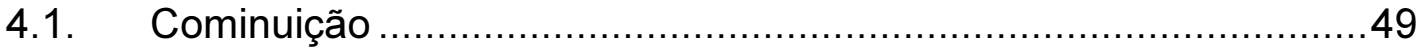

4.2. Caracterização de PCI DL....................................................49

4.2.1. Distribuição Granulométrica ..............................................50

4.2.2. Caracterização de metais - digestão em água régia ...................51

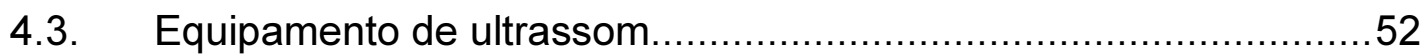

4.4. Cominuição promovida por ultrassom ................................. 53

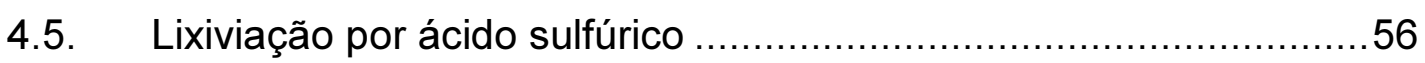

4.6. Ensaio de lixiviação com meio oxidante...................................59

4.7. Comparação entre lixiviação com ácido sulfúrico na ausência e presença de meio oxidante 


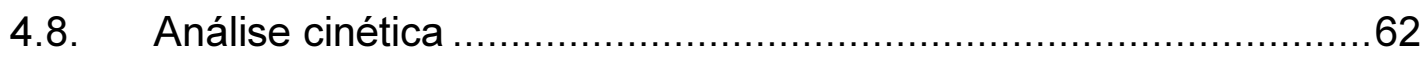

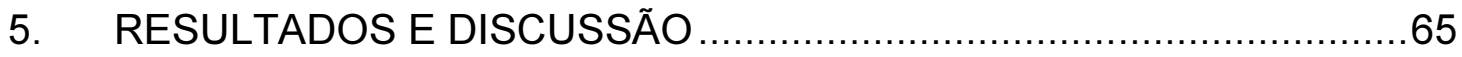

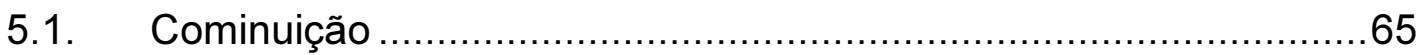

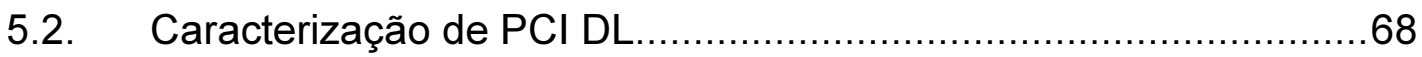

5.3. Cominuição promovida por ultrassom ..................................70

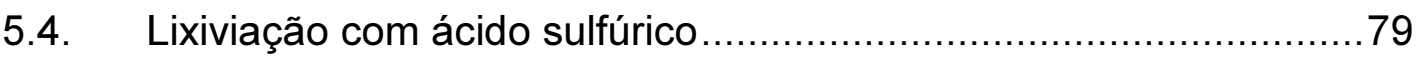

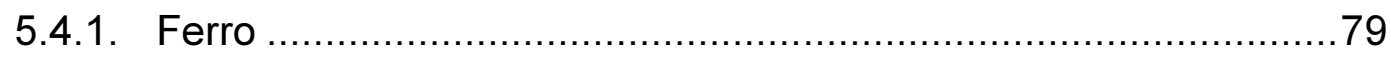

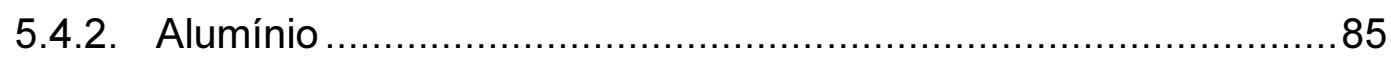

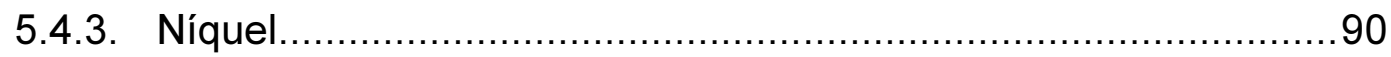

5.5. Lixiviação por ácido sulfúrico com meio oxidante .......................94

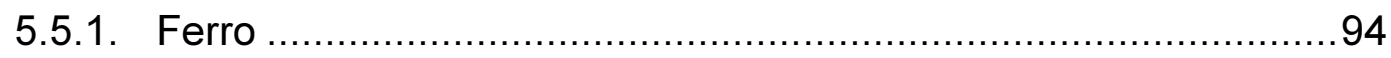

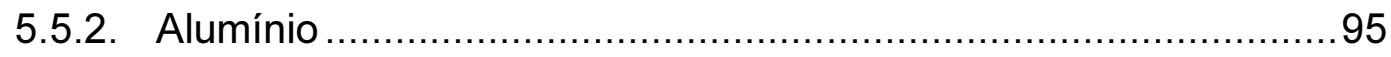

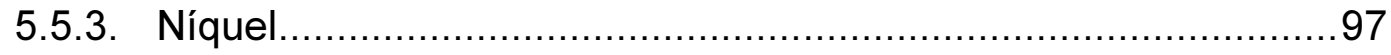

5.6. Comparação entre lixiviação com ácido sulfúrico na ausência e

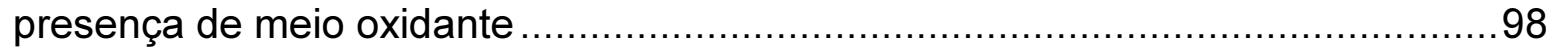

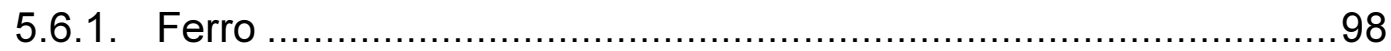

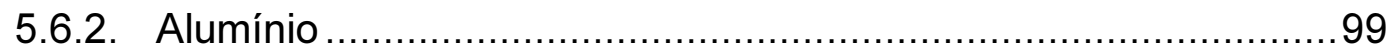

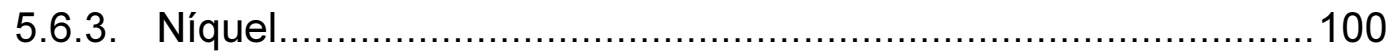

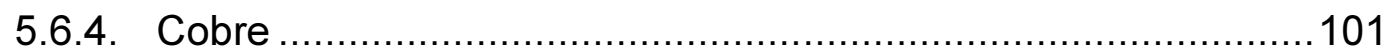

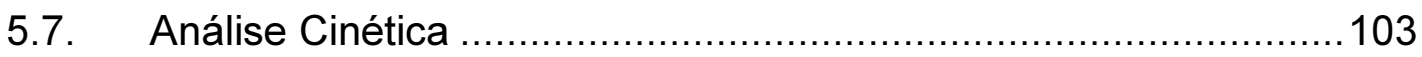

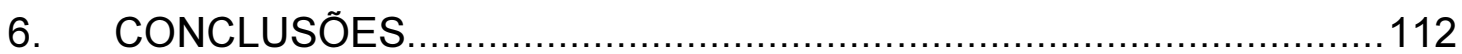

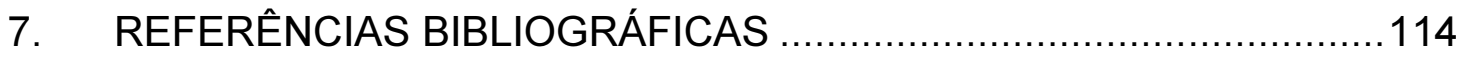




\section{INTRODUÇÃO}

Os equipamentos elétricos e eletrônicos (EEE) possuem uma grande importância na sociedade contemporânea, e estão presentes no cotidiano das pessoas de forma ubíqua. A popularização dos EEE se deu pela produção em massa, o que permitiu redução nos custos de produção, e também o aumento do poder aquisitivo da população. O lançamento de novas funcionalidades e tecnologias causa a redução do tempo de vida do equipamento, que se torna obsoleto mesmo estando em funcionamento. Desta forma, a inovação, que é a força motriz do crescimento das vendas, acaba por ser o vilão para o meio ambiente, pois encurta o tempo de vida dos equipamentos, formando uma nova classe de resíduos, denominada de Resíduos de Equipamentos Elétricos e Eletrônicos (REEE).

O acúmulo destes equipamentos obsoletos traz um problema ambiental, uma vez que o seu descarte não deve ocorrer de forma tradicional, i.e. em aterros, dada sua a composição incluir substâncias potencialmente tóxicas ao homem e ao meio ambiente (1).

As placas de circuito impresso (PCl) são elementos presentes em quase todos os EEE, pois são nelas que são fixados os componentes eletrônicos. $E$ são nas PCls que se concentram os maiores percentuais de metais nobres $(\mathrm{Ag}, \mathrm{Au}, \mathrm{Pt}$, Pd). Assim, a reciclagem destas placas é mandatória para um processo de reciclagem de REEE, tanto pelo ponto de vista ambiental, a fim de não se descartar substâncias poluentes no meio ambiente, quanto pela óptica econômica, uma vez que metais como cobre e ouro fazem parte da composição da placa. Assim, a recuperação de metais deve estar no escopo da reciclagem de $\mathrm{PCl}(2)$.

A recuperação de metais a partir de $\mathrm{PCl}$ se faz por meio das técnicas de metalurgia, por rotas pirometalúrgicas ou hidrometalúrgicas. Métodos pirometalúrgicos são aqueles que utilizam fornos a temperaturas elevadas (acima de $600^{\circ} \mathrm{C}$ ) e são utilizados quando se possui grande oferta de materiais, uma vez que os fornos, por questões econômicas, raramente são desligados (1). 
Já as rotas hidrometalúrgicas caracterizam-se por processos nos quais são empregados soluções aquosas do agente de lixívia, que podem ser ácidos, bases ou sais, e podem ser empregados com temperatura e pressão acima da ambiente. Os equipamentos utilizados nos processos hidrometalúrgicos são, em geral, mais versáteis que aqueles dos processos pirometalúrgicos, uma vez que basta se trocar o agente de lixiviação para se atingir outro metal alvo (1).

O processo de cavitação acústica, promovido por radiação ultrassônica em meios líquidos tem ganhado, recentemente, destaque no processamento de materiais, uma vez que o fenômeno é capaz de alterar caminhos de reação e formar produtos impossíveis por métodos convencionais (i.e. agitação mecânica ou aumento de temperatura ou pressão). A cavitação também pode aumentar a velocidade de reações heterogêneas, graças ao colapso assimétrico da bolha de cavitação próximo a uma superfície. Este evento pode remover impurezas na superfície e aumentar sua reatividade (3).

Esta tese tem como objetivo a investigação do comportamento de $\mathrm{PCl}$ na presença de ultrassom durante o processamento hidrometalúrgico. Para tal, foram utilizados dois sistemas: o primeiro corresponde à cominuição das placas dispersas em água na presença de cavitação acústica. Foram investigadas três granulometrias diferentes de placas, sendo realizada a análise granulometria das placas antes e após a exposição ao ultrassom. No segundo sistema, foi estudada a lixiviação dos metais presentes na $\mathrm{PCl}$ por ácido sulfúrico na presença de ultrassom, e foram investigadas a concentração de ácido, razão sólido-líquido e potência do equipamento de ultrassom. Este sistema foi avaliado também na presença de meio oxidante, sendo utilizado para tal gás oxigênio borbulhado no meio reacional. 


\section{REVISÃO BIBLIOGRÁFICA}

\subsection{EQUIPAMENTOS ELÉTRICOS E ELETRÔNICOS}

Desde a primeira utilização em massa da eletricidade, em meados de 1880 (4), para iluminação pública, já se notava que seus benefícios seriam, entre outros, o conforto para a humanidade. Telégrafo, rádio, refrigerador, televisão, lavadora de roupas, condicionador de ar são exemplos de aparelhos, movidos à eletricidade, que foram inventados para facilitar o cotidiano do homem e reduzir o tempo e o esforço de tarefas antes realizadas manualmente. A revolução eletrônica iniciou-se na década 1950 com a substituição da válvula termiônica pelo transístor, este último por sua vez menor, mais rápido e com maior vida útil. Essa invenção rendeu o prêmio Nobel de Física do ano de 1956 (5). Assim, além da miniaturização de equipamentos, permitiu-se a criação de novos, capazes de realizar novas tarefas. A esse conjunto de aparelhos, alimentados por energia elétrica, transistorizados ou não, que visam o conforto, se dá o nome de Equipamentos Elétricos e Eletrônicos (EEE). Na Figura 1 (6) têm-se o primeiro transístor, inventado em 1947.

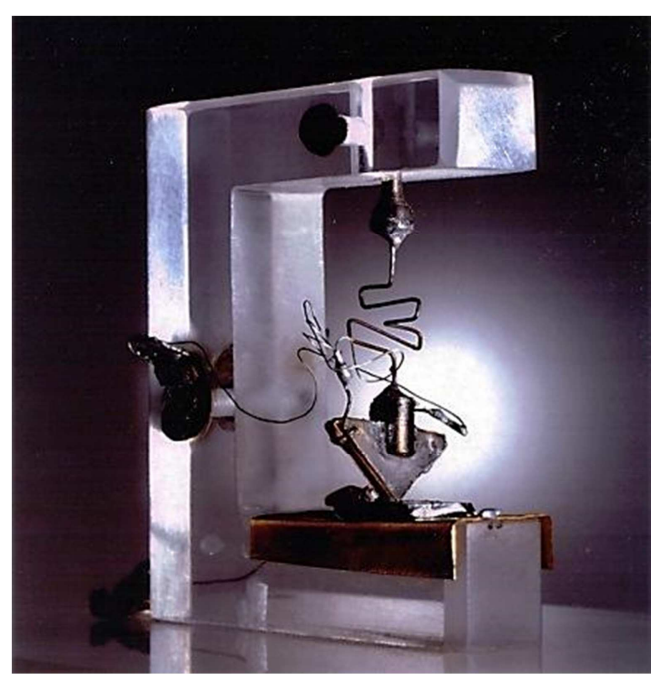

Figura 1. Fotografia do primeiro transístor, de 1947, que veio substituir a válvula termiônica (6).

O desenvolvimento de novos materiais ao longo de décadas vem permitindo a miniaturização dos componentes eletrônicos e consequentemente de seus 
aparelhos, agregando novas funcionalidades e serviços. Atualmente, esse desenvolvimento se dá de forma tão repentina que o proprietário prefere a substituição do EEE antes do mesmo atingir o final de sua vida útil. Ou, quando ocorre defeito ou quebra de algum EEE, prefere-se substituir o equipamento, dado o elevado custo do reparo frente ao valor do EEE novo. A soma destes fatores vem causando, nas últimas décadas, um acúmulo EEE danificados e obsoletos, os quais recebem o nome de Sucata Eletrônica, ou Resíduo de Equipamentos Elétricos e Eletrônicos (REEE).

A sucata eletrônica é o componente do resíduo sólido urbano que possui o maior índice de crescimento (7) e é gerada tanto por consumidores domésticos quanto por empresas. As empresas realizam a substituição de seus computadores com uma maior frequência, devido à alta taxa de amortização (8).

Na Tabela 1 (9) (10), têm-se a evolução de vendas de computadores e celulares no Brasil de 2007 a 2013. A tendência que se observa é que novas tecnologias, como tablets e smartphones, mostram um crescimento acentuado, enquanto os desktops e celulares tradicionais apresentam queda nas vendas. Assim, em 2013, os tablets passam a representar $36 \%$ do mercado de computadores pessoais e os smartphones $52 \%$ do mercado de celulares. 
Tabela 1. Evolução da venda de computadores e celulares no Brasil (em mil unidades) (9) (10)

\begin{tabular}{c|ccc|cc}
\hline \multirow{2}{*}{ Ano } & \multicolumn{3}{|c|}{ Computadores } & \multicolumn{2}{c}{ Celulares } \\
& Desktops & Notebooks & Tablets & Tradicionais & Smartphones \\
\hline $\mathbf{2 0 0 7}$ & 8.071 & 1.912 & & & \\
$\mathbf{2 0 0 8}$ & 7.700 & 4.300 & & & \\
$\mathbf{2 0 0 9}$ & 6.850 & 5.150 & & & \\
$\mathbf{2 0 1 0}$ & 6.850 & 7.150 & & & \\
$\mathbf{2 0 1 1}$ & 6.275 & 9.025 & 1.140 & 58.011 & 8.999 \\
$\mathbf{2 0 1 2}$ & 6.582 & 8.932 & 3.267 & 43.493 & 16.010 \\
$\mathbf{2 0 1 3}$ & 5.715 & 8.251 & 7.910 & 29.083 & 31.978 \\
$\mathbf{2 0 1 4}$ & 4.672 & 8.461 & 10.795 & 16.230 & 51.456 \\
\hline
\end{tabular}

Estima-se que os desktops e notebooks possuam um tempo de vida médio de 5 e 4 anos respectivamente (7), o que indica um rápido acúmulo destes equipamentos quando obsoletos.

O incremento no número de domicílios que possuem celulares e computadores no Brasil foi de $424 \%$ para o primeiro e $172 \%$ para o segundo no período de 2001 a 2008 (11). A produção mundial de PCls aumentou em média $8,7 \%$ nos últimos anos (12), e a tendência é continuar crescendo.

Além dos equipamentos que chegaram ao fim de sua vida útil, existem os equipamentos que se quebram antes disso, e muitas vezes seu conserto fica inviável, pois o preço do conserto pode chegar a custar o mesmo valor de um equipamento novo. Isso ocorre porque há o benefício fiscal do Programa de Inclusão Digital (13), que reduz a alíquota dos impostos sobre computadores, notebooks, tablets e smartphones novos, enquanto que suas peças de reposição possuem taxação normal. Além disso, existe a rápida obsolescência causada pelo avanço tecnológico na área de materiais e manufatura, responsável pela miniaturização dos componentes e aumento de sua capacidade, sendo este mais um fator a ser considerado pelo consumidor ao decidir entre consertar ou comprar um novo equipamento eletrônico. 


\subsection{LEGISLAÇÃO}

Em 2002, a União Européia (UE) sancionou duas diretrizes que tratam dos resíduos de equipamentos elétricos e eletrônicos. A diretiva 2002/95/EC RoHS (Restriction of Certain Hazardous Substances) trata da restrição do uso de substâncias perigosas como chumbo, cromo hexavalente, cádmio, mercúrio, bifenilas polibromadas e éteres de bifenilas polibromadas. Esta diretiva também é conhecida como Diretiva lead-free, pois estabelece a substituição da solda $\mathrm{Sn}-\mathrm{Pb}$, comumente utilizada nos equipamentos elétricos e eletrônicos, por solda livre de chumbo. A diretiva 2002/96/EC WEEE (Waste of Electric and Electronic Equipment) tem como objetivo (14):

[...] a prevenção de resíduos de equipamentos eléctricos e electrônicos (REEE) e, adicionalmente, a reutilização, reciclagem e outras formas de valorização desses resíduos, de modo a reduzir a quantidade de resíduos a eliminar. Pretende igualmente melhorar o comportamento ambiental de todos os operadores envolvidos no ciclo de vida dos equipamentos eléctricos e electrónicos, por exemplo produtores, distribuidores e consumidores, e, em especial, dos operadores diretamente envolvidos no tratamento de REEE.

Revisão da Diretiva Européia WEEE, a Diretiva 2008/34/EC, elevou a meta de coleta de REEE para 45\% dos EEE colocados no mercado em 2013 e para $65 \%$ em cada estado membro da UE em 2016 (15).

No âmbito nacional, foi sancionada em agosto de 2010 a Lei $n^{0} 12.305$, Política Nacional de Resíduos Sólidos (PNRS), que dispõe (16):

[...] sobre seus princípios, objetivos e instrumentos, bem como sobre as diretrizes relativas à gestão integrada e ao gerenciamento de resíduos sólidos, incluídos os perigosos, às responsabilidades dos geradores e do poder público e aos instrumentos econômicos aplicáveis.

Esta lei deve alterar o modo como são tratados os resíduos sólidos, principalmente no tocante à logística reversa, obrigando produtores e distribuidores 
a realizarem a coleta de equipamentos obsoletos e dar outra disposição final ao resíduo que não seja o aterro sanitário, encaminhando-o para reciclagem ou para descontaminação (16).

A falta de uma política que regulamente o descarte de resíduos sólidos faz com que este seja disposto em aterros ou lixões. Este ato permite que elementos nocivos à saúde humana possam contaminar o meio ambiente (17) (18) e permite também o desperdício de matéria prima de origem secundária (19) (20). A reciclagem traz uma economia de energia e uma redução nas emissões de gases do efeito estufa quando comparada à produção a partir de fontes primárias (21).

No estado de São Paulo, o Decreto N 57.817 de 28 de fevereiro de 2012 (22) instituiu o Programa Estadual de Implementação de Projetos de Resíduos Sólidos, que visa a elaboração do Plano Estadual de Resíduos Sólidos e o apoio à gestão municipal de resíduos sólidos e às atividades de reciclagem, coleta seletiva e melhoria da destinação final de resíduos sólidos.

Assim, nota-se uma convergência, juntamente com a PNRS, das ações futuras para se evitar a disposição em aterros e aumentar a taxa de reciclagem, pois esta última gera empregos, poupa energia e recursos naturais.

\subsection{COMPOSIÇÃO}

A composição do REEE é variada e é alterada ao longo do tempo, devido à disponibilidade dos materiais e às mudanças nos métodos produtivos - a fim de se economizar materiais - e da incorporação de novas tecnologias e funcionalidades (1). No entanto, a manufatura de EEE envolve geralmente metais e polímeros em seu chassi, que confere um espaço para afixar os demais componentes e garante uma estrutura rígida com resistência mecânica (23).

O propósito do equipamento está diretamente relacionado com sua composição. Assim, geladeiras possuem fibra de vidro e aço, o primeiro para o isolamento térmico e o último confere a forma e acabamento de seu chassi externo. Já os monitores de LCD (Liquid Crystal Display) e LED (Light Emitting Diode) 
possuem índio em sua composição, encontrado principalmente no óxido de estanho e índio (ITO - indium tin oxide), pelas suas propriedades óptica e elétrica, i.e. transparente e condutor de eletricidade (24). As placas de circuito impresso (PCls) estão presentes de forma ubíqua nos equipamentos elétricos e eletrônicos (25).

\subsection{PLACAS DE CIRCUITO IMPRESSO}

A função das placas de circuito impresso (PCI) nos EEE é conectar eletricamente os distintos componentes eletrônicos, bem como fornecer o suporte mecânico para os mesmos (26). Como o nome em inglês sugere (printed wiring board - placa de fiação impressa, em tradução livre) a $\mathrm{PCl}$ é composta por trilhas de cobre impressas sobre um compósito de polímero reforçado por fibras. Este tipo de montagem de componentes garantiu que os componentes pudessem ser interconectados eletricamente de um modo mais compacto, permitindo a miniaturização dos equipamentos. Na Figura 2 (27) (28), é possível visualizar a diferença entre um tipo de construção ponto-a-ponto, no qual cada componente é unido eletricamente a outro pelos seus terminais (a) e um tipo de construção mais moderno, com os componentes adicionados à placa através de tecnologia SMT (Tecnologia de Montagem Superficial) (b). O primeiro representa um rádio da Motorola datado de 1948, enquanto o segundo é um computador, o Raspberry Pi, que possui as mesmas funcionalidades de um desktop mas com dimensões reduzidas. 


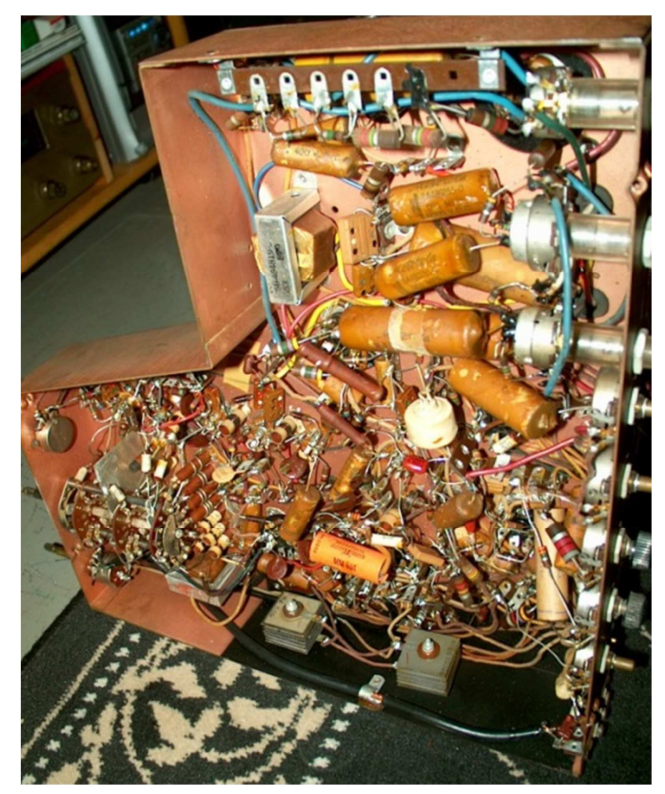

(a)

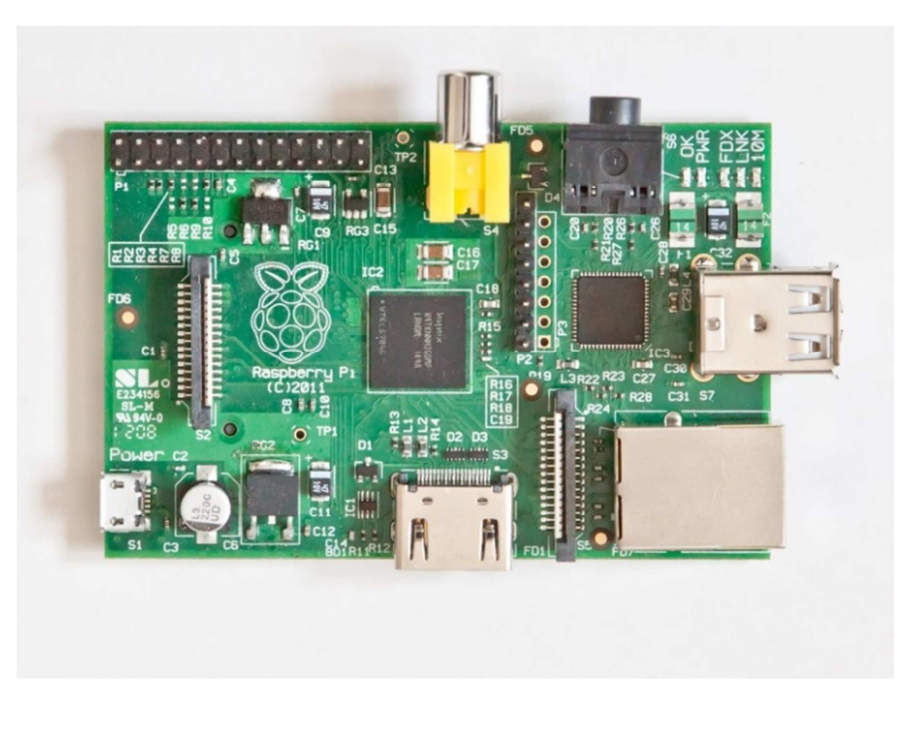

(b)

Figura 2. Exemplo de montagem de duas PCl: em (a) Rádio Motorola VT-71, do ano de 1948, com montagem de componentes tipo ponto-a-ponto (27) e (b) Raspberry $\mathrm{Pi}$, um computador de dimensões reduzidas de 2011 (28)

Quanto à composição das $\mathrm{PCl}$, os materiais para construção da placa podem ser divididos em três classes: resina, reforço e condutor. As resinas comumente utilizadas para se formar o compósito são do tipo fenólica ou epóxi. Como reforço, podem ser empregados: papel de algodão ou tecido de vidro. Ainda, a resina pode possuir ou não agentes de retardância a chama. Um resumo das categorias de placas pode ser visto na Tabela 2, adaptada de (29). 
Tabela 2. Categorias de placas mais usadas (adaptada de (29)).

\begin{tabular}{llll}
\hline Categoria & Resina & \multicolumn{1}{c}{ Reforço } & Agente retardante de chama \\
\hline FR-2 & Fenólica & Papel de Algodão & Sim \\
FR-3 & Epóxi & Papel de Algodão & Sim \\
FR-4 & Epóxi & Tecido de fibra de vidro & Sim \\
CEM-1 & Epóxi & Papel de Algodão & Sim \\
CEM-2 & Epóxi & Papel de Algodão & Não \\
CEM-3 & Epóxi & Papel de Algodão & Sim \\
\hline
\end{tabular}

A categoria mais utilizada é a FR-4, que consiste em tecido de fibra de vidro reforçado por resina epóxi. O termo FR é uma sigla para flame retardant (retardante de chama), o que indica a presença deste componente na fabricação da placa. As propriedades desta construção de placa a tornam mais utilizada, pois suas propriedades elétrica, mecânica e térmica permitem sua utilização em diversas aplicações, como computação pessoal, servidores, telecomunicações, controle industrial e aplicações automotivas (29).

Quanto aos retardantes de chama, existem mais de 175 tipos destes, sendo mais de $27 \%$ correspondentes a compostos orgânicos halogenados (30). Estes agentes são utilizados tanto na placa de circuito quanto nos polímeros que compõe a carcaça dos EEE (31). A Diretiva Europeia RoHS restringe o uso das classes de compostos chamadas de bifenilas polibromadas e éteres difenílicos polibromados, cujas estruturas podem ser vistas na Figura 3. A restrição é devido ao fato de que ao serem incinerados, estes compostos geram dioxinas e furanos (32). 


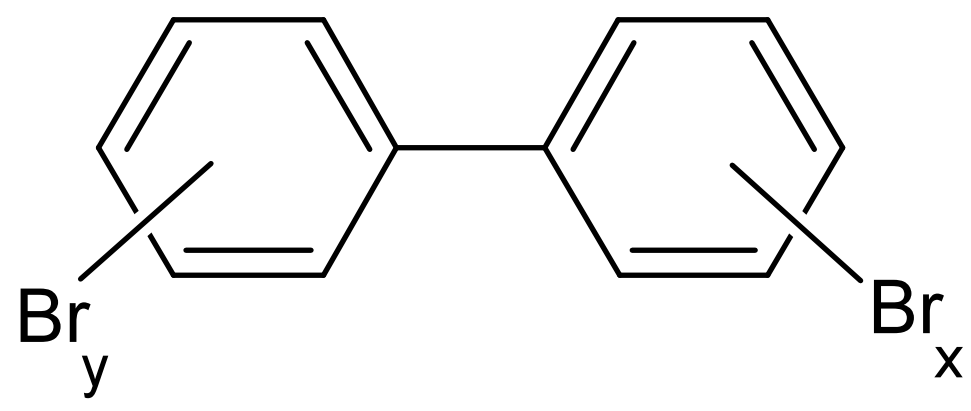

(a)

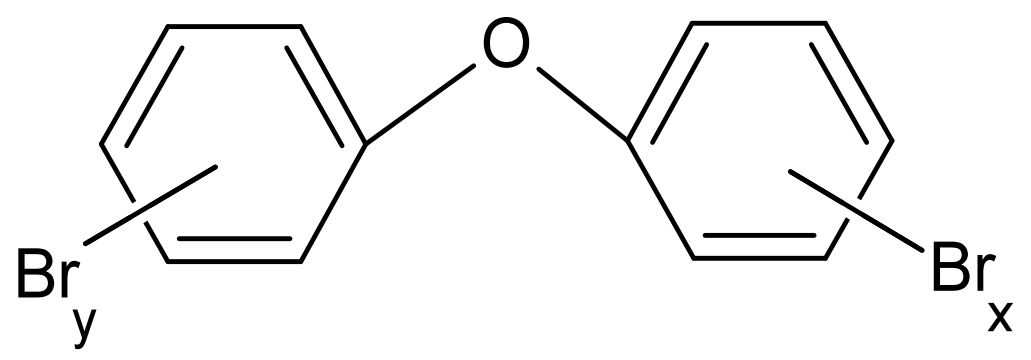

(b)

Figura 3. Estrutura dos agentes retardantes de chama (a) bifenila polibromada e (b) éter difenílico polibromado. Os valores de $\mathrm{x}$ e y podem variar de 1 a $5 \mathrm{em}$ ambos os casos.

As placas são também classificadas quanto ao número de camadas de trilhas de cobre que possuem, podendo ser single-layer, dual-layer e multi-layer, correspondendo a uma, duas ou múltiplas camadas, respectivamente (33). A utilização de múltiplas camadas torna a fabricação da placa mais cara do que as que usam uma ou duas camadas; porém ela se faz necessária para conseguir suprir a demanda por mais conexões elétricas devido ao aumento da densidade de componentes sobre a placa (34). A diferença estrutural entre placas dual-layer e multi-layer pode ser vista na Figura 4 (35). 

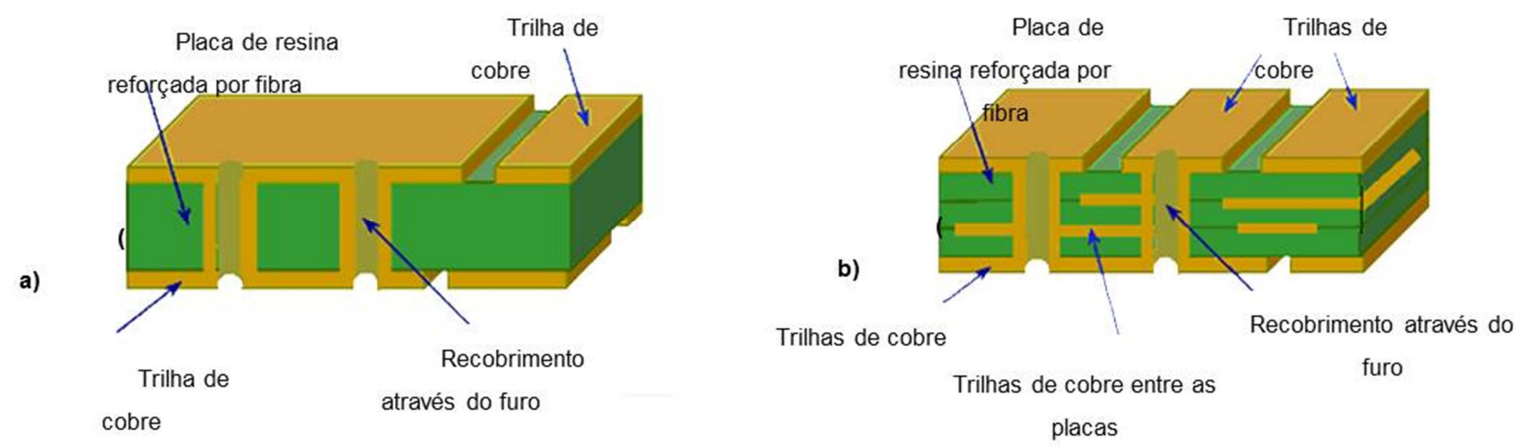

Figura 4. Exemplos de $\mathrm{PCl}$ quanto às suas camadas: (a) dual-layer e (b) multi-layer, adaptada de (35).

O contato elétrico é feito através de trilhas de cobre, que são produzidas num processo no qual a placa de polímero reforçada por fibra é recoberta primeiramente por uma fina folha de cobre. Faz-se, então, uma máscara com substrato para proteger as vias de contato entre os terminais da placa e os componentes. A placa é submetida a um banho de lixívia que remove por corrosão o cobre não protegido (23).

Após confecção da placa, os componentes são montados sobre a mesma. Os processos mais comuns são: pin-through hole (PTH) e surface-mount technology (SMT). O método PTH requer que a placa seja furada, uma vez que o componente é fixado pelos seus terminais, que atravessam a placa e são fixados por solda, realizada num processo de soldagem em fluxo. Na Figura 5 (34), pode-se ver uma representação esquemática de um resistor fixado por tecnologia PTH. Este método de fixação de componente foi um dos primeiros a ser utilizado devido a sua praticidade. No entanto, com o adensamento dos componentes e das conexões entre eles, este método foi preterido em lugar da tecnologia SMT, que permite que componentes sejam fixados em ambos os lados da placa, diferentemente dos componentes PTH. Dentre os problemas desta técnica, pode ser citado o problema que a furação da placa acarreta, como a ondulação na placa causado pelo aquecimento excessivo causado pela ferramenta (34). 


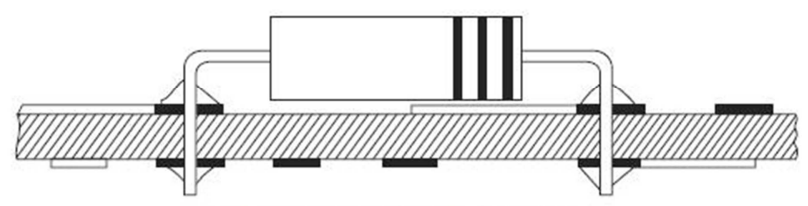

Figura 5. Exemplo de componente fixado por tecnologia PTH. (34)

No outro método, o SMT, os componentes são fixados na superfície da placa por seus pontos de solda. Assim, inicialmente a pasta de solda é colocada sobre a superfície da placa e em seguida o componente é colocado sobre a solda e finalmente ocorre sua refusão em forno para fixação definitiva do componente. $O$ processo que adiciona os componentes é automatizado, sendo a máquina capaz de adicionar de 10.000 a 40.000 deles por hora (36). A Figura 6, adaptada de (34), mostra os dois tipos de montagem. Nota-se, pela figura, que o método SMT permite fixação dos componentes em ambos os lados da placa.
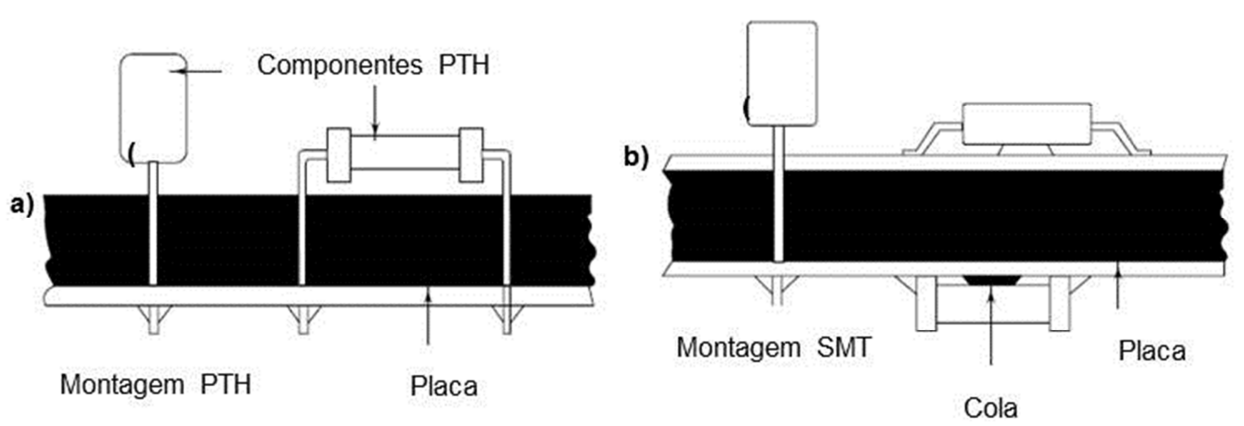

Figura 6. Diferença entre os métodos de montagem: (a) PTH e (b) SMT, adaptada de (34).

Após a fixação dos componentes, as placas passam por um rigoroso processo de inspeção, visual e elétrica, e só assim são encaminhadas à distribuição (37).

As $\mathrm{PCl}$ possuem complexidade em sua composição, uma vez que estão presentes diversos componentes eletrônicos, como resistores, capacitores, diodos, transístores, transformadores de tensão, solenoides, relês e circuitos 
integrados (38). As PCls representam a fração de maior valor agregado na sucata eletrônica (39), pois possuem $\mathrm{Cu}, \mathrm{Fe}, \mathrm{Ni}, \mathrm{Sn}, \mathrm{Al}$ e metais nobres. Estes últimos apresentam-se em quantidades da ordem de partes por milhão, mas seu valor comercial faz com que sejam priorizados na recuperação para que esta seja economicamente viável. Na Tabela 3 (40), têm-se os valores de mercado dos metais, obtidos do London Market Exchange (LME). Nota-se que os metais mais valiosos são a platina e o ouro.

Tabela 3. Valor de mercado dos metais presentes na PCI (40).

\begin{tabular}{cc}
\hline Metal & Preço (US\$/kg) \\
\hline $\mathrm{Pt}$ & $41.086,82$ \\
$\mathrm{Au}$ & $36.160,77$ \\
$\mathrm{Ag}$ & 558,52 \\
$\mathrm{Sn}$ & 20,22 \\
$\mathrm{Ni}$ & 16,66 \\
$\mathrm{Cu}$ & 6,67 \\
$\mathrm{Zn}$ & 2,33 \\
$\mathrm{Al}$ & 1,92 \\
$\mathrm{Fe}$ & 0,70 \\
\hline
\end{tabular}

A Tabela 4 (41) apresenta valores de composição dos metais nas PCls obtidos da literatura. Pode-se notar que não há homogeneidade nos dados, uma vez que os materiais utilizados na manufatura das placas dependem do processo produtivo, da patente, da localização geográfica e da disponibilidade dos materiais (42). 
Tabela 4. Composição dos metais mais significativos presentes em placas de circuito impresso, (valores expressos em percentual em massa).

\begin{tabular}{cccccccccc}
\hline Metal & $\mathbf{( 4 3 )}$ & $\mathbf{( 4 4 )}$ & $\mathbf{( 4 5 )}$ & $\mathbf{( 4 6 )}$ & $\mathbf{( 4 7 )}$ & $\mathbf{( 4 8 )}$ & $\mathbf{( 4 1 )}$ & $\mathbf{( 4 9 )}$ & $\mathbf{( 5 0 )}$ \\
\hline $\mathbf{A l}$ & 2 & 4,7 & 7 & - & - & 4,78 & 1,33 & 4,01 & 1,33 \\
$\mathbf{C u}$ & 20 & 26,5 & 10 & 15,6 & 22 & 17,85 & 23,47 & 19,19 & 18,5 \\
$\mathbf{F e}$ & 8 & 5,3 & - & 1,4 & 3,6 & 2,0 & 1,22 & 1,13 & 2,05 \\
$\mathbf{N i}$ & 2 & 0,47 & 0,85 & 0,28 & 0,32 & 1,63 & 2,35 & 0,165 & 0,43 \\
$\mathbf{P b}$ & 2 & - & 1,2 & 1,35 & 1,55 & 4,19 & 0,99 & 0,385 & 2,66 \\
$\mathbf{S b}$ & 0,4 & 0,06 & - & - & - & - & - & 0,370 & - \\
$\mathbf{S n}$ & 4 & 1,0 & - & 3,24 & 2,6 & 5,28 & 1,54 & 0,689 & 4,91 \\
$\mathbf{Z n}$ & 1 & 1,5 & 1,6 & 0,16 & - & 2,17 & 1,51 & 0,840 & - \\
$\mathbf{A g}(\mathbf{p p m})$ & 2000 & 3300 & 110 & 1240 & - & 1300 & 3301 & 704,31 & 694 \\
$\mathbf{A u}(\mathbf{p p m})$ & 1000 & 80 & 280 & 420 & 350 & 350 & 570 & 130,25 & 86 \\
$\mathbf{P d}(\mathbf{p p m})$ & 50 & - & - & 10 & - & 250 & 294 & 27,59 & 97 \\
$\mathbf{P t}$ (ppm) & - & - & - & - & - & 4,6 & 30 & - & - \\
\hline
\end{tabular}

A Diretiva Europeia 2002/95/EC limita o uso de componentes nocivos em equipamentos elétricos e eletrônicos. Dentre estas substâncias, inclui-se o chumbo, presente principalmente nas soldas das placas de circuito impresso, na forma de liga $\mathrm{Sn}-37 \mathrm{~Pb}$. Como substitutos desta solda, foram desenvolvidas ligas binárias de $\mathrm{Sn}$ empregando $\mathrm{Ag}, \mathrm{Cu}, \mathrm{In}, \mathrm{Bi}, \mathrm{Sb}$ ou $\mathrm{Zn}$, e algumas ligas ternárias e quaternárias (51) (52).

Há um estudo (53) que utiliza o teste padrão da US-EPA (US-Environmental Protection Agency, na tradução livre Agência de Proteção Ambiental) para avaliar a toxicidade de 4 tipos de solda lead-free, juntamente com a solda $63 \mathrm{Sn} / 37 \mathrm{~Pb}$. As soldas avaliadas continham a seguinte composição:

\footnotetext{
- 99,3Sn/0,7Cu

- 95,5Sn/4Ag/0,5 Cu

- $96 \mathrm{Sn} / 2,5 \mathrm{Ag} / 1 \mathrm{Bi} / 0,5 \mathrm{Cu}$

- 42Sn/1Ag/57Bi
} 
O primeiro teste, chamado de toxicity characteristic leaching procedure (TCLP), determina se o resíduo é perigoso, para isso realiza-se a lixiviação com solução tampão de ácido acético, com pH aproximadamente 5 por 18 horas. $\mathrm{O}$ segundo teste, chamado synthetic precipitation leaching procedure (SPLP), utiliza uma solução contendo mistura de ácidos nítrico e sulfúrico, com pH aproximadamente 4,2 , por 18 horas. Dentre as amostras analisadas, a solda $63 \mathrm{Sn} / 37 \mathrm{~Pb}$ apresentou maior concentração de chumbo no liquor lixiviado, o que caracteriza o resíduo que a contém como perigoso por aquela agência. As outras soldas apresentaram teores de lixiviação de prata dentro do padrão limite (53).

Há uma recomendação da Associação Internacional de Placas de Circuito Impresso de que sejam utilizadas ligas $\mathrm{Sn}-3 \mathrm{Ag}-0,5 \mathrm{Cu}$, também chamada de SAC305, pois suas propriedades mecânicas cumprem os quesitos de manufatura e confiabilidade (51) além de seus componentes possuírem uma maior disponibilidade, em comparação ao índio e bismuto (20).

No Brasil, as iniciativas de reciclagem de sucata eletrônica que existem se restringem à comercialização das carcaças plásticas e metálicas e da exportação das PCls. Em 2009, a Universidade de São Paulo inaugurou o Centro de Descarte e Reuso de Resíduos de Informática (Cedir-USP), cujo objetivo é receber os equipamentos obsoletos da Universidade, de seus docentes, alunos e funcionários, para que sejam reutilizados ou descartados sem agressão ao meio ambiente (54).

\subsection{MÉTODOS DE TRATAMENTO DE PCI}

As $\mathrm{PCls}$ constituem um tipo de resíduo relativamente novo e por isso não possuem um mecanismo consolidado de coleta e de tratamento no Brasil. Pode-se exemplificar dois tipos distintos de resíduos que já possuem coleta estabelecida: as baterias automotivas do tipo chumbo-ácido e as latas de alumínio. Na primeira, as baterias obsoletas são retidas na oficina e encaminhadas para reciclagem, constituindo assim um ciclo fechado, com os elementos necessários para sua reciclagem - i.e. logística reversa, tratamento e recuperação. Isso garante o fornecimento de chumbo ao país, uma vez que não há fontes primárias de chumbo 
disponíveis no Brasil (55). Na segunda, as latas de alumínio são coletadas por catadores informais, que, pela facilidade de se obtê-las e pelo valor de mercado atraente $(\sim R \$ 3,00 / \mathrm{kg}$ de lata), faz com que seu ciclo de vida seja de cerca de 30 dias (56).

$\mathrm{Na}$ reciclagem de REEE, inicialmente é realizada uma etapa de pré-tratamento, sendo efetuado o desmonte do EEE com a separação de fios, cabos, conectores, PCls, carcaças, telas, parafusos e arrebites, ventoinhas, pilhas e baterias, i.e. todas as peças que são removíveis por chave de fenda ou descoladas.

O processamento de $\mathrm{PCl}$ inicia-se por operações unitárias de tratamento de minérios. Assim, a primeira etapa consiste na cominuição das placas, para que haja a liberação e a redução de tamanho. Os equipamentos comumente utilizados nesta etapa são trituradores do tipo shredder e/ou moinhos de martelos. O primeiro consiste em rotores de baixa velocidade e alto torque, que reduzem a amostra pelo corte das facas posicionadas ao longo dos rotores. O segundo utiliza-se da força de cisalhamento causado pelo impacto dos martelos no material e pela bigorna (57).

$\mathrm{Na}$ Figura 7, adaptada de (58), é possível se observar um diagrama esquemático de um moinho de martelos oscilantes.

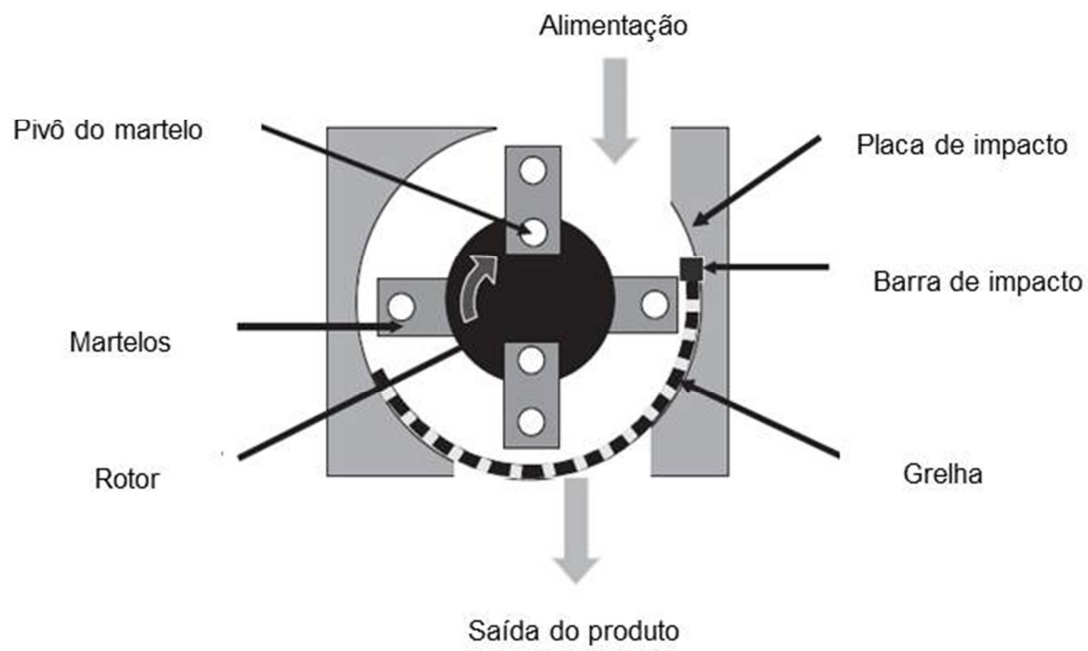

Figura 7. Diagrama esquemático de um moinho a martelos oscilantes, adaptada de (58). 
Na Figura 8 (59), têm-se uma fotografia de um moinho tipo shredder, utilizado para cominuição mais grosseira.

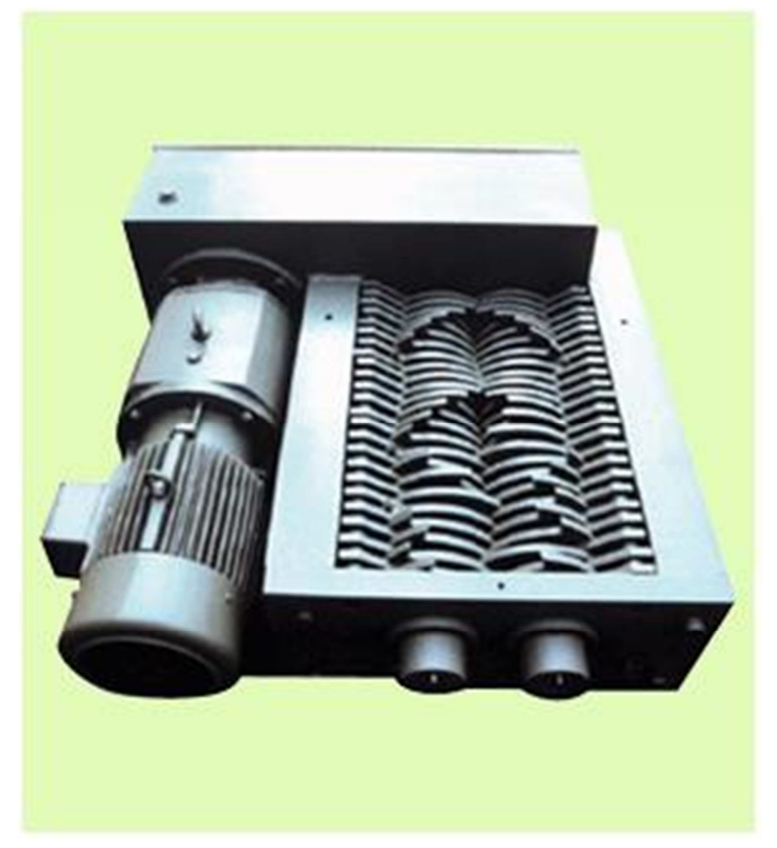

Figura 8. Fotografia de um moinho tipo shredder, utilizado para cominuição mais grosseira (59).

Esta etapa busca a liberação do material, permitindo a exposição do metal, principalmente aquele que está associado às peças plásticas e cerâmicas, e.g. cobre nas placas multi-layers que compõe as trilhas internas da placa. São empregados processos diversos de junção de materiais, utilizando-se solda, cola, adesivo, arrebite, recobrimento, formação de ligas, que realizam conexões pontuais ou superficiais (60). Desta forma, o impacto do moinho de martelos não garante a separação destes materiais, restando, na maioria das vezes, pelo menos dois materiais distintos em um fragmento contíguo.

A cominuição também facilita o carregamento de material nos reatores. $O$ grau de cominuição depende do processo ulterior: para processos térmicos, uma granulação grosseira é suficiente, dada que a força motriz do processo (energia térmica) se dá por propagação de calor. Os processos hidrometalúrgicos, por sua vez, requerem uma granulação fina, pois a eficiência da reação depende do contato do agente lixiviante com a superfície do metal (61). 
É inevitável a formação de finos ao se cominuir as PCls, portanto deve-se proteger os funcionários utilizando-se coletores de poeira e filtros manga, para evitar a aspiração de finos (17).

Após a cominuição, o material pode ser encaminhado para a separação mecânica, que se dá pelas diferentes propriedades físicas, intrínsecas e distintas, apresentadas pelos materiais. Assim, gravidade específica, condutividade elétrica, suscetibilidade magnética são exploradas nos processos de separação (61).

Uma breve revisão dos métodos de separação mecânica pode ser encontrada na Tabela 5. A separação mecânica, apesar de ser preferível pelo menor custo, muitas vezes acumula perdas de metais preciosos, e.g. uma fração de Au pode ser arrastado pelo $\mathrm{Fe}$ em uma separação magnética (62), ocorrendo então a perda de metal nobre, que já se encontra em pequenas quantidades na $\mathrm{PCl}$ (vide Tabela 4).

Tabela 5. Revisão dos métodos de separação mecânica de REEE.

\begin{tabular}{|c|c|c|c|c|}
\hline Ref. & Material & Preparação & Separação & Resultados \\
\hline (45) & $\begin{array}{l}-45 \mathrm{~kg} \mathrm{PC} \text { e } \mathrm{PCl} \\
\text { de diferentes } \\
\text { fontes }\end{array}$ & Não houve & $\begin{array}{l}\text { - Quantificação } \\
\text { do formato }\end{array}$ & $\begin{array}{l}\text { - Há influencia no formato da } \\
\text { partícula sobre o grau de } \\
\text { separação }\end{array}$ \\
\hline$(63)$ & $\begin{array}{l}-45 \mathrm{~kg} \mathrm{PC} \mathrm{e} \mathrm{PCl} \\
\text { de diferentes } \\
\text { fontes }\end{array}$ & $\begin{array}{l}\text { - Moinho de } \\
\text { martelos }(10 \mathrm{~mm}) \\
\text { - Grau de } \\
\text { liberação }\end{array}$ & $\begin{array}{l}\text { - Separação por } \\
\text { corrente } \\
\text { parasita } \\
\text { - Separação por } \\
\text { formato da } \\
\text { partícula }\end{array}$ & $\begin{array}{l}\text { - Completa liberação em } \\
\text { partículas < } 3 \text { mm } \\
\text { - "Separação liberação" deve } \\
\text { favorecer formação de } \\
\text { partículas no formato de folha } \\
\text { para maximizar a deflecção } \\
\text { - Concentração de Cu e Au na } \\
\text { fração }-1,0+0,6 \mathrm{~mm} \text { e Ag nos } \\
\text { finos }\end{array}$ \\
\hline (64) & $\begin{array}{l}-3 \mathrm{~kg} \text { de } \mathrm{PCl} \\
\text { inteiras } \\
-4 \mathrm{~kg} \text { de } \\
\text { componentes }\end{array}$ & $\begin{array}{l}\text { - Moinho de facas } \\
(1 \mathrm{~mm}) \\
\text { - Separação } \\
\text { granulométrica } \\
1,00 ; 0,50 \text { e } 0,25 \\
\text { mm e } \\
\text { Caracterização } \\
\text { química }\end{array}$ & $\begin{array}{l}\text { - Separação } \\
\text { magnética } \\
\text { - Separação } \\
\text { eletrostática }\end{array}$ & $\begin{array}{l}\text { - Dada pequena \% de } \mathrm{Fe} \text {, a } \\
\text { separação magn. não teve } \\
\text { eficiência } \\
\text { - Separação eletrostática } \\
\text { concentrou } 50 \% \text { de } \mathrm{Cu}, 25 \% \\
\text { de } \mathrm{Sn} \text { e } 8 \% \text { de } \mathrm{Pb}\end{array}$ \\
\hline (65) & $\begin{array}{l}100 \mathrm{~kg} \mathrm{PCI} \text { de } \\
\text { diferentes fontes }\end{array}$ & $\begin{array}{l}\text { - Placas cortadas } \\
\text { em } 1,5 \mathrm{~cm} \\
\text { - Cominuição } \\
\text { moinho de bolas, } \\
\text { retirando-se finos } \\
\text { para evitar } \\
\text { ultrafinos }\end{array}$ & $\begin{array}{l}\text { - Separação por } \\
\text { densidade } \\
\text { - Flotação } \\
\text { - Separação } \\
\text { eletrostática }\end{array}$ & $\begin{array}{l}\text { - A combinação de processos } \\
\text { por via seca e úmida permitiu } \\
\text { um incremento na } \\
\text { recuperação total }\end{array}$ \\
\hline
\end{tabular}


Realizado o pré-processamento, o material moído é encaminhado para o processamento de fato. As técnicas principais de tratamento distinguem-se em processos pirometalúrgicos e rotas hidrometalúrgicos.

\subsection{PROCESSOS PIROMETALÚRGICOS}

Um processo pirometalúrgico consiste na utilização de fornos com temperaturas comumente acima de $600^{\circ} \mathrm{C}$. Neste tratamento, ocorre a fusão dos metais, a queima da fração polimérica e os óxidos formam a escória (1). Durante a queima da fração polimérica, ocorre sua separação juntamente com o aproveitamento de seu poder calorífico. Contudo, os agentes retardantes de chama presentes nas PCls auxiliam a conversão de resinas epóxi e fenólica em furanos e dioxinas (66), além de liberar ácido bromídrico gasoso (67), o que eleva o custo de operação, dado o controle dos efluentes gasosos exigido pelos órgãos ambientais.

O tratamento de REEE por rotas pirometalúrgicas é realizado de forma tradicional na Europa (1). Sua operação é realizada em larga escala, o que demanda um volume de PCls maior em relação a métodos de tratamento que segue por rotas hidrometalúrgicas. Como exemplo de usinas de recuperação de metais de REEE empregando-se rotas pirometalúrgicas, pode-se citar:

- Processo Noranda: situado na cidade de Quebec, Canadá, utiliza banho metálico fundido a $1250^{\circ} \mathrm{C}$ agitado por uma mistura de ar enriquecido a $39 \%$ de oxigênio. Assim, ferro, chumbo e zinco são convertidos em seus respectivos óxidos e segregam-se do banho para a escória. Esta é então transferida, resfriada e encaminhada para a recuperação antes da disposição final. O concentrado de cobre é levado aos conversores para remoção de impurezas, onde atinge um teor de cobre de $99,1 \%$, sendo a impureza restante principalmente constituída de metais preciosos, como ouro, prata, platina e paládio. O cobre é então fundido na forma de ânodos, que são encaminhados para o refino eletrolítico, atingindo-se pureza maior que $99,9 \%(1)(68)$. 
- Boliden Ltd. Rönnskär Smelter: localizado na Suécia, possui uma planta cuja sucata pode ser adicionada em distintas etapas do processo de refino, de acordo com sua pureza. Sucata contendo alto teor de cobre é encaminhada direto para o conversor. Já a sucata de baixo teor de cobre segue para o Kaldo Furnace, que é alimentado por uma lança de óleo e oxigênio. $O$ forno possui um reator pós-queima, a $1200^{\circ} \mathrm{C}$ e também um sistema de trocadores de calor para aproveitar a energia térmica (1). Este forno produz uma liga de cobre que segue para refino e recuperação de cobre, prata, ouro, paládio, níquel, selênio e zinco, sendo os finos do processo, que contém chumbo, antimônio, índio e cádmio, encaminhados para outra planta para recuperação dos metais. Com um recente investimento de 1,3 bilhões de coroas suecas ( US\$ 200 milhões), houve uma expansão da capacidade para 120.000 toneladas métricas de REEE anuais, tornando-se a maior recicladora deste setor (69).

- Umicore: com planta situada em Hoboken, na Bélgica, possui foco na recuperação de ouro, prata, platina, paládio, ródio, irídio, rutênio, selênio, telúrio, índio, antimônio, estanho, arsênio, bismuto, cobre, chumbo e níquel. Seus resíduos vêm de REEE, lama anódica, mates e drosses. A planta está dividida em Precious Metal Operation (PMO) e Base Metals Operation (BMO). Na primeira, o material é alimentado em um forno de fundição, com a adição de ar enriquecido de oxigênio e coque, sendo este último substituído em partes pelo polímero contido no material de alimentação. Os metais preciosos são coletados pelo cobre e a maioria dos outros metais migra para a escória, majoritariamente de chumbo. A escória segue para o refino na BMO. O cobre, juntamente com os metais nobres contidos nele, segue para lixiviação e eletrorrefino e a lama anódica resultante segue para o refino dos metais preciosos, sendo utilizados cupelação e um processo próprio para a recuperação dos metais nobres (62).

No processamento por rota pirometalúrgica, ocorre a formação de escória e é inevitável que se perca uma fração de metais preciosos, que entram em equilíbrio com a mesma (1). 
Apesar de bem estabelecida, estudos sobre pirólise de $\mathrm{PCl}$ ainda são conduzidos. Hao e colaboradores (70) reportam a co-pirólise contendo diferentes misturas de $\mathrm{PCl}$ e pó de carvão e concluem que em mistura de $40 \%$ de carvão em $\mathrm{PCI}$ não há desprendimento de gases contendo bromo, provavelmente devido à sua incorporação no resíduo.

Os resíduos da pirólise de $\mathrm{PCl}$ foram analisados por Quan e colaboradores (71). Os autores reportam que foram utilizadas placas despopuladas, i.e. sem seus componentes, em um forno com temperatura de $700^{\circ} \mathrm{C}$. Os resíduos sólido, líquido e gasoso foram calculados em 76,8\%, 17,8\% e 5,4\% respectivamente. A fração líquida foi analisada por espectroscopia na região do infravermelho e ressonância magnética nuclear, na qual a maioria dos compostos encontrados eram fenóis substituídos, sendo sugerida sua utilização como combustível ou como matéria-prima química. Os autores reportam também a reciclagem das fibras de carbono através da remoção das cinzas, provenientes do processo anterior, por queima controlada (71).

A maioria dos processos de reciclagem de REEE por rota pirometalúrgica demanda um processo de refino posterior, comumente sendo empregada uma técnica hidrometalúrgica.

\subsection{PROCESSOS HIDROMETALÚRGICOS}

Uma técnica hidrometalúrgica é aquela que utiliza para a extração dos metais de interesse soluções aquosas de bases, ácidos ou sais. As rotas hidrometalúrgicas possuem algumas vantagens frente às pirometalúrgicas, apresentando-se mais exatas, mais preditivas e mais facilmente controláveis (72), além da possibilidade de operação em escala menor. Este último fator se mostra relevante quando se considera a situação atual do REEE no Brasil, especificamente no tocante à logística reversa, uma vez que ainda não há obrigatoriedade do fabricante em recolher seus produtos, sendo a ação de coleta a cargo de recicladores informais, cujo montante coletado possui sua limitação. 
A etapa de lixiviação é a etapa na qual o agente de lixívia oxida o metal de interesse, tornando-o cátion solubilizado. Como agente de lixiviação pode-se utilizar ácidos (sulfúrico, nítrico, clorídrico e também suas misturas, como água régia ou sulfonítrica), bases (hidróxido de sódio ou de amônio) ou sais (tiouréia ou tiossulfato). Um sumário das técnicas reportadas na literatura pode ser visto na Tabela 6 (19) (73) (8) (74) (75) (76). 
Tabela 6. Sumário dos métodos de recuperação de metais por lixiviação.

\begin{tabular}{|c|c|c|c|c|}
\hline Referência & Materiais & Metal Alvo & Agente de lixívia $^{1}$ & Informações Adicionais \\
\hline \multirow{3}{*}{ (19) } & - Resíduo de joalheria & - Ouro & - $\mathrm{HNO}_{3} /$ Água Régia & $\mathrm{N} / \mathrm{A}$ \\
\hline & - Cinzas de combustível de asfalto & - Vanádio & $-\mathrm{NaOH}$ & $N / A$ \\
\hline & - Água Residual de Eletrodeposição & - Cromo & - Eletrooxidação & $\mathrm{N} / \mathrm{A}$ \\
\hline (73) & Resíduo de minério de prata & - Prata & $-\mathrm{H}_{2} \mathrm{SO}_{4}+$ Tiouréia $+\mathrm{O}_{2}$ & $\begin{array}{l}\text { - Planejamento Fatorial } \\
\text { - Ultrassom }\end{array}$ \\
\hline (8) & PCls & $\begin{array}{l}\text { - Cobre } \\
\text { - Estanho }\end{array}$ & $-\mathrm{HCl}$ & - Pirólise seguida de lixiviação \\
\hline (74) & Lodo proveniente da produção de $\mathrm{PCl}$ & - Cobre & $-\mathrm{H}_{2} \mathrm{SO}_{4}+\mathrm{H}_{2} \mathrm{O}_{2}$ & - Ultrassom \\
\hline (75) & PCls & $\begin{array}{l}\text { - Cobre } \\
\text { - Zinco } \\
\text { - Estanho } \\
\text { - Chumbo }\end{array}$ & $-\mathrm{Cl}_{2}$ & - Formação de $\mathrm{Cl}_{2}$ por eletrólise \\
\hline (76) & $\mathrm{PCl}$ de celulares & $\begin{array}{l}\text { - Ouro } \\
\text { - Prata }\end{array}$ & - Tiouréia $+\mathrm{H}_{2} \mathrm{SO}_{4}$ & $\begin{array}{l}\text { - Recuperação dos metais pela adsorção em } \\
\text { gel de tanino de caqui. }\end{array}$ \\
\hline
\end{tabular}

1 "l" indica duas etapas sequenciais; enquanto que "+" indica o emprego simultâneo. 
Lee e colaboradores (77) reportaram a lixiviação de circuitos integrados obsoletos. Como pré-tratamento, foi realizada a queima dos circuitos para facilitar a liberação, uma vez que os componentes estão selados dentro de uma estrutura polimérica, seguida de moagem em moinho de bolas. Foi realizada, então, a separação granulométrica, sendo encontrados metais ferrosos na fração maior que 50 mesh $(0,368 \mathrm{~mm})$, os quais foram separado com o auxílio de um imã. O material restante acima de 20 mesh $(1,04 \mathrm{~mm})$ era formado por peças metálicas liberadas, e foi encaminhado para fusão em forno a $1300^{\circ} \mathrm{C}$. $\mathrm{O}$ restante do material foi submetido a lixiviação com diferentes agentes - e.g. água régia, amônia aquosa, ácido sulfúrico e tiouréia - para remoção de ouro, prata e cobre, sendo o melhor resultado a lixiviação com água régia, com remoção de $100 \%$ de ouro e cobre e $88 \%$ de prata. Porém, os autores preferiram utilizar a lixiviação com tiouréia devido aos problemas associados com a contaminação. A remoção neste caso foi de $100 \%$ para $\mathrm{Ag}$ e Cu e de $69 \%$ para $\mathrm{Au}$. Assim, para se remover completamente $\circ \mathrm{Au}$, novos experimentos foram realizados, sendo que os parâmetros encontrados foram

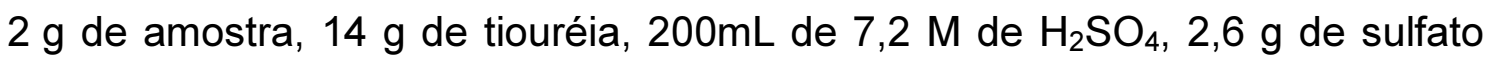
férrico em temperatura ambiente por 7 horas.

Koyama e colaboradores (78) reportaram um processo para recuperação de cobre de $\mathrm{PCl}$ a partir da lixiviação utilizando-se solução amoniacal de $\mathrm{Cu}^{2+}$ em meio alcalino. Foi proposto um sistema no qual $\mathrm{Cu}$ (II) foi utilizado como agente lixiviante do cobre metálico, formando $\mathrm{Cu}(\mathrm{l})$. Esta forma do íon é instável em solução e é facilmente oxidada por oxigênio, assim, foi utilizada uma solução de amônia, cujo complexo com $\mathrm{Cu}(\mathrm{l})$ é estável e os experimentos foram realizados em atmosfera de nitrogênio. As vantagens deste processo são: seletividade, pois $\mathrm{Fe}$ e Al não são lixiviados; consumo de energia no eletrorrefino posterior é menor, uma vez que o potencial aplicado é cerca de 4 vezes menor que o eletrorrefino convencional e agente oxidante $(\mathrm{Cu}(\mathrm{II}))$ é recuperado durante o refino, na reação anódica. A lixiviação de cobre em $10 \mathrm{~g}$ de $\mathrm{PCl}$ cominuída em tamanho médio de $1,5 \mathrm{~mm}$, utilizando $0,3 \mathrm{~mol} \cdot \mathrm{L}^{-1}$ de $\mathrm{CuSO}_{4}, 5$ mol.L-1 de $\mathrm{NH}_{3}$ e 1 mol.L-1 $\left(\mathrm{NH}_{4}\right)_{2} \mathrm{SO}_{4}$, durante 2,5 horas foi de $93 \%$.

A lixiviação de níquel depositado sobre alumina de catalisador exaurido com ácido sulfúrico foi investigado por Abdel-Aal e Rashad (79). Utilizando a 
fração menor que $74 \mathrm{~mm}$ e maior que $53 \mathrm{~mm}$, com ácido sulfúrico $50 \%$, com razão sólido-líquido $1: 20 \mathrm{~g} \cdot \mathrm{mL}^{-1}$ a $85{ }^{\circ} \mathrm{C}$, por 150 minutos, foi extraído $94 \%$ do níquel presente. Os autores reportam que o mecanismo pelo qual a reação procede é controlado por reação química na superfície do níquel.

A extração de metais de $\mathrm{PCl}$ utilizando o sistema $\mathrm{H}_{2} \mathrm{SO}_{4}-\mathrm{CuSO}_{4}-\mathrm{NaCl}$ foi estudado por Yazici e Deveci (50), sendo estudada particularmente a influência da concentração de $\mathrm{Cu}^{2+}, \mathrm{Cl}^{-}$e temperatura. Das placas utilizadas, foram manualmente removidos os capacitores, cabos, resistores e transistores previamente à cominuição. As $\mathrm{PCl}$ foram então moídas em $3,55 \mathrm{~mm}$ em um moinho tipo shredder, e então moído em moinho de facas em grelha de $1 \mathrm{~mm}$ e por último a amostra foi cominuída em um moinho ultracentrífugo com grelha de $250 \mu \mathrm{m}$. Dentre estes fatores, a maior influência na lixiviação foi da temperatura e da concentração de $\mathrm{Cu}^{2+}$. A razão sólido líquido utilizada foi de $1: 100 \mathrm{~g} / \mathrm{mL}$, com concentração de ácido sulfúrico de $0,5 \mathrm{~mol} . \mathrm{L}^{-1}$. Os autores reportam uma completa extração de cobre, $>90 \%$ de ferro, níquel e prata e $58 \%$ de paládio utilizando $4 \mathrm{~g} \cdot \mathrm{L}^{-1}$ de $\mathrm{Cu}^{2+}, 46,6 \mathrm{~g} \cdot \mathrm{L}^{-1}$ de $\mathrm{Cl}^{-}$a $80^{\circ} \mathrm{C}$. Ainda, os autores reportam que para razão sólido líquido maior que $1: 10 \mathrm{~g} \cdot \mathrm{mL}^{-1}$ não houve lixiviação de cobre. A extração somente foi possível com a introdução de oxigênio a $2{\mathrm{~L} . \mathrm{min}^{-1}}^{-1}$ que regenera o agente lixiviante $\mathrm{Cu}^{2+}$, cuja remoção de cobre foi de $94 \%$.

Para se poupar etapas posteriores de separação e purificação, pode-se utilizar uma rota de lixiviação seletiva, sendo variada a força do ácido de modo a oxidar os metais de acordo com sua reatividade (80).

Após a etapa de lixiviação, os metais de interesse estão solubilizados na solução de lixívia. Uma ou mais etapas de beneficiamento do licor são requeridas, de modo que ocorra a separação dos metais para posterior recuperação. Dentre as técnicas utilizadas, pode-se citar extração por solvente, coluna de troca iônica, precipitação, cementação ou eletro-obtenção (1).

Há ainda, uma técnica hidrometalúrgica na qual a lixiviação é auxiliada por bactérias, que é denominada biohidrometalurgia e o processo de lixiviação é denominado biolixiviação. Neste processo, o agente lixiviante é produzido por bactérias ou fungos, e geralmente é necessária uma etapa de adaptação, na 
qual é realizada uma seleção artificial das bactérias que sobrevivem a doses crescentes de $\mathrm{PCl}$. Alguns trabalhos na literatura reportam o uso de bactérias na biolixiviação de placas de circuito impresso (81) (82).

\subsection{CINÉTICA QUÍMICA}

Para o estudo cinético de reações de lixiviação, as condições experimentais possuem influência (83):

- Natureza do agente lixiviante

- Concentração do agente lixiviante

- Temperatura

- Razão sólido-líquido (S/L)

- Tamanho de partícula

A natureza do agente lixiviante permite a lixiviação dos metais de forma seletiva, dada a diferente reatividade do agente com o metal de interesse.

A concentração influencia a velocidade da reação, pois aumenta a probabilidade de encontro entre o agente lixiviante e a superfície a ser lixiviada (83).

A temperatura influencia a velocidade da reação, de acordo com a equação de Arrhenius (83):

$$
k=A \cdot e^{-\frac{E}{R T}}
$$

Na qual $k$ é a constante de velocidade da reação, $A$ é o fator pré-exponencial, também chamado de fator de frequência com que as moléculas colidem, $E$ é a energia de ativação, $R$ a constante dos gases ideais $\mathrm{e}$ $T$ a temperatura na qual a reação ocorre (83). A energia de ativação para processos controlados por difusão é geralmente da ordem de 4-13 kJ.mol ${ }^{-1}$ enquanto que reações que são controladas por processos químicos tem 
energia de ativação maiores que $42 \mathrm{~kJ} \mathrm{~mol}^{-1}$. Assim, os processos controlados por difusão não dependem tanto da temperatura, enquanto processos controlados por reação química dependem fortemente da temperatura (83).

A razão sólido-líquido, também chamada de densidade de polpa, é expressa em massa de resíduo por volume de solução, sendo menores volumes preferidos, para que haja maior concentração de metais na solução de lixívia e redução no volume de efluentes gerados.

Quanto ao tamanho de partícula, as mais finas são preferidas, pois possuem maior superfície de contato além de promoverem um maior grau de liberação do material. Ainda, o tempo necessário para que a reação de complete é diretamente proporcional ao raio da partícula (84 p. 135).

As reações de lixiviação são do tipo heterogênea, na qual o agente lixiviante está solubilizado na fase aquosa e o resíduo está na fase sólida. Os passos para que envolvem uma reação heterogênea podem ser listados conforme os processos (85 p. 167) (83):

i. Transporte do reagente em solução até a interface sólido-líquido;

ii. Adsorção dos reagentes à superfície sólida;

iii. Reação química entre o agente lixiviante e a partícula sólida;

iv. Dessorção dos produtos solúveis;

v. Difusão dos produtos através da camada de filme, para o seio da solução.

Uma reação que ocorre em etapas é sempre limitada por sua etapa mais lenta. A reação é controlada por difusão se a etapa lenta for ou (i) ou (v). Caso o processo mais lento seja uma das etapas (ii), (iii) ou (iv), a reação possui o controle químico. Ainda, a taxa de difusão pode possuir uma ordem de grandeza próxima à taxa de reação química. Neste caso, o processo global possui controle misto (86).

À medida que ocorre a lixiviação de material de uma partícula, dois comportamentos distintos podem ocorrer de acordo com a particularidade da reação. No primeiro, o diâmetro da partícula pode ser reduzido, ocasionando a diminuição progressiva de seu tamanho, até que no final da reação a partícula 
desapareça. No segundo, pode-se formar uma camada na superfície da partícula, que pode ser ou um produto insolúvel ou uma fração do material não-reativo ao meio lixiviante. Neste último caso, a partícula se mantém do mesmo tamanho durante todo o curso da reação. Com efeito, esta camada formada sobre a partícula pode oferecer uma resistência difusiva, podendo dificultar tanto $o$ acesso do reagente a interface sólido-líquido quanto a saída do produto para a solução (86 p. 566$)$.

\subsubsection{Reação controlada por difusão}

Considerando a reação:

$$
A_{(a q)}+b B_{(s)} \rightarrow p P_{(a q)}
$$

Sendo $A \circ$ agente lixiviante, $B \circ$ sólido a ser lixiviado e $P$ o produto da reação. $A$ velocidade com que os reagentes são consumidos e o produto é formado segue a relação:

$$
V=-\frac{d N_{A}}{d t}=-\frac{1}{b} \frac{d N_{B}}{d t}=\frac{1}{p} \frac{d N_{P}}{d t}
$$

Considerando-se que o controle da reação é feito pela difusão do reagente $A$, têm-se o perfil de concentração de acordo com o raio da partícula B, considerada esférica, mostrado na Figura 9 (adaptada de (86 p. 577)). Como a reação química na superfície da partícula neste modelo é mais veloz do que a difusão da espécie $A$, sua concentração na superfície da partícula é considerada nula. 


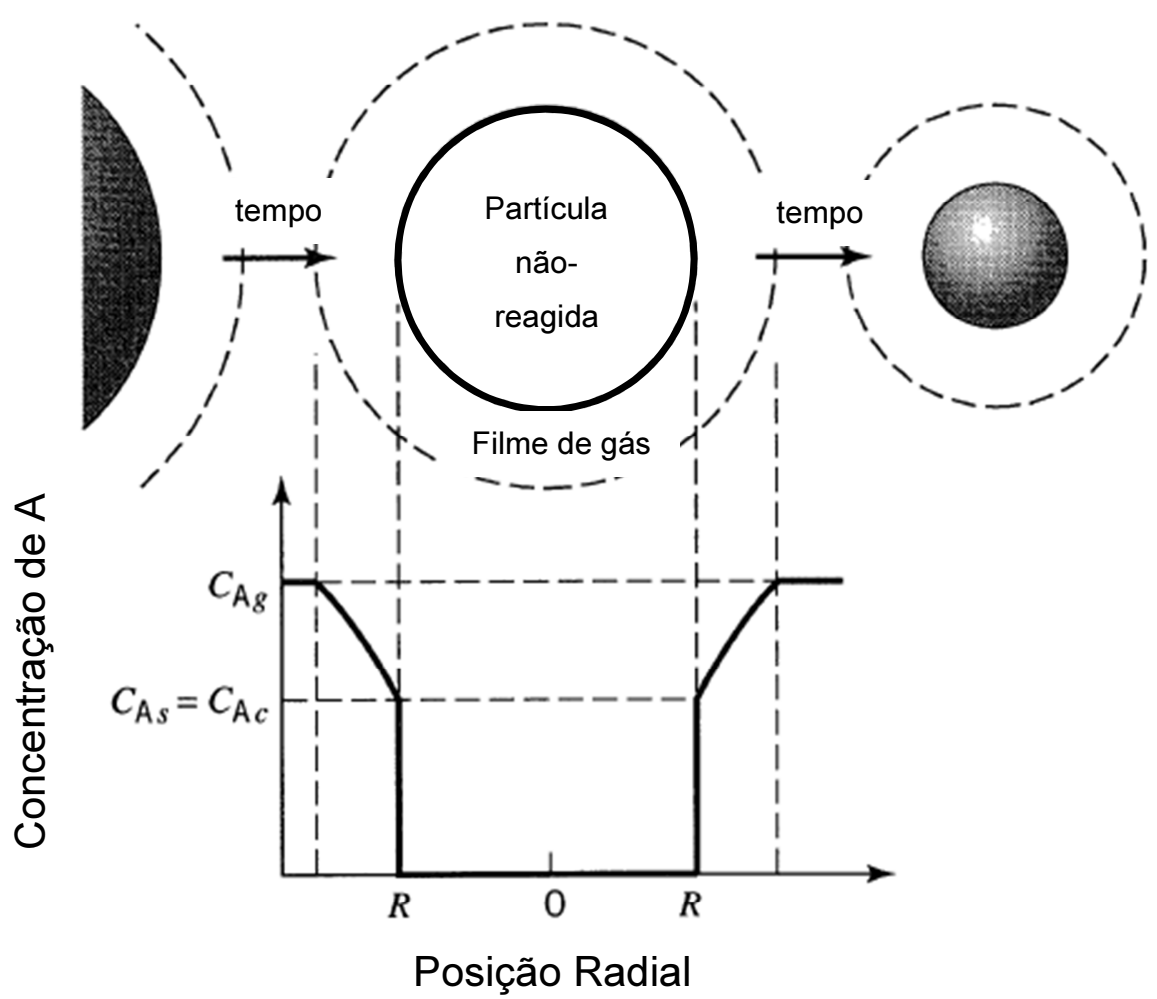

Figura 9. Perfil de concentração do reagente $A$ em relação à partícula $B$ a ser lixiviada (adaptada de (86 p. 577)).

Assim, a taxa com que B é consumido pode ser expressa por:

$-\frac{1}{S_{B}} \frac{d N_{B}}{d t}=-\frac{1}{4 \pi R^{2}} \frac{d N_{B}}{d t}=\frac{b}{4 \pi R^{2}} \frac{d N_{A}}{d t}=b k_{d}\left(C_{A}-C_{A_{S}}\right)$

Com $S_{B}$ correspondendo à superfície de $B, R$ o raio da partícula $B, k_{d}$ a constante cinética do controle por difusão, $C_{A}$ a concentração de $A$ na solução e $C_{A_{S}}$ a concentração de $A$ na superfície de $B$, que neste caso é considerada nula. Para se obter a função que representa o perfil cinético, obtém-se o termo $d N_{B}$ em função de sua densidade, utilizando as expressões de volume molar e de volume da esfera: 


$$
N_{B}=\rho_{B} V=\rho_{B} \frac{4}{3} \pi R^{3}
$$

Derivando a equação 5 e substituindo na equação 4, obtém-se:

$$
-\rho_{B} \frac{d R}{d t}=b k_{d} C_{A}
$$

Considerando-se uma partícula de diâmetro muito reduzido (Regime de Stokes), a constante $k_{D}$ se assume a forma:

$$
k_{D}=\frac{D}{R}
$$

Sendo $D$ a difusividade do reagente $A$ na camada limite e $R$ o raio da partícula. Assim, substituindo-se a equação 7 na equação 6 e rearranjando-a, obtém-se:

$$
\int_{R_{0}}^{R} R d R=-\frac{b k_{d} C_{A}}{\rho_{B}} \int_{0}^{t} d t
$$

Após a integração, a equação assume a forma:

$$
t=\frac{\rho_{B}}{2 b D C_{A}}\left(R_{0}^{2}-R^{2}\right)=\frac{\rho_{B} R_{0}^{2}}{2 b D C_{A}}\left(1-\left(\frac{R}{R_{0}}\right)^{2}\right)
$$

É comum se expressar a equação em função da fração reagida, $X_{B}$, expressa por:

$$
1-X_{B}=\left(\frac{R}{R_{0}}\right)^{3}
$$

O tempo total para que a reação se complete é dado pela equação: 


$$
\tau=\frac{\rho_{B} R_{0}^{2}}{2 b D C_{A}}
$$

Assim, dividindo-se a equação 9 pela equação 11, e substituindo pela fração reagida, chega-se à expressão:

$$
\frac{t}{\tau}=1-\left(1-\frac{R}{R_{0}}\right)^{\frac{2}{3}}
$$

Esta expressão representa a cinética de uma reação heterogênea controlada por difusão na camada limite.

\subsubsection{Controle por reação química}

Quando o controle da lixiviação é realizado pela reação química, o perfil de concentração da espécie A é aquele mostrado na Figura 10 (adaptada de (86 p. 576)). 


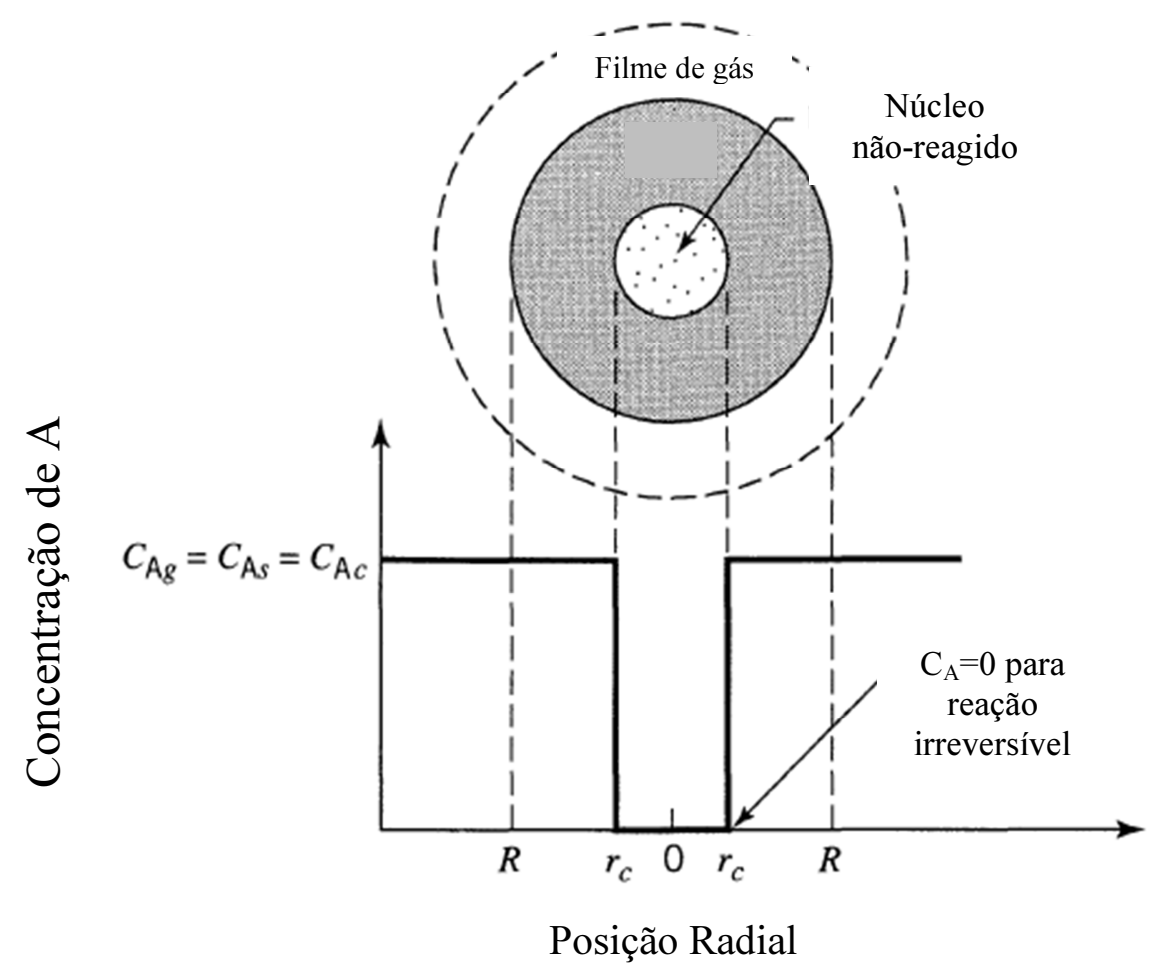

Figura 10. Concentração do reagente $A$ em função do raio da partícula $B$, considerando-se o controle por reação química (adaptada de (86 p. 576)).

Uma vez que a reação é mais lenta que a difusão, considera-se que a concentração da espécie A na camada limite é a mesma daquela encontrada no seio da solução. Desta forma, a partir da equação de velocidade:

$$
-\frac{1}{S_{B}} \frac{d N_{B}}{d t}=-\frac{1}{4 \pi R^{2}} \frac{d N_{B}}{d t}=\frac{b}{4 \pi R^{2}} \frac{d N_{A}}{d t}=b k_{Q} C_{A}
$$

$\mathrm{Na}$ qual $\mathrm{k}_{\mathrm{Q}}$ representa a constante de primeira-ordem de controle químico. Substituindo por $\mathrm{N}_{\mathrm{B}}$ em função do raio da esfera, a equação assume a forma:

$$
-\rho_{B} \frac{d R}{d t}=b k_{Q} C_{A}
$$


Integrando-se a equação 14:

$$
-\rho_{B} \int_{R_{0}}^{R} d R=b k_{Q} C_{A} \int_{0}^{t} d t
$$

Obtém-se a equação que representa a reação em função do tempo:

$$
t=\frac{\rho_{B}}{b k_{Q} C_{A}}\left(R_{0}-R\right)=\frac{\rho_{B} R_{0}}{b k_{Q} C_{A}}\left(1-\frac{R}{R_{0}}\right)
$$

O tempo total para a completude da reação é dado pela expressão:

$$
\tau=\frac{\rho_{B} R_{0}}{b k_{Q} C_{A}}
$$

Desta forma, transformando a equação 16 em função da fração reagida, obtém-se (85 p. 201):

$$
\frac{t}{\tau}=1-\left(1-\frac{R}{R_{0}}\right)^{\frac{1}{3}}
$$

Esta expressão representa a cinética de reação heterogênea com controle por reação química.

Uma reação heterogênea de lixiviação de um metal por ácido pode ser representada por:

$$
M e+n H^{+} \rightarrow M e^{+n}+\frac{n}{2} H_{2}
$$

na qual $M e$ corresponde ao metal em questão. A velocidade de reação pode ser descrita pela equação (83): 


$$
V=\frac{d\left[M e^{+n}\right]}{d t}=k \cdot\left[H^{+}\right]^{a} \cdot A_{M e}^{b}
$$

na qual $V$ é a velocidade de reação, $k$ é a constante de velocidade intrínseca, $a$ e $b$ correspondem à ordem de reação para a concentração de ácido e área de metal, respectivamente. Quando a concentração é expressa em mol. $L^{-1}$ e a área em $\mathrm{cm}^{2}$, a constante assume dimensões de $\mathrm{cm}^{-2} \cdot \mathrm{min}^{-1}$. Aplicando-se o logaritmo em ambos os termos da equação, têm-se:

$$
\log V=\log k+a \cdot \log \left[H^{+}\right]+b \cdot \log A_{M e}
$$

Para se obter experimentalmente os parâmetros cinéticos, i.e. os valores de $k$, a e $b$, pode-se utilizar o método das velocidades iniciais, na qual se monitora uma das espécies envolvidas na reação em função do tempo utilizando-se diferentes condições iniciais de reagentes. A partir da derivada da curva no tempo inicial obtêm-se os parâmetros pelas equações:

$$
\begin{aligned}
& \log V_{0}=\log k^{\prime}+a \cdot \log \left[H^{+}\right]_{0} \\
& \log V_{0}=\log k^{\prime \prime}+b \cdot \log A_{M e_{0}}
\end{aligned}
$$

Sendo $k^{\prime}=k \cdot A_{M e}^{b}$ e $k^{\prime \prime}=k \cdot\left[H^{+}\right]^{a}$. Desta forma, com posse dos dados de velocidade inicial, obtida através da derivada da formação (ou consumo) de uma das espécies no tempo zero, juntamente com a concentração inicial de ácido e paralelamente com a área inicial de metal, é possível se obter os parâmetros cinéticos, uma vez que a coeficiente angular da reta formada resulta na ordem de reação e o coeficiente linear o valor da constante de reação. Somente na reação elementar a ordem de reação é igual ao coeficiente estequiométrico da reação, fato este que permite se determinar uma alteração do mecanismo caso haja mudança na ordem da reação (87).

A cinética de dissolução de ouro, promovida por solução de sulfato férrico e tiouréia foi estudada por $\mathrm{Li}$ e Miller (88). Em seu experimento, os autores utilizaram o disco rotativo, um recurso experimental comum quando se deseja reduzir os efeitos de difusão. Assim, eles encontraram as ordens de 
reação correspondentes às concentrações de tiouréia, de íon férrico e de ácido, cuja expressão empírica se torna:

$$
\frac{d[A u(I)]}{d t}=k \cdot[T u]^{0,25} \cdot\left[H^{+}\right]^{-0,2}
$$

Cujo termo $\mathrm{Tu}$ corresponde à concentração de tiouréia e $\mathrm{H}^{+}$à concentração de ácido. A ordem de reação para o tiouréia encontrado foi de um quarto, em relação ao ácido foi de um quinto negativo e em relação ao íon férrico a reação se mostrou insensível, i.e. ordem zero.

\subsection{SONOQUÍMICA}

Ultrassom é o nome dado às ondas mecânicas com frequência acima do limite médio audível humano (> $20 \mathrm{kHz}$ ). É um fenômeno utilizado naturalmente como ecolocalizador por morcegos, baleias e golfinhos e também utilizado por barcos de pesca (89).

Existem dois principais tipos de ultrassom, classificados de acordo com sua frequência. $O$ de alta frequência e o de baixa frequência. $O$ primeiro é utilizado em diagnóstico, como na medicina e na inspeção de dutos. Já o de baixa frequência possui uma alta potência e é utilizado principalmente pela sua ação mecânica de limpeza de superfícies, pelo fenômeno da cavitação acústica (89).

A cavitação acústica é o fenômeno central da sonoquímica. Esta, por sua vez, tem ganhado muito espaço nas últimas décadas, pois é possível aumentar o rendimento de reações, alterar o mecanismo e viabilizar reações biológicas, químicas e eletroquímicas (90).

Para que haja o processo de cavitação, é necessária uma heterogeneidade na solução, e.g. um gás solubilizado no líquido. Essa heterogeneidade atua como sítio de nucleação, criando uma bolha que entra em ressonância com a fonte de ultrassom, durante os ciclos de compressão e 
rarefação. Durante o ciclo de expansão, a bolha aumenta de diâmetro numa taxa maior do que sua redução durante a rarefação. $O$ aumento da bolha ocorre até que seu tamanho ultrapasse um diâmetro limite $(\sim 170 \mu \mathrm{m}$ para $20 \mathrm{kHz}$ ), no qual ela não está mais em ressonância com o campo acústico e, sem absorver energia, a bolha fica instável e implode. Este fenômeno está representado na Figura 11 (adaptada de (91)). Nesta implosão, ocorre a formação do hot spot, que pode atingir temperaturas de $5000 \mathrm{~K}$ e pressões de $500 \mathrm{~atm}$ localmente (90) (92) (93).

Em meio heterogêneo, a implosão da bolha cria um jato de líquido próximo à superfície (Figura 12) (91). Este jato, que pode atingir velocidade de

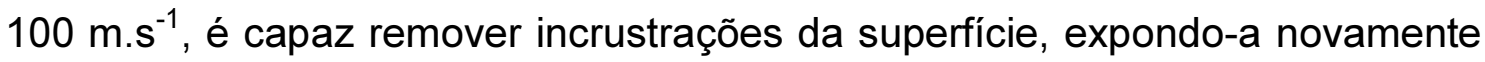
ao solvente.

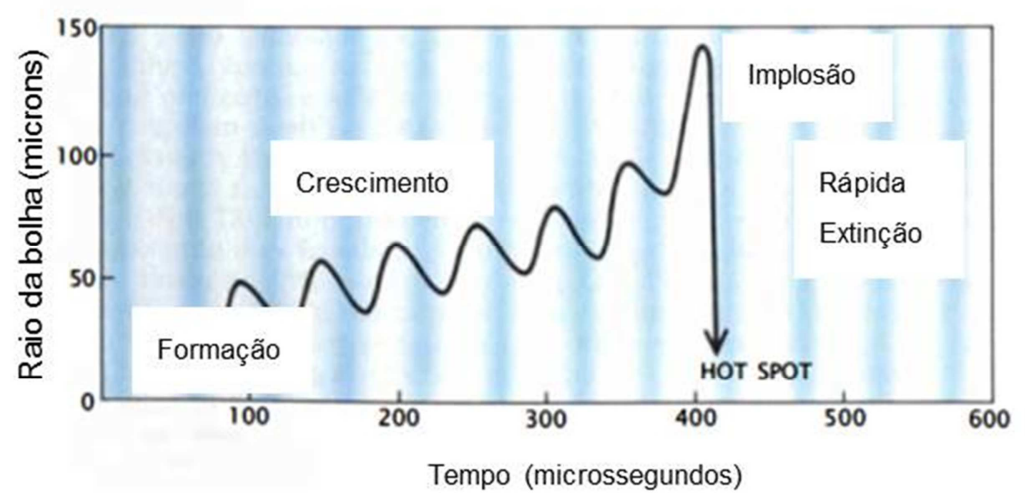

Figura 11. Exemplo dos ciclos de compressão e descompressão sofridos por uma bolha de cavitação, causando o crescimento e a implosão com o tempo, adaptada de (91). 


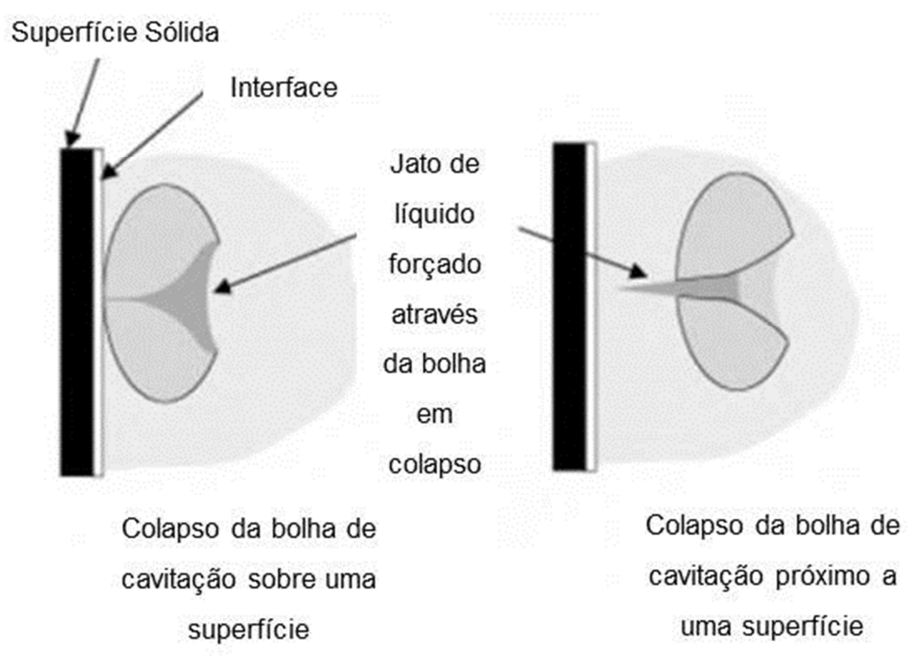

Figura 12. Representação esquemática da implosão da bolha, evidenciando o jato de líquido, adaptada de (91).

A cavitação acústica pode ter diferentes efeitos nos materiais. Em materiais frágeis, como cerâmicos, ocorre a fragmentação de partículas. Raman e Abbas (94) estudaram a quebra de partículas de alumina em diferentes temperaturas. O equipamento de ultrassom utilizado possuía frequência de $24 \mathrm{kHz}$. Segundo o autor, a redução do comprimento médio das partículas foi mais pronunciada quando utilizada maior potência do equipamento $(350 \mathrm{~W})$, resultando uma redução de $15 \%$ em 10 minutos de experimento. Ainda, o autor reporta o efeito da temperatura sobre a quebra das partículas. Há um aumento da quebra das partículas com o aumento da temperatura, pois maiores temperaturas resultam na redução no limiar de cavitação acústica, i.e. há maior facilidade de a cavitação ocorrer, pois ocorre redução da tensão superficial e viscosidade do líquido. Essa redução das forças coesivas do líquido facilita a formação das bolhas de cavitação. No entanto, o autor conclui que a faixa de temperatura que promove uma maior quebra está entre 25 e $37^{\circ} \mathrm{C}$. Este fato decorre do aumento da pressão de vapor, que satura o interior da bolha de cavitação, amortecendo seu colapso e consequentemente a quebra das partículas (94). 
Franco e colaboradores (95) realizaram o tratamento de caulinita com ultrassom de $600 \mathrm{~W}$, no qual foi observada a redução de $17 \%$ no tamanho das partículas após 40 horas de tratamento, sem tornar o material amorfo.

Em metais, a implosão assimétrica das bolhas de cavitação promove a remoção de camadas de passivação, aumentando sua reatividade e o acesso do reagente à superfície (3). Nos metais alcalinos, que podem ser considerados metais macios, de acordo com a escala contida na Tabela 7 , adaptada de (3), a deformação plástica causada pela onda de choque da cavitação ocasiona a quebra da camada de óxido, que pode ser visualizado na Figura 13 (adaptada de (3)). Este fenômeno acontece mesmo no caso do alumínio, cuja camada de óxido é considerada dura.

Tabela 7. Escala de dureza de alguns metais e seus respectivos óxidos (adaptada de (3)).

\begin{tabular}{lccc}
\hline Metal & $\begin{array}{c}\text { Mohs } \\
\text { (metal) }\end{array}$ & $\begin{array}{c}\text { Mohs } \\
\text { (óxido) }\end{array}$ & $\begin{array}{c}\text { Brinell } \\
\text { (metal) }\end{array}$ \\
\hline $\mathrm{K}$ & 0,4 & - & 0,36 \\
$\mathrm{Na}$ & 0,5 & - & 0,69 \\
$\mathrm{Li}$ & 0,6 & - & - \\
$\mathrm{Sn}$ & 1,5 & - & 51 \\
$\mathrm{Ca}$ & 1,75 & $3-4$ & 167 \\
$\mathrm{Mg}$ & 2,3 & $5-6$ & 260 \\
$\mathrm{Zn}$ & 2,5 & 5 & 412 \\
$\mathrm{Al}$ & 2,75 & 9 & 314 \\
$\mathrm{Cu}$ & 3 & $3-4$ & 400 \\
$\mathrm{Ni}$ & 4 & 5,5 & 650 \\
$\mathrm{Mo}$ & 5,5 & - & - \\
$\mathrm{Cr}$ & 8,5 & 9 & - \\
\hline
\end{tabular}



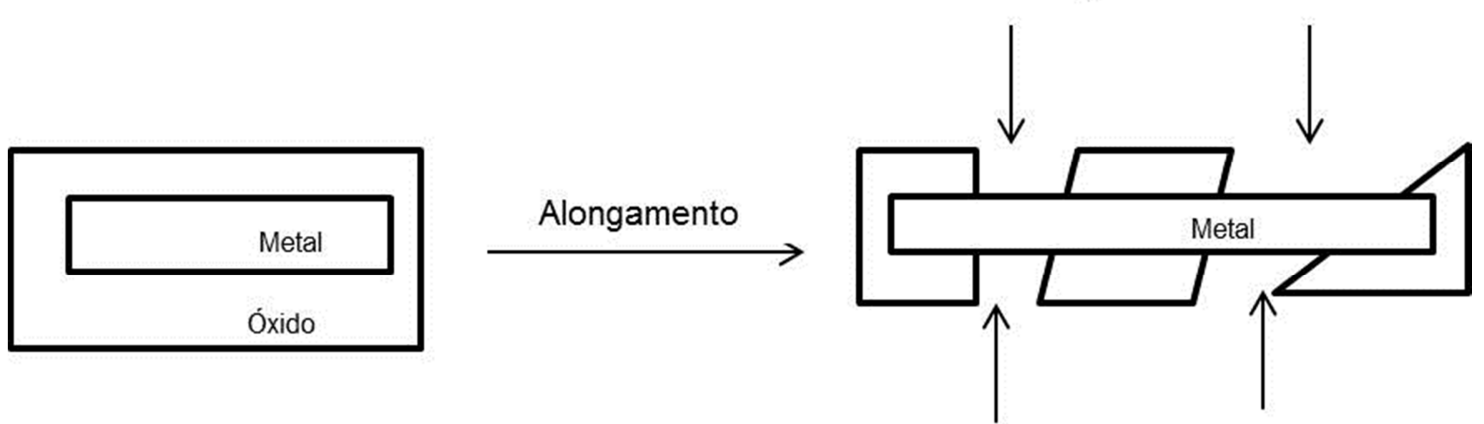

Regiôes ativadas

Figura 13. Mecanismo de ativação por alongamento em metais alcalinos, adaptada de (3).

Em metais considerados duros, como níquel, cuja camada de óxido também é dura, a ativação vai depender da energia de coesão entre ambos. No caso do níquel, é possível a remoção de sua camada de óxido, dada sua baixa coesão (Figura 14, adaptada de (3)).
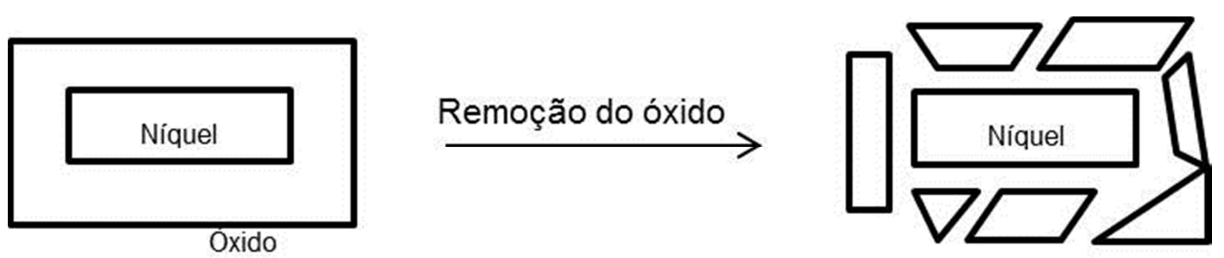

Figura 14. Ativação de níquel pelo desprendimento da camada de óxido, adaptada de (3).

Doktycz e Suslick (96) estudaram o efeito do ultrassom sobre pós metálicos para se determinar a temperatura máxima atingida pela colisão das partículas. Pós de zinco ( $5 \mu \mathrm{m}$ de diâmetro), estanho ( $44 \mu \mathrm{m}$ de diâmetro), ferro ( $5 \mu \mathrm{m}$ de diâmetro), cromo ( $3 \mu \mathrm{m}$ de diâmetro), molibdênio ( 10 $\mu \mathrm{m}$ de diâmetro) e tungstênio ( 10 $\mu \mathrm{m}$ de diâmetro) foram sonicados, separadamente, em decano, com potência de $50 \mathrm{~W} . \mathrm{cm}^{-2}$ por 30 minutos. As partículas foram analisadas em microscópio eletrônico de varredura, sendo que $\mathrm{Zn}, \mathrm{Fe}, \mathrm{Ni}, \mathrm{Cr}$ e Mo apresentaram fusão parcial de suas partículas, com aparecimento de um pescoço entre elas. A Figura 15, adaptada de (96), mostra 
uma microscopia eletrônica de varredura de duas partículas de $\mathrm{Zn}$ parcialmente fundidas, devido à colisão em alta velocidade entre as partículas. Esta velocidade foi estimada em 100 a $500 \mathrm{~m} . \mathrm{s}^{-1}$. Em polímeros pode ocorrer a degradação (92) (97). Porém, segundo (93), partículas de metal menores que $200 \mu \mathrm{m}$ podem se fundir, dada a temperatura local de implosão da bolha $\left(\sim 3.000^{\circ} \mathrm{C}\right)$.

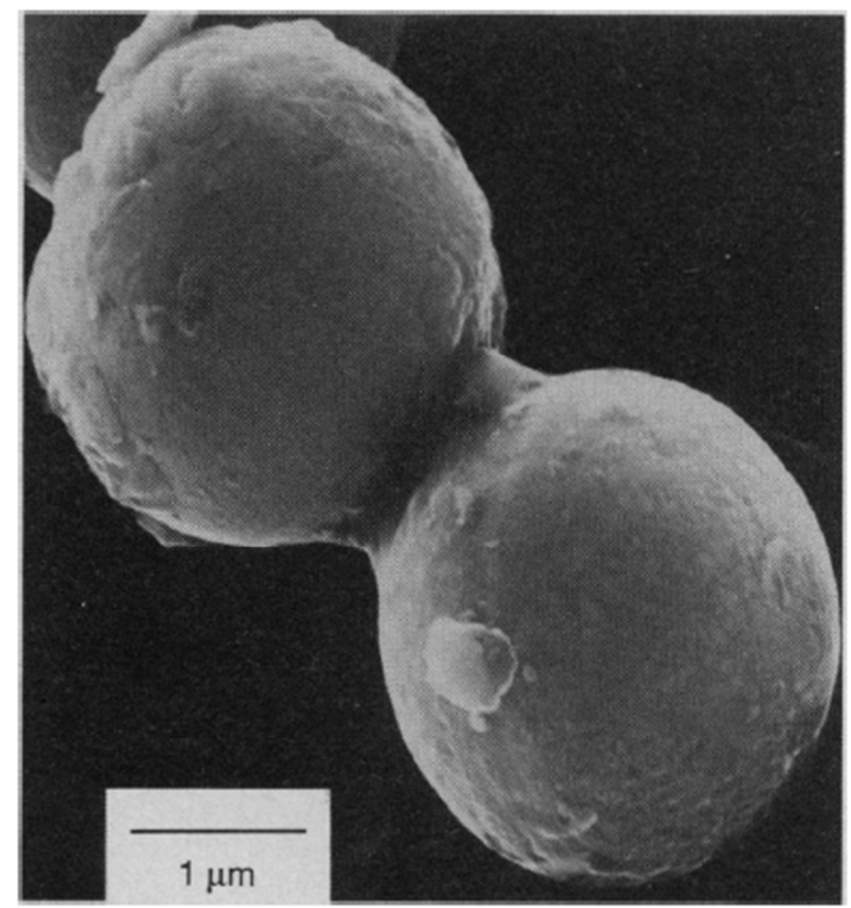

Figura 15. Microscopia eletrônica de varredura de duas partículas de zinco, parcialmente fundidas pela colisão à alta velocidade, promovida pelo efeito do ultrassom (96).

A cominuição por ultrassom foi estudada por Yerkovic e colaboradores (98), no qual o transdutor ultrassônico de $20 \mathrm{kHz}$ foi adaptado a um dos rolos de moinho de rolos, utilizado para cominuição de minério oxidado de cobre. A cominuição a úmido mostrou-se mais eficiente, devido à melhor propagação das ondas acústicas na água. O produto obtido pela moagem com este moinho adaptado apresentou-se mais fino do que o obtido pelo moinho de bolas convencional, efeito explicado pelo efeito sinérgico entre o stress vibracional e compressivo, causados pelo transdutor ultrassônico e pelos rolos. 
A influência do ultrassom na lixiviação de minério oxidado de cobre por solução amoniacal foi avaliada por Murty e colaboradores (99), e foi encontrado que o ultrassom de ponteira ( $20 \mathrm{kHz}$ e $375 \mathrm{~W}$ ) aumentou em 6 vezes a taxa de lixiviação em comparação à mesma reação realizada com agitação magnética. A economia de reagente também foi abordada pelos autores, na qual a reação com 2 mol. $\mathrm{L}^{-1}$ de amônia no sistema sonicado apresentou uma lixiviação de $81 \%$ em 20 minutos, enquanto que o sistema com 5 mol.L L $^{-1}$ com agitação mecânica apresentou $75 \%$ de lixiviação em 120 minutos. Ainda, este estudo mostra que o ultrassom aplicado na forma pulsada (30/70) removeu $91 \%$ de cobre frente a $81 \%$ de remoção no sistema irradiado de forma contínua e $70 \%$ de remoção com agitação mecânica.

O auxílio do ultrassom na lixiviação de lama vermelha por ácido sulfúrico foi estudado por Sayan e Bayramoglu (100). Neste trabalho, foi feito o planejamento fatorial para se otimizar a potência do ultrassom, temperatura, tempo de reação, concentração de ácido e razão sólido-líquido, para lixiviar $\mathrm{TiO}_{2}, \mathrm{Al}_{2} \mathrm{O}_{3}$ e $\mathrm{Fe}_{2} \mathrm{O}_{3}$. Os fatores mais importantes para a lixiviação de $\mathrm{TiO}_{2}$ foram a concentração de ácido e temperatura e como resultado final o ultrassom aumentou em $20 \%$ a extração de $\mathrm{TiO}_{2}$ frente à reação nas mesmas condições mas na ausência de ultrassom.

Saterlay e colaboradores (101) estudaram o efeito do ultrassom na lixiviação de chumbo de monitores de tubos de raios catódicos com ácido nítrico. Os autores utilizaram potência de $14 \mathrm{~W} \mathrm{~cm}^{-2}$, e concentração de ácido de 0,1 mol. $\mathrm{L}^{-1}$, nas granulometrias:

$$
\begin{aligned}
& -0,5 \mathrm{~mm} \\
& +0,5 \mathrm{~mm}-1,0 \mathrm{~mm} \\
& +1,0 \mathrm{~mm}-2,0 \mathrm{~mm} \\
& +2,0 \mathrm{~mm}-5,0 \mathrm{~mm}
\end{aligned}
$$

Como resultado, o ensaio sonicado removeu de 7 a 11 vezes mais chumbo em comparação ao ensaio silencioso. Os autores atribuem este incremento na lixiviação à erosão causada pela cavitação, que permite que o 
ácido penetre mais profundamente no vidro. Um segundo efeito associado é a redução no tamanho de partícula, dada pela fratura mecânica do vidro.

A cinética de lixiviação de zinco assistida por ultrassom de resíduo proveniente de uma planta metalúrgica foi estudada por Wang e colaboradores (102). Neste trabalho, o resíduo continha aproximadamente $12 \%$ em massa de zinco e como agente lixiviante foi utilizado ácido sulfúrico, com intervalo de concentração entre 0,3 e 1,7 mol. $\mathrm{L}^{-1}$. O equipamento de ultrassom utilizado possuía frequência fixa de $20 \mathrm{kHz}$ e foram utilizadas nos ensaios 3 potências distintas, 80,160 e $240 \mathrm{~W}$. A temperatura foi variada nos ensaios, sendo utilizados os valores de $55,65,75$ e $85^{\circ} \mathrm{C}$. A influência da potência na recuperação de zinco foi mais pronunciada quando esta foi aumentada de 80 para $160 \mathrm{~W}$. Já na potência de $240 \mathrm{~W}$, este aumento na lixiviação do zinco foi menos pronunciado. Os autores reportam que o processo é controlado por difusão e encontraram a ordem de reação para o ácido sulfúrico e para o raio da partícula. A energia de ativação do processo também foi calculada, sendo o valor de $6,57 \mathrm{~kJ} \mathrm{~mol}^{-1}$ encontrado. A expressão para a velocidade se torna (102):

$$
V=k_{0} \cdot\left[H_{2} S_{4}\right]^{0,94} \cdot r_{0}^{-0,12} \cdot e^{\left(-\frac{6,57}{R T}\right) t}
$$

A ordem de reação encontrada para o ácido foi de 0,94 e a ordem em relação ao raio da partícula foi de $-0,12$. A condição experimental que apresentou maior percentual de remoção de zinco foi com potência de ultrassom de $160 \mathrm{~W}$, temperatura de $65^{\circ} \mathrm{C}$ em 180 minutos, com concentração de ácido de 1,4 mol. $\mathrm{L}^{-1}$, em partículas com diâmetro entre 74 e $89 \mu \mathrm{m}$. Nestas condições, a extração de zinco obtida foi de 80\% (102). 


\section{OBJETIVOS}

Esta tese tem por objetivos caracterizar a placa dual-layer DL e verificar o efeito do ultrassom na cominuição de placas dual-layer DL e multi-layer ML e seu efeito também na lixiviação de metais em meio sulfúrico e em meio sulfúrico oxidante em placas DL. 


\section{MATERIAIS E MÉTODOS}

Neste trabalho foram utilizados 2 tipos distintos de placas de circuito impresso obsoletas:

- PCl de celular multi-layer,

- PCl de desktop dual-layer.

As placas de celulares multi-layer, denominadas apenas ML daqui em diante, foram utilizadas nos ensaios de cominuição por ultrassom, para se verificar quantitativamente o efeito físico do ultrassom nas placas. Com a disposição das trilhas em camadas neste tipo de placa, espera-se que o ultrassom separe as camadas, aumentando a superfície exposta das trilhas formadas de cobre.

As placas de desktop dual-layer, denominadas apenas DL daqui em diante, foram utilizadas nos ensaios de lixiviação com ácido sulfúrico e ácido sulfúrico em meio oxidante. Esta amostra foi utilizada nestes ensaios uma vez que estava disponível em maior quantidade. As placas DL foram recebidas como doação pelo Cedir-USP e também através de sucateiros situados na região da Rua Santa Ifigênia, cidade de São Paulo. Na Figura 16 é possível observar a placa ML (a) e DL (b).

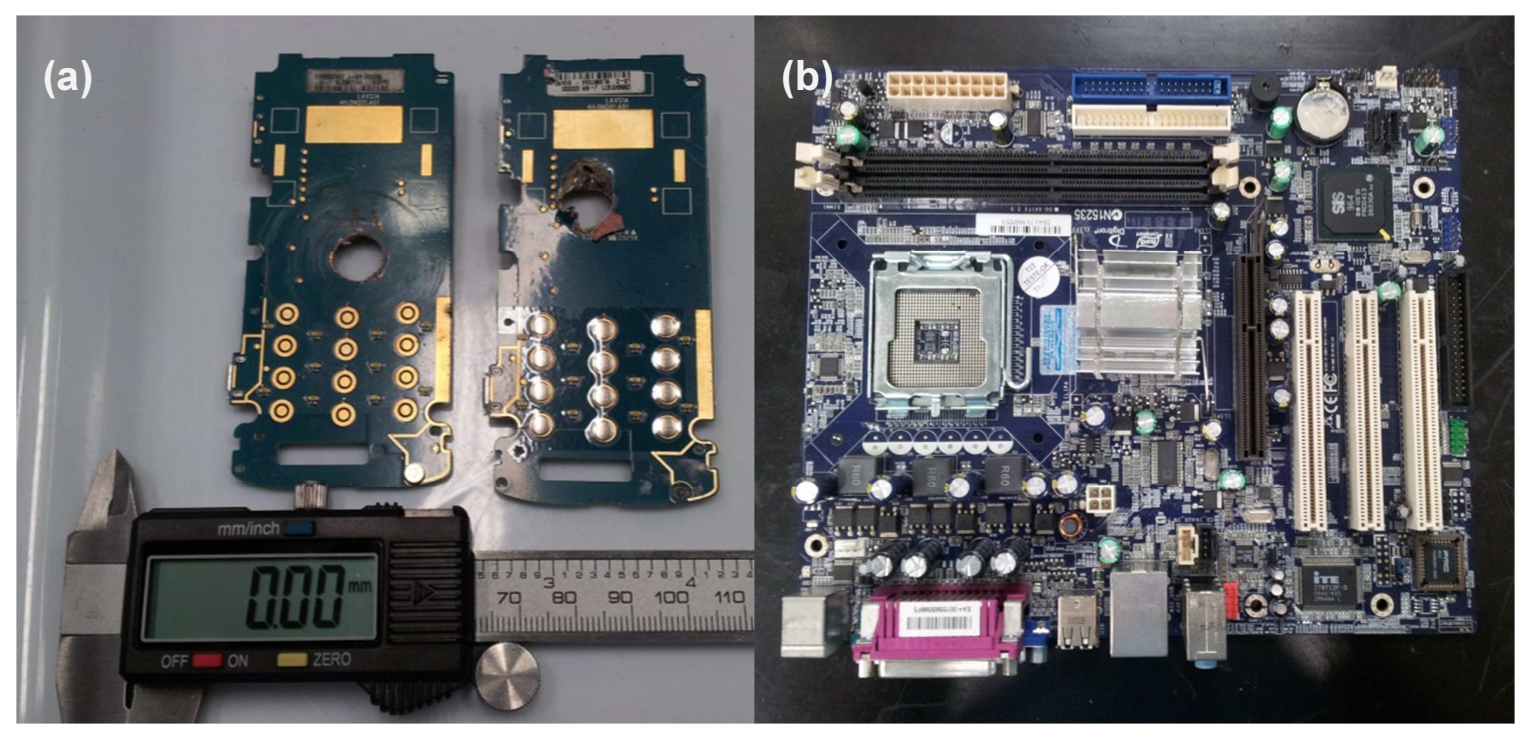

Figura 16. Placas utilizadas nos experimentos: ML (a) e DL (b). 


\subsection{COMINUIÇÃO}

A cominuição de ambos os tipos de placas foi realizada em moinho de martelos, marca Astecma, modelo MDM 18/18. As placas foram cominuídas separadamente utilizando-se grelhas com tamanho de abertura de 6, 4 e $2 \mathrm{~mm}$. A massa inicial de placas $D L$ foi de $2.735,6 \mathrm{~g}$ e a de $\mathrm{ML}$ foi de $403,4 \mathrm{~g}$. Após a cominuição, o material não-passante foi recolhido, pesado e guardado. $O$ material que se perdeu no chão também foi recolhido, pesado e guardado. $A$ amostra foi recolhida, pesada e o rendimento da cominuição foi calculado. $O$ material foi quarteado até se chegar em amostras de aproximadamente $20 \mathrm{~g}$. 0 quarteador utilizado foi do tipo Jones, marca Marconi, modelo MA065, de 18 canais e com abertura de $13 \mathrm{~mm}$ por canal. O material foi armazenado em sacos plásticos para servirem como amostra nos ensaios posteriores.

\subsection{CARACTERIZAÇÃO DE PCI DL}

A caracterização das placas DL foi realizada quanto sua composição de metais e quanto sua distribuição granulométrica. Um esquema pode ser visto na Figura 17. 


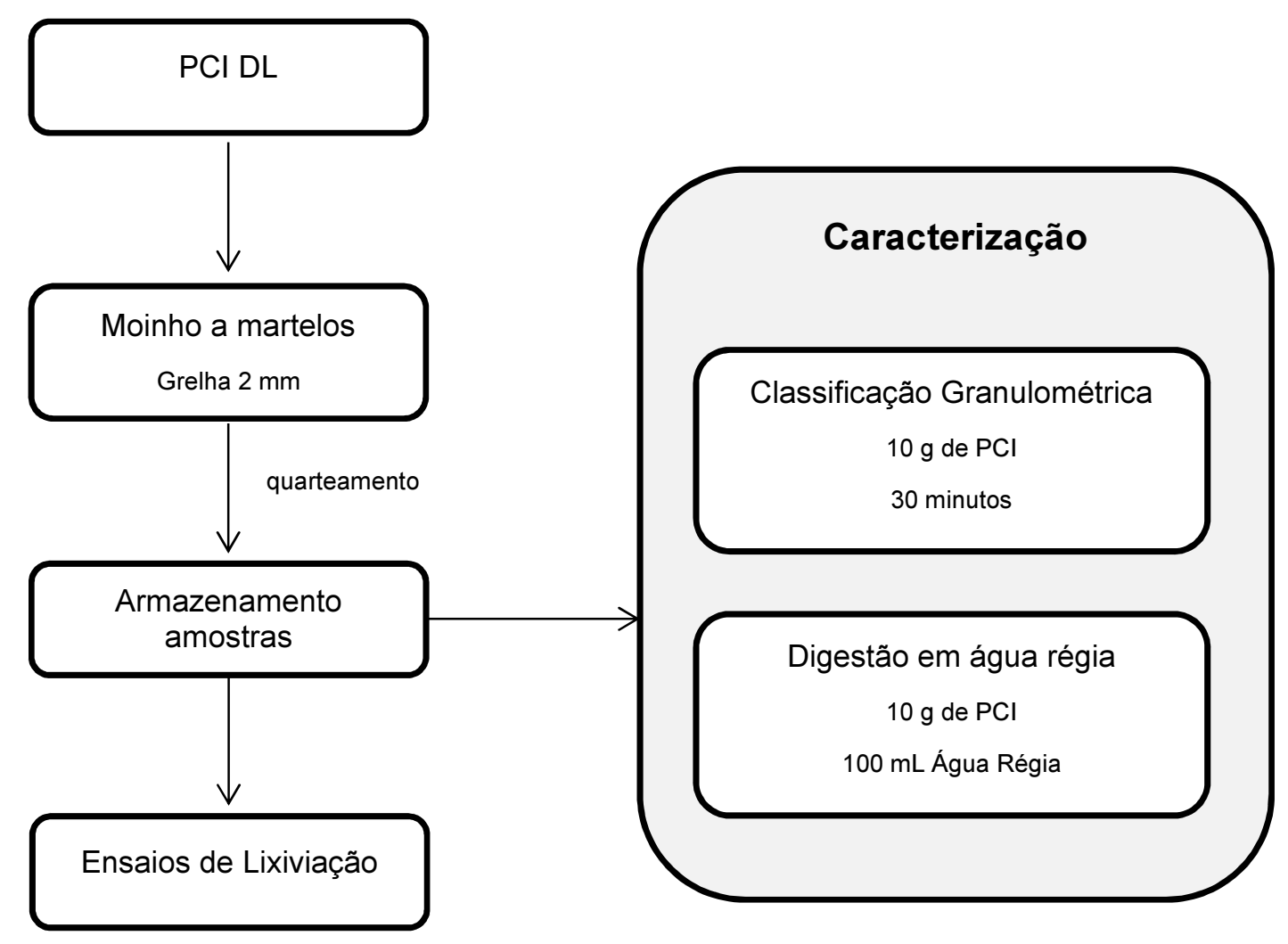

Figura 17. Fluxograma dos ensaios realizados com a placa DL.

\subsubsection{Distribuição Granulométrica}

A distribuição granulométrica foi realizada com as peneiras relacionadas na Tabela 8. As peneiras utilizadas possuíam diâmetro de $8 \mathrm{~cm}$ e altura de 5 $\mathrm{cm}$, o que possibilitou a utilização de quantidade reduzida de amostra. Uma amostra de aproximadamente $10 \mathrm{~g}$ foi adicionada ao topo das peneiras previamente taradas, ordenadas em tamanho decrescente de abertura. $O$ conjunto foi então colocado em um agitador de peneiras marca Bronzinox, por 30 minutos. O retido em cada peneira foi determinado por diferença de massa e assim foi levantada a curva de passante acumulado. 
Tabela 8. Relação de peneiras utilizadas na caracterização da distribuição granulométrica das amostras DL.

\begin{tabular}{cc}
\hline Abertura de peneiras $(\mathbf{m m})$ & Mesh (Tyler) \\
\hline 1,00 & 22 \\
0,50 & 32 \\
0,250 & 60 \\
0,125 & 115 \\
0,075 & 200 \\
0,038 & 400 \\
& Fundo \\
\hline
\end{tabular}

\subsubsection{Caracterização de metais - digestão em água régia}

A quantidade dos metais $\mathrm{Fe}, \mathrm{Zn}, \mathrm{Al}, \mathrm{Ni}, \mathrm{Sn}$, Cu e Ti foi determinada por digestão em água régia. Os metais $\mathrm{Fe}, \mathrm{Zn}, \mathrm{Al}, \mathrm{Ni}$ e $\mathrm{Sn}$ foram caracterizados porque constituem o alvo da análise cinética. A quantificação do Cu se deu por representar a maior fração em massa de metal e o Ti foi avaliado para que fosse possível identificar uma possível contaminação causada pela dissolução da ponteira do sonotrodo do equipamento de ultrassom utilizado nas lixiviações, constituída de liga de Ti-6Al-4V.

A digestão foi realizada adicionando-se cerca de $10 \mathrm{~g}$ de $\mathrm{PCl}$ moída a $100 \mathrm{~mL}$ de água régia $\left(3: 1 \mathrm{v} / \mathrm{v} \mathrm{HCl} / \mathrm{HNO}_{3}\right)$ recém-preparada, por $24 \mathrm{~h} \mathrm{e} \mathrm{em}$ capela, em temperatura ambiente (aproximadamente $25^{\circ} \mathrm{C}$ ), em sistema aberto. O material foi então filtrado utilizando-se filtro lento quantitativo. $\mathrm{O}$ filtro foi lavado com pequenas porções de água deionizada para retirada do ácido remanescente no filtrado e seco em estufa até que as pesagens subsequentes não apresentassem variação de massa. A solução foi transferida para um balão volumétrico para que o volume final fosse aferido, sendo esta solução encaminhada para análise química, realizada por Espectrômetro de Fluorescência de Raios X por Energia Dispersiva (EDXRF), marca PANalytical, modelo Epsilon 3 - XL ânodo de Ag. A fração de metais foi calculada pela 
diferença entre as massas final e inicial, assumindo-se que somente os metais foram lixiviados pela água régia.

As placas ML não foram caracterizadas quanto sua composição química pois não foram realizados ensaios de lixiviação com as mesmas. Com efeito, somente a caracterização de sua granulometria foi realizada.

\subsection{EQUIPAMENTO DE ULTRASSOM}

O equipamento de ultrassom utilizado é da marca Sonics and Materials (EUA), modelo VCX750, com frequência fixa de $20 \mathrm{kHz}$, com ponteira rosqueável de $13 \mathrm{~mm}$, feita de liga Ti-6Al-4V, e potência máxima de $750 \mathrm{~W}$. Os ensaios foram realizados em um frasco encamisado de fundo cônico, que foi desenvolvido sob medida para os ensaios sonicados. Um esquema do aparato experimental pode ser visto na Figura 18, no qual (a) é a fonte de energia, (b) transdutor de ultrassom, também chamado de sonotrodo, (c) frasco encamisado de fundo cônico, (d) elevador tipo Jack para laboratório, (e) entrada de água proveniente do banho termostático, mantido a $25^{\circ} \mathrm{C}$, (f) saída de água e (g) banho termostático. 


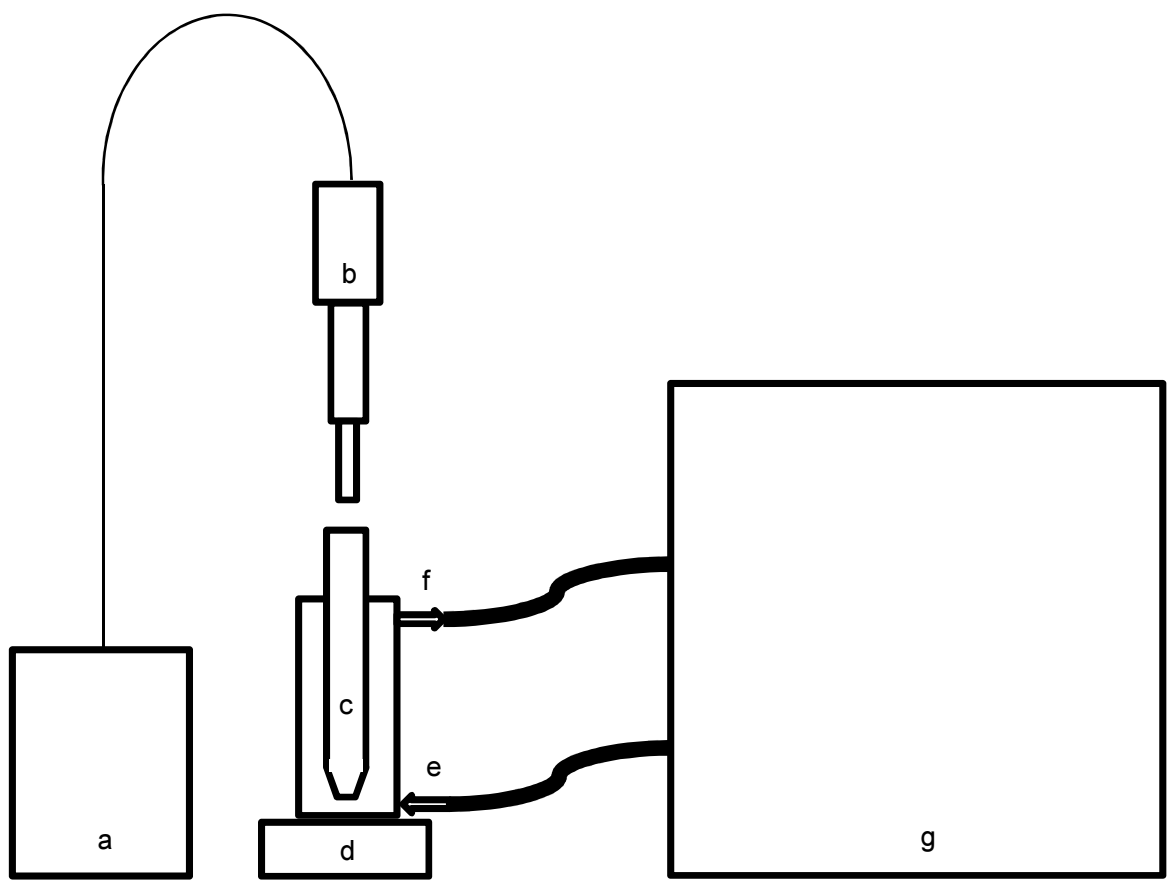

Figura 18. Esquema do aparato experimental utilizado: (a) fonte de energia, (b) transdutor de ultrassom, (c) frasco encamisado de fundo cônico, (d) elevador tipo Jack para laboratório, (e) entrada de água, (f) saída de água e (g) banho termostático.

\subsection{COMINUIÇÃO PROMOVIDA POR ULTRASSOM}

A cominuição causada pelo ultrassom foi investigada sistematicamente nas placas $M L$ e $D L$. O equipamento de ultrassom utilizado é o mesmo descrito na Figura 18. A série de experimentos realizada visou determinar a influência do tamanho de partícula e da potência de ultrassom na redução do tamanho de partícula de PCI ML. Ainda, foram realizados ensaios para se determinar a influência no número de camadas de cobre presentes na placa na cominuição promovida pelo ultrassom. Para isso, foram usadas placas DL moídas em grelhas de 6,4 e $2 \mathrm{~mm}$ e potência de ultrassom de $700 \mathrm{~W}$. A temperatura foi mantia em $25^{\circ} \mathrm{C}$ no decorrer do experimento, com auxílio do banho termostático.

Foi determinada a distribuição granulométrica da amostra inicial das placas ML e DL através do peneiramento em agitador mecânico marca 
Bronzinox, por 30 minutos, com as peneiras relacionadas na Tabela 9. As peneiras utilizadas tinha diâmetro de 3 polegadas e altura de 2 polegadas, 0 que permitiu que uma massa relativamente pequena fosse utilizada nos ensaios.

Tabela 9. Conjuntos de peneiras utilizadas para as diferentes amostras no ensaio granulométrico.

\begin{tabular}{ccc}
\hline Amostra de $6 \mathbf{m m}$ & Amostra de $\mathbf{4 m m}$ & Amostra de $\mathbf{~ m m}$ \\
\hline $4 \mathrm{~mm}$ & - & - \\
$2 \mathrm{~mm}$ & $2 \mathrm{~mm}$ & - \\
$1 \mathrm{~mm}$ & $1 \mathrm{~mm}$ & $1 \mathrm{~mm}$ \\
$0,50 \mathrm{~mm}$ & $0,50 \mathrm{~mm}$ & $0,50 \mathrm{~mm}$ \\
$0,250 \mathrm{~mm}$ & $0,250 \mathrm{~mm}$ & $0,250 \mathrm{~mm}$ \\
$0,125 \mathrm{~mm}$ & $0,125 \mathrm{~mm}$ & $0,125 \mathrm{~mm}$ \\
$0,075 \mathrm{~mm}$ & $0,075 \mathrm{~mm}$ & $0,075 \mathrm{~mm}$ \\
$0,038 \mathrm{~mm}$ & $0,038 \mathrm{~mm}$ & $0,038 \mathrm{~mm}$ \\
Fundo & Fundo & Fundo \\
\hline
\end{tabular}

Desta forma, cada amostra de $10 \mathrm{~g}$ foi submetida ao contato com ultrassom em potência pré-estabelecida por 1 hora, utilizando-se $200 \mathrm{~mL}$ de água destilada. A seguir, a amostra foi filtrada em sistema de vácuo com funil de Büchner de $150 \mathrm{~mm}$ e filtro quantitativo de filtragem lenta. A amostra foi levada para secagem em estufa a vácuo a $90^{\circ} \mathrm{C}$ por 24 horas e depois colocada em dessecador para resfriamento. Após a pesagem, a amostra foi cuidadosamente removida do filtro e novamente submetida ao ensaio granulométrico descrito e levada ao ensaio sonicado por mais 1 hora. Este procedimento foi repetido até que um total de 4 horas de contato com ultrassom fosse atingido. $O$ ensaio com placas $M L$ foi repetido para cada granulometria da amostra - 6, 4 e $2 \mathrm{~mm}$ - para cada potência - 700, 500 e $250 \mathrm{~W}$, e o ensaio com as placas DL foi feito com amostras de 6, 4 e $2 \mathrm{~mm}$ em potência de $700 \mathrm{~W}$. 
A Figura 19 traz um esquema no qual pode-se visualizar o ciclo de ensaios realizados. No total foram feitos 30 ensaios sonicados com as placas ML, cuja relação pode ser vista na Tabela 10 . Com as placas DL foram realizados 12 ensaios.

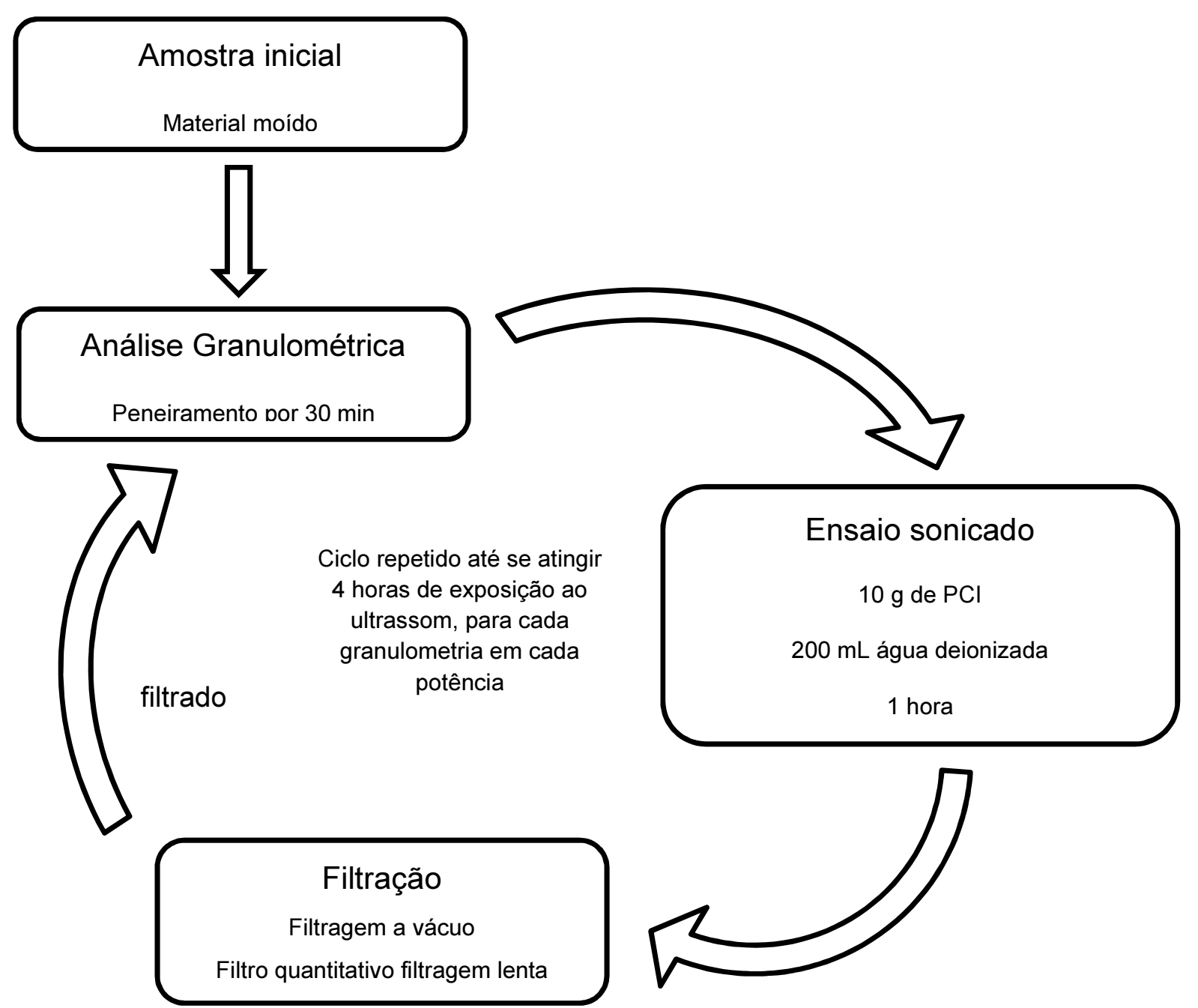

Figura 19. Esquema de ensaios realizados para averiguar a cominuição de $\mathrm{PCl}$ promovidas por ultrassom. 
Tabela 10. Relação de amostras de placa ML analisadas nas diferentes potências de ultrassom.

\begin{tabular}{lll}
\hline $\mathbf{7 0 0 W}$ & $\mathbf{5 0 0 W}$ & $\mathbf{2 5 0 W}$ \\
\hline $6 \mathrm{~mm}$ & $6 \mathrm{~mm}$ & $6 \mathrm{~mm}$ \\
$4 \mathrm{~mm}$ & $4 \mathrm{~mm}$ & $4 \mathrm{~mm}$ \\
$2 \mathrm{~mm}$ & $2 \mathrm{~mm}$ & $2 \mathrm{~mm}$ \\
\hline
\end{tabular}

A partir da distribuição granulométrica, foi feito o gráfico de passante acumulado e foi determinado o tamanho médio de partícula $\left(D_{50}\right)$ para cada amostra em cada tempo de exposição ao ultrassom. A determinação do percentual de cominuição foi realizada pela análise da redução do tamanho médio de partícula por tempo, utilizando-se a equação:

$$
\% \text { redução }=1-\frac{D_{50}^{i, j}}{D_{50}^{i, 0}}
$$

Na qual $D_{50}^{i, j}$ representa o tamanho médio de partícula da amostra $i$, após $j$ horas de contato com o ultrassom e $D_{50}^{i, 0}$ representa o tamanho médio de partícula da amostra $i$ inicial.

\subsection{LIXIVIAÇÃO POR ÁCIDO SULFÚRICO}

Os ensaios de lixiviação de $\mathrm{PCI} D L$ com ácido sulfúrico foram realizados de duas formas distintas: utilizando-se agitação mecânica com 300 rotações por minuto e irradiando-se ultrassom. Ao primeiro tipo de ensaio deu-se o nome de "silencioso" e ao segundo, "sonicado". O ensaio silencioso foi utilizado como referência ao ensaio sonicado. As mesmas condições utilizadas na realização dos ensaios silenciosos foram também aplicadas aos ensaios sonicados, sendo a única diferença entre ambos a utilização de agitação mecânica (silencioso) e irradiação com ultrassom (sonicado) na potência pré-determinada.

Os ensaios realizados visaram a determinação da influência da razão sólido-líquido (S/L) e da concentração de ácido na lixiviação de $\mathrm{Fe}, \mathrm{Al}$ e $\mathrm{Ni}$ 
presentes nas placas de circuito impresso. Para a determinação da influência da razão $S / L$ na lixiviação, a concentração de ácido foi fixada em $0,5 \mathrm{~mol} \cdot \mathrm{L}^{-1}$, sendo avaliadas as razões $S / L$ de 1:10, 1:20 e 1:40, em g.mL ${ }^{-1}$. A influência da concentração de ácido na lixiviação foi avaliada para as concentrações 0,01 ; 0,1; 0,5 e 1 mol. $\mathrm{L}^{-1}$, sendo a razão $\mathrm{S} / \mathrm{L}$ fixada em 1:20 neste conjunto de ensaios. A influência destes 2 parâmetros foi investigada no ensaio silencioso $e$ no ensaio sonicado, sendo este último realizado com potência de $700 \mathrm{~W}$. A Tabela 11 mostra o resumo dos parâmetros fixos e variáveis para esta investigação. A temperatura nestes ensaios foi mantida em $25^{\circ} \mathrm{C}$ com auxílio do banho termostático. Estes valores de razão $S / L$ foram escolhidos por representarem valores intermediários àqueles encontrados na literatura e aqueles aplicados na indústria. Em escala laboratorial, razões menores são preferidas pois permitem, em geral, maior extração dos metais (103). No entanto, em escala industrial, valores baixos de razão $S / L$ significam um grande volume de resíduos para se tratar posteriormente. Da mesma forma a concentração de ácido é aumentada no processamento industrial, para se reduzir o volume de efluentes líquidos.

Tabela 11. Condições utilizadas para investigação da influência dos parâmetros na lixiviação, para os ensaios silencioso e sonicado a 700W.

\begin{tabular}{ccc}
\hline & Razão S/L (g.mL $\left.{ }^{-1}\right)$ & {$\left[\mathrm{H}_{2} \mathbf{S O}_{4}\right]\left(\mathbf{m o l}^{\left.-L^{-1}\right)}\right.$} \\
\hline & $1: 10$ & 0,01 \\
Parâmetros Variáveis & $1: 20$ & 0,1 \\
& $1: 40$ & 0,5 \\
Parâmetros Fixados & {$\left[\mathrm{H}_{2} \mathrm{SO}_{4}\right]=0,5$ mol.L $^{-1}$} & Razão S/L 1:20 \\
\hline
\end{tabular}

A influência da potência de ultrassom também foi investigada, sendo utilizada razão $S / L$ de 1:20 e concentração de ácido de $0,5 \mathrm{~mol} \cdot \mathrm{L}^{-1}$. As potências investigadas foram 700,500 e $250 \mathrm{~W}$. A Tabela 12 contém os parâmetros utilizados para a verificação da influência da potência de ultrassom na lixiviação dos metais. 
Tabela 12. Condições utilizadas para investigação da influência dos parâmetros na lixiviação.

\begin{tabular}{cc}
\hline & Potência de ultrassom (W) \\
\hline Parâmetros Fixados & Razão S/L 1:20 \\
& {$\left[\mathrm{H}_{2} \mathrm{SO}_{4}\right]=0,5 \mathrm{~mol}^{-1} \mathrm{~L}^{-1}$} \\
& 250 \\
Parâmetros Variáveis & 500 \\
& 700 \\
\hline
\end{tabular}

O volume de solução foi padronizado em $200 \mathrm{~mL}$. Para cada ensaio, foi utilizada a massa de $\mathrm{PCl}$ correspondente, obtida por quarteamento em pilhas cônicas. O sistema de lixiviação foi mantido em temperatura de $25^{\circ} \mathrm{C}$ por um banho termostático Quimis, com tempo de estabilização de no mínimo 1 hora antes do início de cada experimento. $O$ ácido foi diluído previamente utilizando-se balão volumétrico e a solução também foi mantida em banho termostático por no mínimo 1 hora antes do experimento.

Para o levantamento da curva de formação de ion metálico, foi feita a amostragem de $3 \mathrm{~mL}$ utilizando-se micropipeta em tempos de 5, 10, 15, 30 e 60 minutos. Cada amostra foi filtrada com auxílio de uma seringa e filtro marca Sartorius ${ }^{\circledR}$ de $0,45 \mu \mathrm{m}$ e vedada com Parafilm. Nos ensaios sonicados, foi considerado apenas o tempo de contato da amostra com a irradiação de ultrassom, sem ser considerado o tempo de retirada de amostra (aprox. $20 \mathrm{seg}$ ). Ao final de 1 hora, o material foi filtrado em vácuo em filtro quantitativo de filtragem lenta e em seguida foi levado para secagem em estufa a vácuo a $90^{\circ} \mathrm{C}$ por 1 hora. Ao final da secagem, a massa foi aferida para o balanço de massa. As análises químicas foram realizadas por Espectrômetro de Fluorescência de Raios X por Energia Dispersiva (EDXRF), marca PANalytical, modelo Epsilon 3 - XL ânodo de $\mathrm{Ag}$, sendo analisados os metais $\mathrm{Fe}, \mathrm{Zn}, \mathrm{Ni}, \mathrm{Al}$, $\mathrm{Sn}, \mathrm{Cu}$ e Ti. As curvas de calibração foram obtidas a partir da diluição de solução padrão de 10.000 ppm, nas concentrações de 1, 5, 10, 50, 100, 500 e $1000 \mathrm{ppm}$. 
O percentual de extração de metal para cada amostra foi calculado com base na equação:

$$
\% \text { extração }=\frac{[M e]_{i}}{[M e]_{\infty}} \cdot 100 \%
$$

Sendo o termo $[\mathrm{Me}]_{i}$ a concentração do metal obtida no tempo $i$ e $[M e]_{\infty}$ a concentração obtida se todo o metal fosse lixiviado, sendo utilizado para este cálculo a equação:

$$
[M e]_{\infty}=\frac{x_{M e} \cdot m_{\text {ensaio }}}{V}
$$

$\mathrm{Na}$ qual $x_{M e}$ corresponde à fração de metal obtida pela caracterização com água régia (item 4.2.2), $m_{\text {ensaio }}$ à massa de placa utilizada no ensaio e $V$ o volume da reação, sendo utilizado $200 \mathrm{~mL}$.

No experimento em que foi utilizada a razão $S / L$ de 1:40, concentração de ácido de $0,5 \mathrm{~mol} . \mathrm{L}^{-1}$ e potência de ultrassom de $700 \mathrm{~W}$ houve um desgaste da ponteira rosqueável, o que ocasionou uma sobrecarga no equipamento e sua consequente falha elétrica. Este fato provocou a interrupção do experimento antes do tempo estipulado, por isson nas figuras em que são utilizados estes resultados, falta o ponto referente ao tempo de 60 minutos. No entanto, é possível realizar a análise das curvas, utilizando-se o início da reação.

\subsection{ENSAIO DE LIXIVIAÇÃO COM MEIO OXIDANTE}

Além dos ensaios de lixiviação com ácido sulfúrico, foram realizados ensaios com ácido sulfúrico em meio oxidante. Neste caso, foi utilizado oxigênio gasoso, inserido na reação através de um difusor convencional ligado a um cilindro de $\mathrm{O}_{2}$, marca Linde, com $99,5 \%$ de pureza.

Ao se utilizar meio oxidante juntamente com ácido sulfúrico, espera-se que haja uma maior lixiviação dos metais, uma vez que o oxigênio introduzido forneça uma maior quantidade de agente oxidante. Além disto, a introdução de oxigênio gasoso no meio reacional em presença de ultrassom causa a 
formação de radical hidróxido, HO., o que pode alterar a taxa de lixiviação (104).

Os metais analisados foram $\mathrm{Fe}, \mathrm{Al}$ e $\mathrm{Ni}$, de acordo com a seção 4.5, juntamente com cobre. O cobre foi analisado somente nesta seção pois o ácido sulfúrico sem nenhum agente oxidante não é capaz de lixiviar este metal.

Foram realizados ensaios silencioso e sonicado. A concentração de ácido sulfúrico foi fixada em 0,5 mol. $L^{-1}$, razão $S / L$ de 1:40 e uma vazão de $\mathrm{O}_{2}$ de $100 \mathrm{~mL} \cdot \mathrm{min}^{-1}$. No ensaio silencioso foi utilizada agitação mecânica, com um agitador a 300 rotações por minuto, e no ensaio sonicado foi utilizada potência de $700 \mathrm{~W}$. Foram retiradas alíquotas de $3 \mathrm{~mL}$ nos tempos 5, 10, 15, 30, 60, 120 e 180 minutos. A Figura 20 mostra o frasco encamisado de fundo cônico com o sistema de inserção de oxigênio, composto por uma mangueira incolor e no fundo do frasco, o difusor na cor rosa.

O ensaio com potência de $700 \mathrm{~W}$ apresentou uma sobrecarga devido ao desgaste precoce da ponteira, o que causou seu interrompimento antes do final predeterminado. No entanto, é possível se comparas as curvas obtidas com as curvas do ensaio silencioso. 


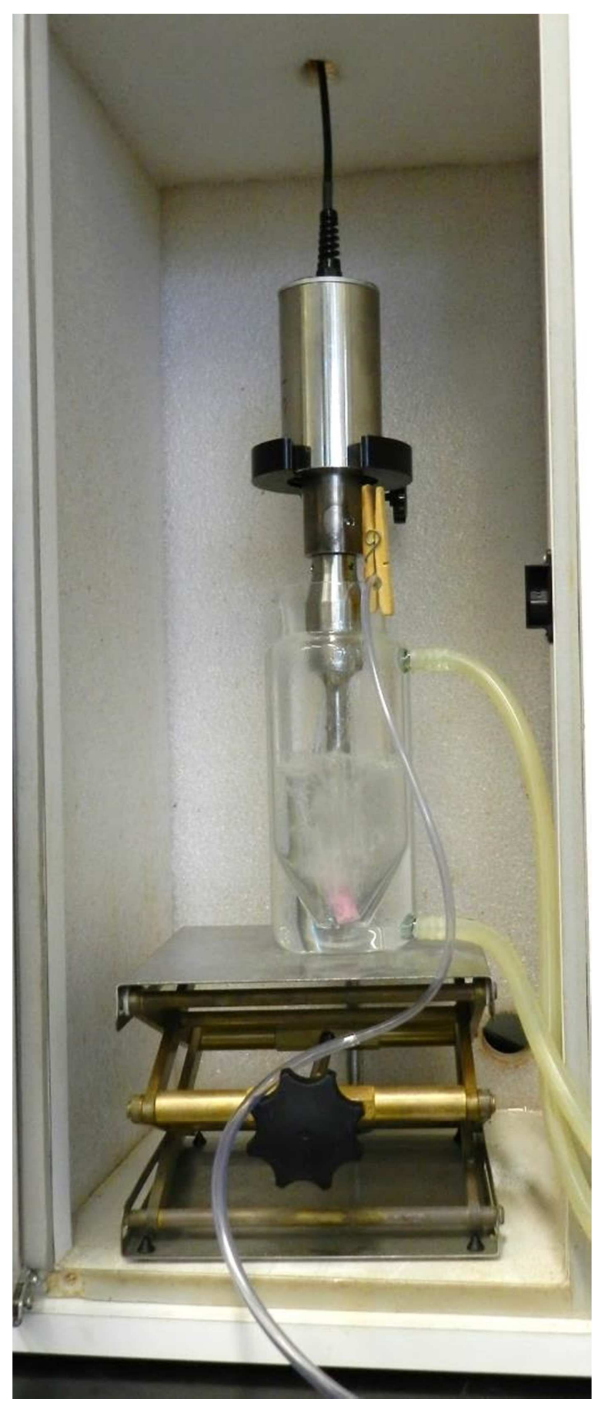

Figura 20. Configuração do experimento utilizando-se ácido sulfúrico em meio oxidante.

4.7. COMPARAÇÃO ENTRE LIXIVIAÇÃO COM ÁCIDO SULFÚRICO NA AUSÊNCIA E PRESENÇA DE MEIO OXIDANTE

Com os dados de lixiviação dos metais presentas na placa de circuito impresso foi realizada uma comparação entre os percentuais de extração na situação em que foi empregado somente ácido sulfúrico com os ensaios nos quais foram empregados ácido sulfúrico com meio oxidante. Neste caso, foram comparados os metais ferro, alumínio, níquel e cobre. 


\subsection{ANÁLISE CINÉTICA}

Como descrito no item 2.8 (Cinética Química), diversas equações podem ser analisadas no intuito de identificar o mecanismo controlador da cinética de reações heterogêneas. Essas equações são usualmente expressas na forma $f\left(X_{B}\right)=k t$, onde $X_{B}$ é a fração reagida, $k$ é a constante de velocidade e $t$ é o tempo.

As equações 12 e 18 apresentam as expressões para controle por difusão na camada limite e controle por reação química, respectivamente. Essas equações são reescritas:

$$
\begin{aligned}
& \frac{t}{\tau}=1-\left(1-\frac{R}{R_{0}}\right)^{\frac{2}{3}} \\
& \frac{t}{\tau}=1-\left(1-\frac{R}{R_{0}}\right)^{\frac{1}{3}}
\end{aligned}
$$

Fazendo-se a mudança de variável expressa na equação 10 , que supõe as partículas de forma esférica, e rearranjando no formato $f\left(X_{B}\right)=k t$, obtém-se as equações 29 e 30 . Nessas e nas próximas equações, o termo $X_{B}$ corresponde a fração de metal que foi lixiviada em relação à quantidade total deste metal presente na placa de circuito impresso. O valor total foi obtido a partir da caracterização em água régia, descrita na seção 4.2.2.

$$
\begin{aligned}
& 1-\left(1-X_{B}\right)^{\frac{2}{3}}=k \cdot t \\
& 1-\left(1-X_{B}\right)^{\frac{1}{3}}=k \cdot t
\end{aligned}
$$


Outras funções que podem ser utilizadas para linearizar os resultados experimentais são expressas pelas equações 30 e 33 :

$$
\begin{gathered}
1-3\left(1-X_{B}\right)^{\frac{2}{3}}+2\left(1-X_{B}\right)=k \cdot t \\
\ln \left(1-X_{B}\right)=k \cdot t
\end{gathered}
$$

Enquanto que a equação 31 é utilizada para representar reações controladas por difusão através da camada porosa de produtos sólidos reação, a equação 32 representam reações químicas de $1^{\text {a }}$ ordem (105).

Para identificar o modelo cinético, utilizou-se o método do tempo reduzido (105) (106), descrito a seguir.

Escolhe-se uma função $f\left(X_{B}\right)$ para verificação. Se a expressão for válida para qualquer instante de tempo $t$, então ela será válida para um instante de tempo específico, definido anteriormente e representado por $\mathrm{t}^{*}$; a este instante de tempo, está associada uma fração reagida $X^{*}$. No presente trabalho, o tempo escolhido foi alterado de acordo com o conjunto de resultados experimentais obtidos. Dessa forma, é válido que:

$$
f\left(X_{B}=X^{*}\right)=f\left(X^{*}\right)=k . t^{*}
$$

Como a constante de velocidade não é alterada, pode-se isolá-la na equação 33 e na forma geral. Igualando essas duas expressões, obtém-se:

$$
\frac{f\left(X_{B}\right)}{f\left(X^{*}\right)}=\frac{t}{t^{*}}
$$

A equação 34 independe da constante de velocidade e é adimensional. Deste modo, para uma determinada função $f$, pode-se calcular $f$ para cada $X_{B}$ e 
dividir pelo valor de $f\left(X^{*}\right)$, obtendo-se o valor de $\frac{t}{t^{*}}$ (parâmetro chamado de "tempo reduzido") para cada $X_{B}$. Com esses pontos, são construídas as curvas de $X_{B}$ em função de $\frac{t}{t^{*}}$ para cada função $f$ que se quer verificar. Os pontos experimentais coincidirão com a curva da função que representa a cinética global do processo.

No presente trabalho, foram utilizados dados referentes aos ensaios silenciosos com e sem adição de oxidante, além do ensaio sonicado com potencia de $700 \mathrm{~W}$. A análise cinética foi utilizada para razão sólido/líquido 1:40 e concentração de ácido $0,5 \mathrm{~mol} / \mathrm{L}$. Foi tentado avaliar os resultados dos metais ferro, alumínio, níquel e cobre, contudo a análise somente foi possível para o primeiro metal, que apresentou maiores extrações. A discussão dessas análises e justificativas para a não realização para os demais metais são apresentadas na seção 5.7 . 


\section{RESULTADOS E DISCUSSÃO}

\subsection{COMINUIÇÃO}

A cominuição das placas $M L$ foi realizada com 37 placas de celular $M L$, um total de $514,6 \mathrm{~g}$. Previamente à cominuição, foram removidas as placas de proteção dos chips, baterias, alto-falantes e motores excêntricos (vibrador). A massa destes itens corresponde a 109,0 g, restando 403,4 g de placas ML para moagem. As placas foram então cortadas em guilhotina para facilitar a alimentação no moinho. Uma fotografia das placas pode ser vista na Figura 21.

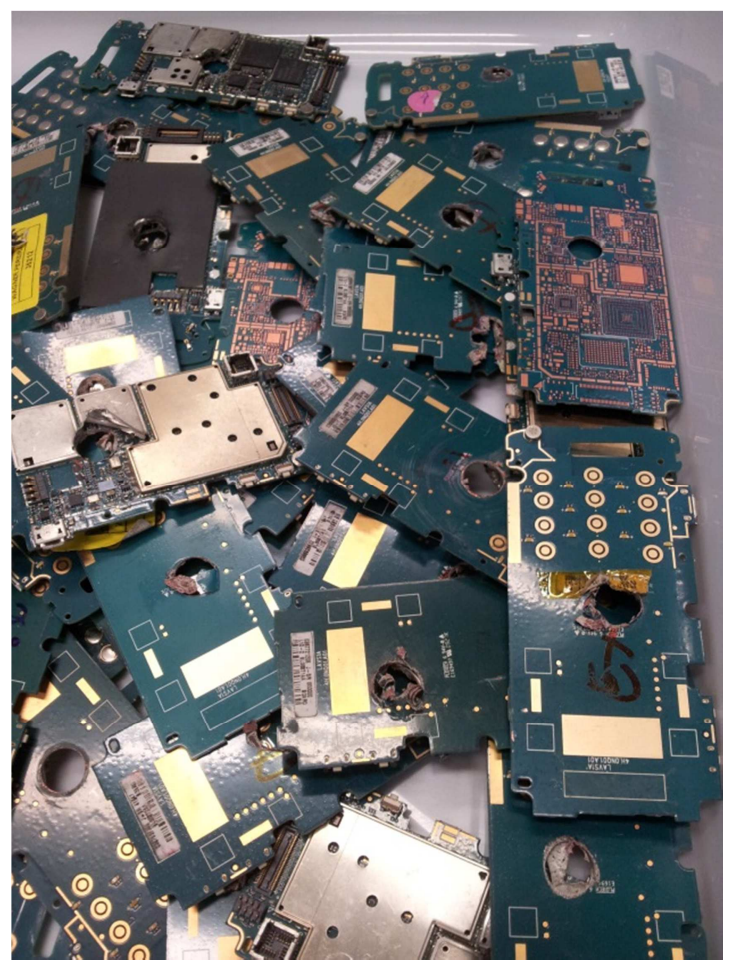

Figura 21. Placas ML previamente ao tratamento. 
As placas foram cominuídas inicialmente em grelha de $6 \mathrm{~mm}$. O material moído foi quarteado para retirada de uma amostra de aproximadamente $100 \mathrm{~g}$ e o restante foi moído em grelha de $4 \mathrm{~mm}$. Após a nova moagem, a amostra foi quarteada, sendo retirada uma amostra de aproximadamente $130 \mathrm{~g}$, sendo o restante do material moído em grelha de $2 \mathrm{~mm}$. Foi escolhido este procedimento para garantir a homogeneidade da amostra, uma vez que a moagem de algumas placas em cada fração poderia causar diferença na composição, pois as placas não apresentavam todos os componentes. $O$ balanço da cominuição e as perdas podem ser vistas na Tabela 13.

Tabela 13. Balanço de massa da cominuição em moinho de martelos da amostra ML.

$\begin{array}{cccccc} & \text { inicio (g) } & \text { fim (g) } & \text { perda (g) } & \% \text { perda } & \begin{array}{c}\text { massa } \\ \text { reservada (g) }\end{array} \\ \text { massa grelha de 6mm } & 403,4 & 384,2 & 19,2 & 4,8 \% & 98,8 \\ \text { massa grelha de } 4 \mathrm{~mm} & 285,4 & 273,0 & 12,4 & 4,3 \% & 130,0 \\ \text { massa grelha de } 2 \mathrm{~mm} & 143,0 & 101,0 & 42,0 & 29,4 \% & 101,0 \\ \text { coletado no chão } & - & - & - & - & 36,0\end{array}$

A cominuição nas grelhas de 6 e $4 \mathrm{~mm}$ tiveram perdas baixas ( $\sim 4 \%$ em cada) quando comparado à grelha de $2 \mathrm{~mm}(\sim 30 \%)$. Este aumento na perda relativa à cominuição se dá pelo fato de o material de entrada já estar moído, o que acarreta perdas pela exaustão da capela. Além disto, para o material atingir o tamanho de saída de $2 \mathrm{~mm}$, é necessário um maior tempo de contato com os martelos e consequentemente um maior tempo de retenção dentro do moinho, o que também aumenta a perda de finos.

Já a cominuição das placas $\mathrm{DL}$ foi realizada com 6 placas-mãe, resultando em aproximadamente $3,5 \mathrm{~kg}$. Foram removidos previamente à cominuição, os dissipadores de calor, parafusos, suporte do processador, bateria, jumpers e a carcaça das saídas (USB, P2, VGA, ethernet). A massa total destes componentes foi em torno de $0,6 \mathrm{~kg}$, restando aproximadamente $2,7 \mathrm{~kg}$ de placas para moagem. As placas foram então cortadas em uma 
guilhotina, para que fosse facilitada a alimentação no moinho. A placa utilizada pode ser vista na Figura 22 (a). Os itens removidos de uma placa estão na Figura 22 (b) e as placas cortadas em pedaços pode ser vista na Figura 22 (c).
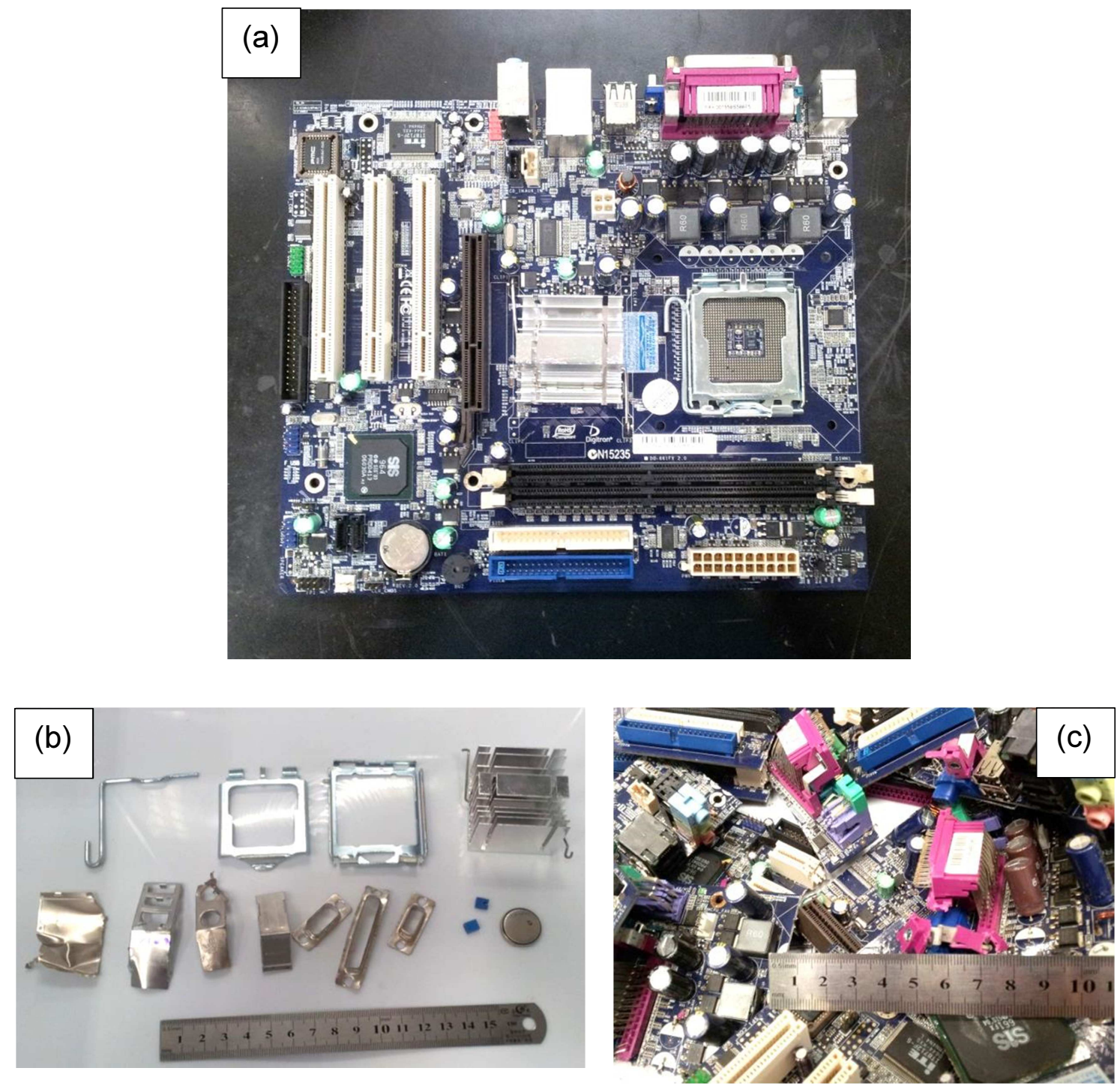

Figura 22. PCI DL de desktop antes da cominuição (a); itens removidos manualmente (b) e $\mathrm{PCl}$ cortada em pedaços (c).

Após a separação e pré-cominuição, as placas foram então cominuídas em moinho de martelos. $O$ balanço de massa pode ser visualizado na Tabela 14. 
Tabela 14. Balanço de massa da etapa de cominuição em moinho de martelos.

$$
\text { inicio (g) fim (g) perda (g) \% perda } \begin{gathered}
\text { massa } \\
\text { reservada }(g)
\end{gathered}
$$

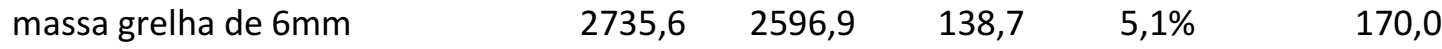

$\begin{array}{lllll}\text { massa grelha de } 4 \mathrm{~mm} & 2426,9 & 2267,4 & 159,5 & 6,6 \%\end{array}$

$\begin{array}{llllll}\text { massa grelha de } 2 \mathrm{~mm} & 2047,4 & 1689,6 & 357,8 & 17,5 \% & 1689,6\end{array}$

$\begin{array}{lllllll}\text { coletado no chão } & - & - & - & - & - & \end{array}$

O material recolhido do chão foi coletado com uma vassoura e uma pá e reservado. A cominuição em grelha de $2 \mathrm{~mm}$ apresentou o maior percentual relativo de perda pois ao se alimentar o moinho com um material previamente moído aumanta-se a perda de finos pela exaustão. As amostras oriundas de cada etapa da cominuição foram quarteadas e reservadas.

\subsection{CARACTERIZAÇÃO DE PCI DL}

A fração em massa de metais das placas DL está reportada na Tabela 15. A maior fração corresponde ao cobre $(19,7 \%)$, seguido de alumínio $(6,8 \%)$, estanho $(5,0 \%)$, zinco $(2,2 \%)$, ferro $(0,6 \%)$ e por último, níquel $(0,2 \%)$.

O percentual de ferro encontrado abaixo de $1 \%$ se deu pela retirada das carcaças metálicas durante o pré-tratamento. $\mathrm{O}$ cobre é encontrado principalmente como material condutor nas trilhas internas da placa (29), bem como nos indutores e representa o metal com maior percentual em massa. $O$ estanho se encontra principalmente na solda. Zinco está presente em ligas, como o latão, nos conectores de jumpers (107). O alumínio está nos capacitores eletrolíticos, tanto na forma metálica, compondo as placas, como no dielétrico, na forma de óxido (108). O níquel é usado no recobrimento de contatos elétricos (109). 
Tabela 15. Resultados da caracterização das placas DL.

$\begin{array}{cc}\text { Metal } & \text { Percentual em } \\ \mathrm{Cu} & 19.7 \% \\ \mathrm{Al} & 6.8 \% \\ \mathrm{Sn} & 5.0 \% \\ \mathrm{Zn} & 2.2 \% \\ \mathrm{Fe} & 0.6 \% \\ \mathrm{Ni} & 0.2 \%\end{array}$

A distribuição granulométrica da placa DL pode ser visualizada na Tabela 16 e na Figura 23.

Tabela 16. Distribuição granulométrica da amostra DL

\begin{tabular}{|c|c|c|}
\hline Peneira (mm) & Retido & Passante Acumulado \\
\hline 1,00 & $12.6 \%$ & $87.4 \%$ \\
\hline 0,50 & $31.4 \%$ & $56.0 \%$ \\
\hline 0,25 & $25.4 \%$ & $30.6 \%$ \\
\hline 0,125 & $13.7 \%$ & $16.9 \%$ \\
\hline 0,075 & $5.1 \%$ & $11.8 \%$ \\
\hline 0,038 & $5.8 \%$ & $6.0 \%$ \\
\hline Fundo & $6.0 \%$ & $0.1 \%$ \\
\hline
\end{tabular}

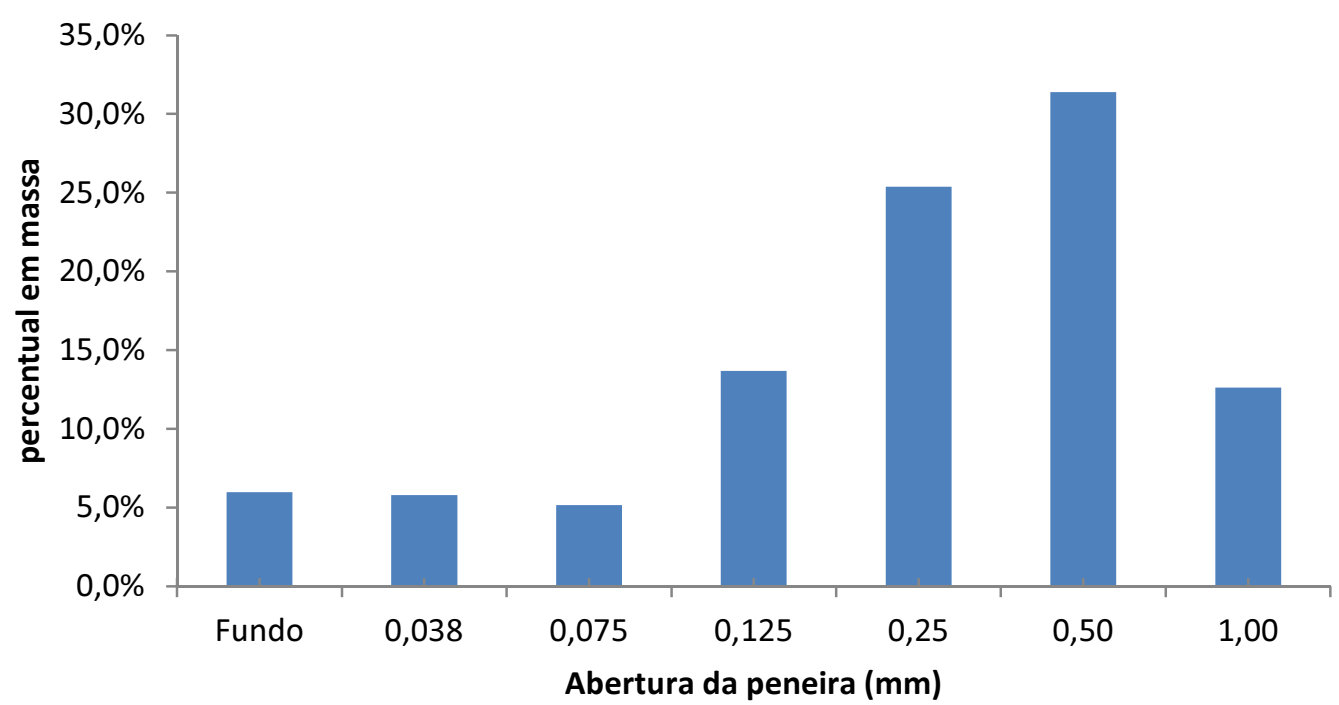

Figura 23. Distribuição granulométrica da amostra DL cominuída em grelha de $2 \mathrm{~mm}$. Percentual retido em cada peneira.

Há maior concentração de material nas frações de $0,50 \mathrm{~mm}$, seguido pela fração de $0,250 \mathrm{~mm}$. 


\subsection{COMINUIÇÃO PROMOVIDA POR ULTRASSOM}

Com os ensaios realizados, foi possível verificar quantitativamente 0 efeito do ultrassom na cominuição de placas ML e nas placas DL.

A Figura 24 mostra as curvas do material passante acumulado da placa ML moída em grelha de $6 \mathrm{~mm}$, em sucessivos tempos de ultrassom, utilizandose potência de $700 \mathrm{~W}$. Nota-se que as curvas vão se deslocando para tamanhos menores de partícula com o aumento do tempo de exposição de ultrassom, o que indica que há cominuição pelo efeito do ultrassom.

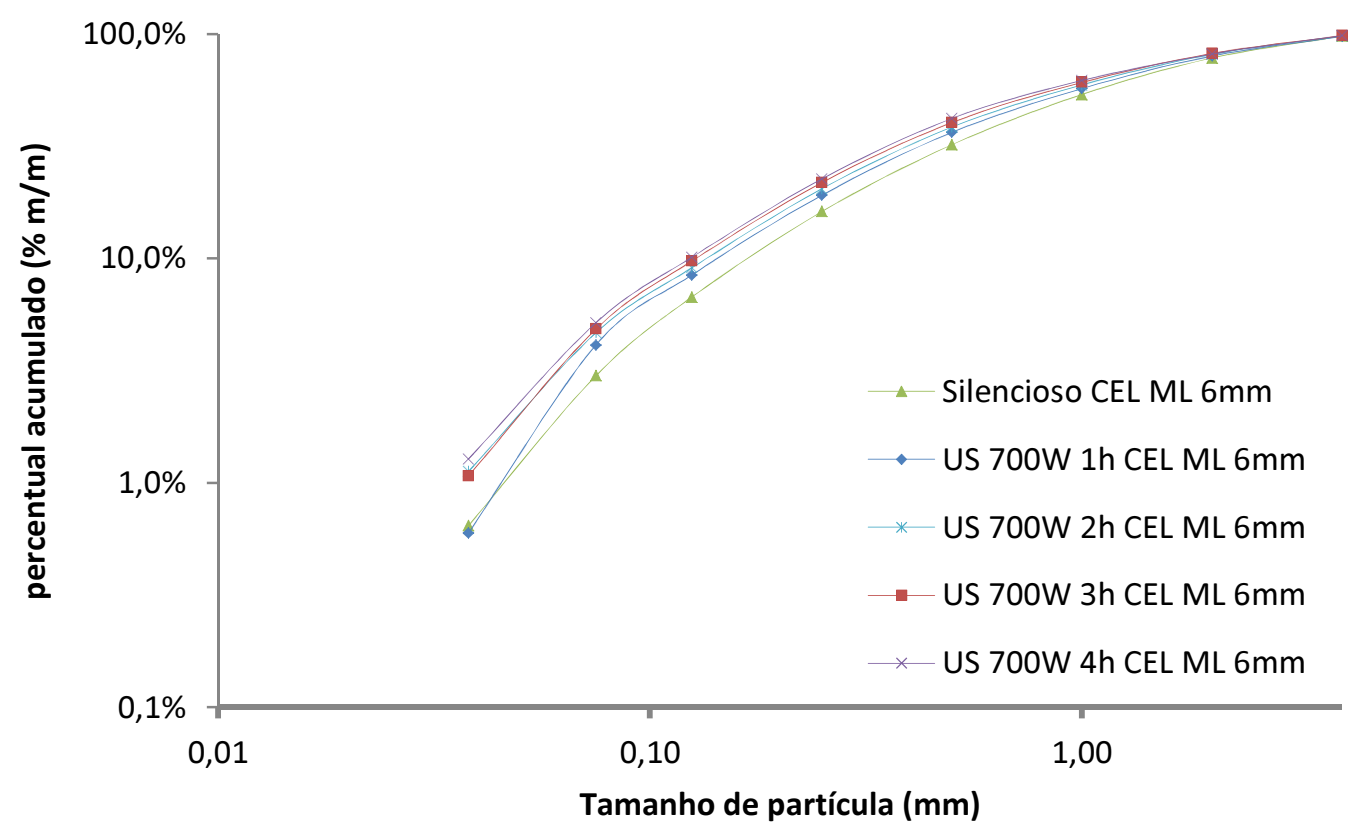

Figura 24. Material passante acumulado: ML moída em grelha de $6 \mathrm{~mm}$ em tempos distintos de exposição ao ultrassom, com potência de $700 \mathrm{~W}$.

Na Figura 25 têm-se as curvas de material passante acumulado das placas ML de $6 \mathrm{~mm}$ em tempos sucessivos de exposição ao ultrassom, em potência de $500 \mathrm{~W}$. Novamente, há um deslocamento das curvas para tamanhos menores de partículas com o aumento de exposição o ultrassom, porém este deslocamento é mais tênue do que aquele da Figura 24, uma vez que a menor potência causa uma menor quantidade de bolhas de cavitação. 


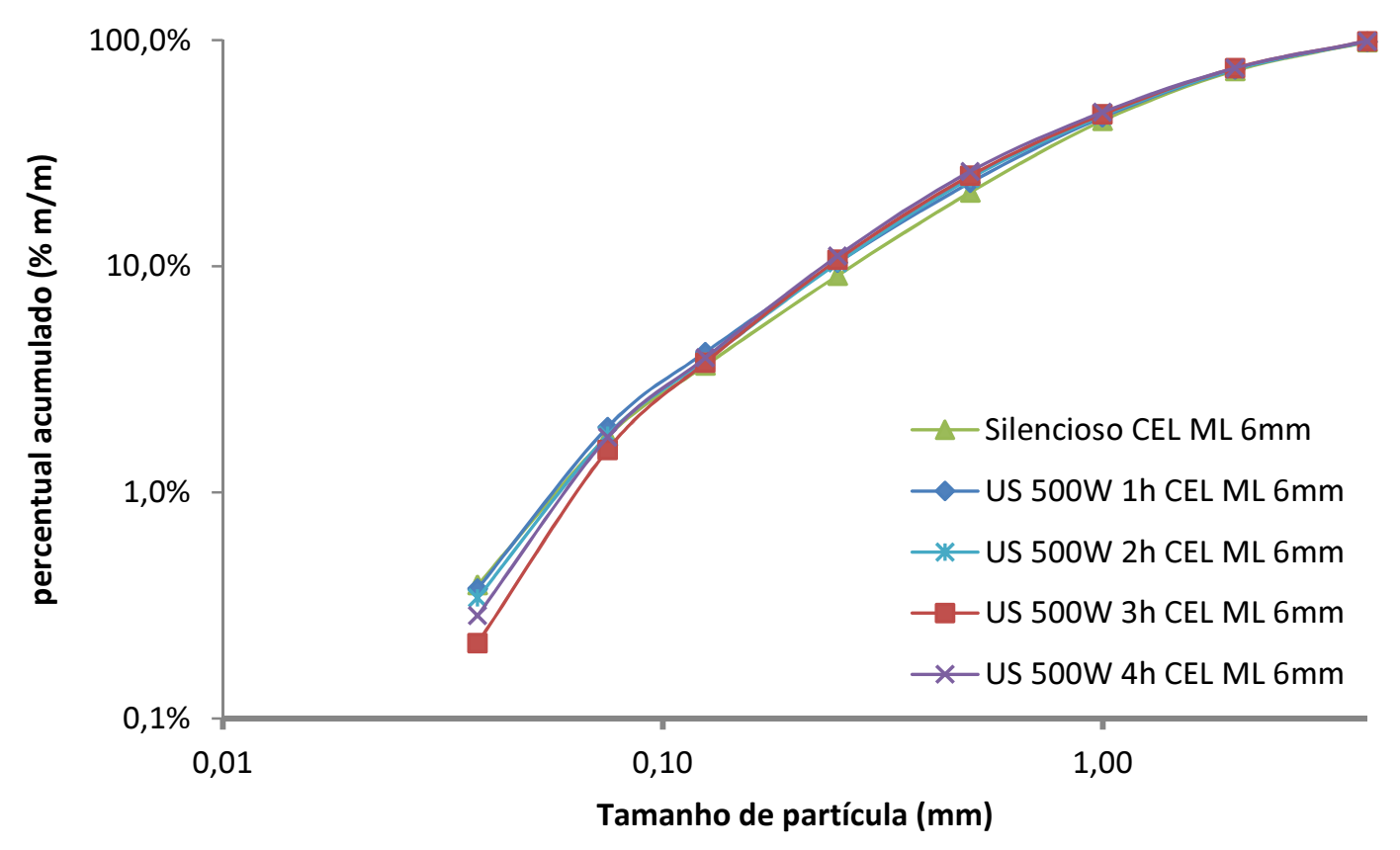

Figura 25. Material passante acumulado: ML moída em grelha de $6 \mathrm{~mm}$ em tempos distintos de exposição ao ultrassom, com potência de 500W.

Os ensaios realizados com a placa $\mathrm{DL}$ de $6 \mathrm{~mm}$ em potência de $700 \mathrm{~W}$ são apresentados na

Figura 26.

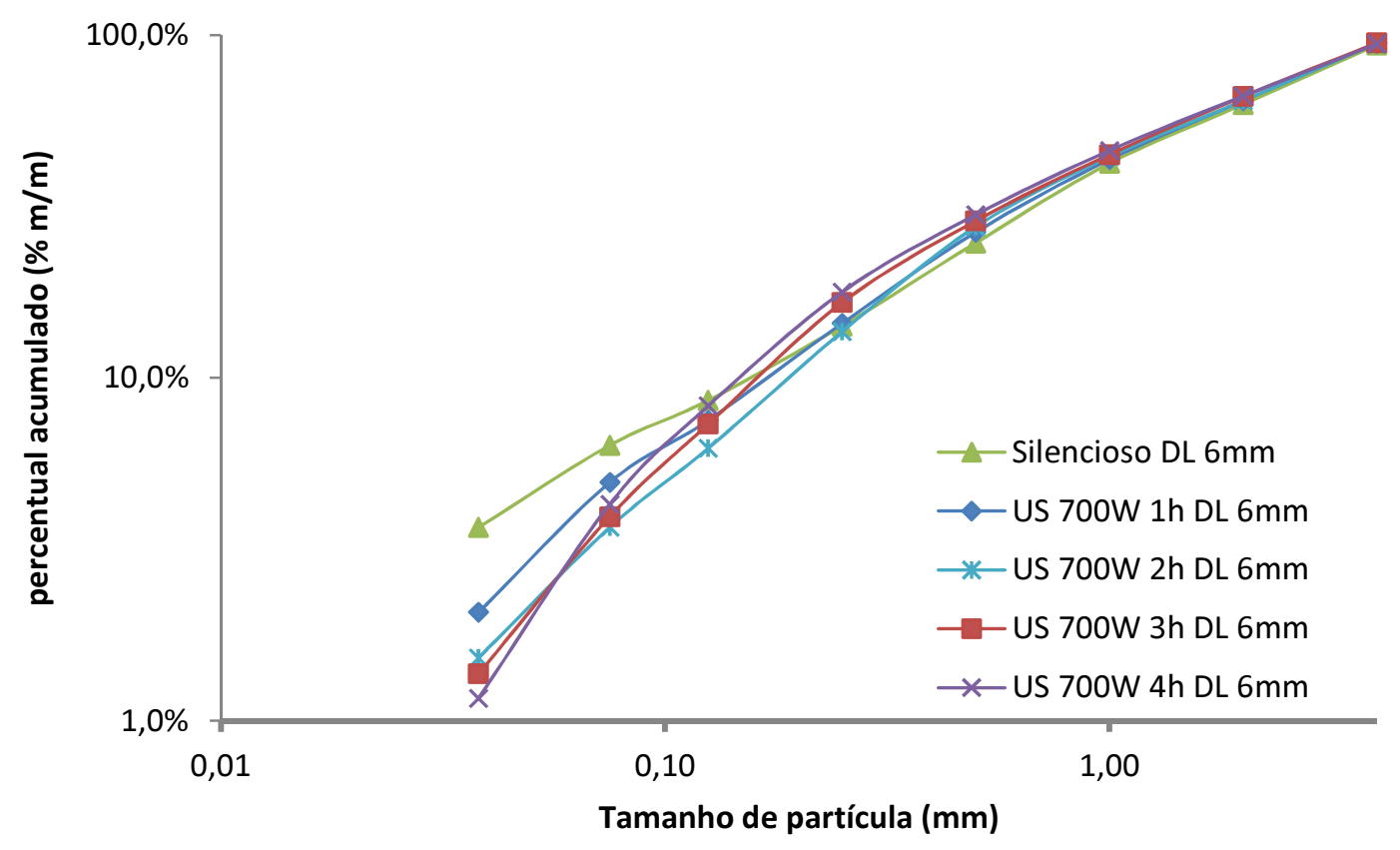


Figura 26. Material passante acumulado: DL moída em grelha de $6 \mathrm{~mm}$ em tempos distintos de exposição ao ultrassom, com potência de $700 \mathrm{~W}$.

A Figura 27 foi obtida a partir dos valores de tamanho médio de partícula para a placa ML $6 \mathrm{~mm}$ exposta ao ultrassom em potências de 700,500 e $250 \mathrm{~W}$.

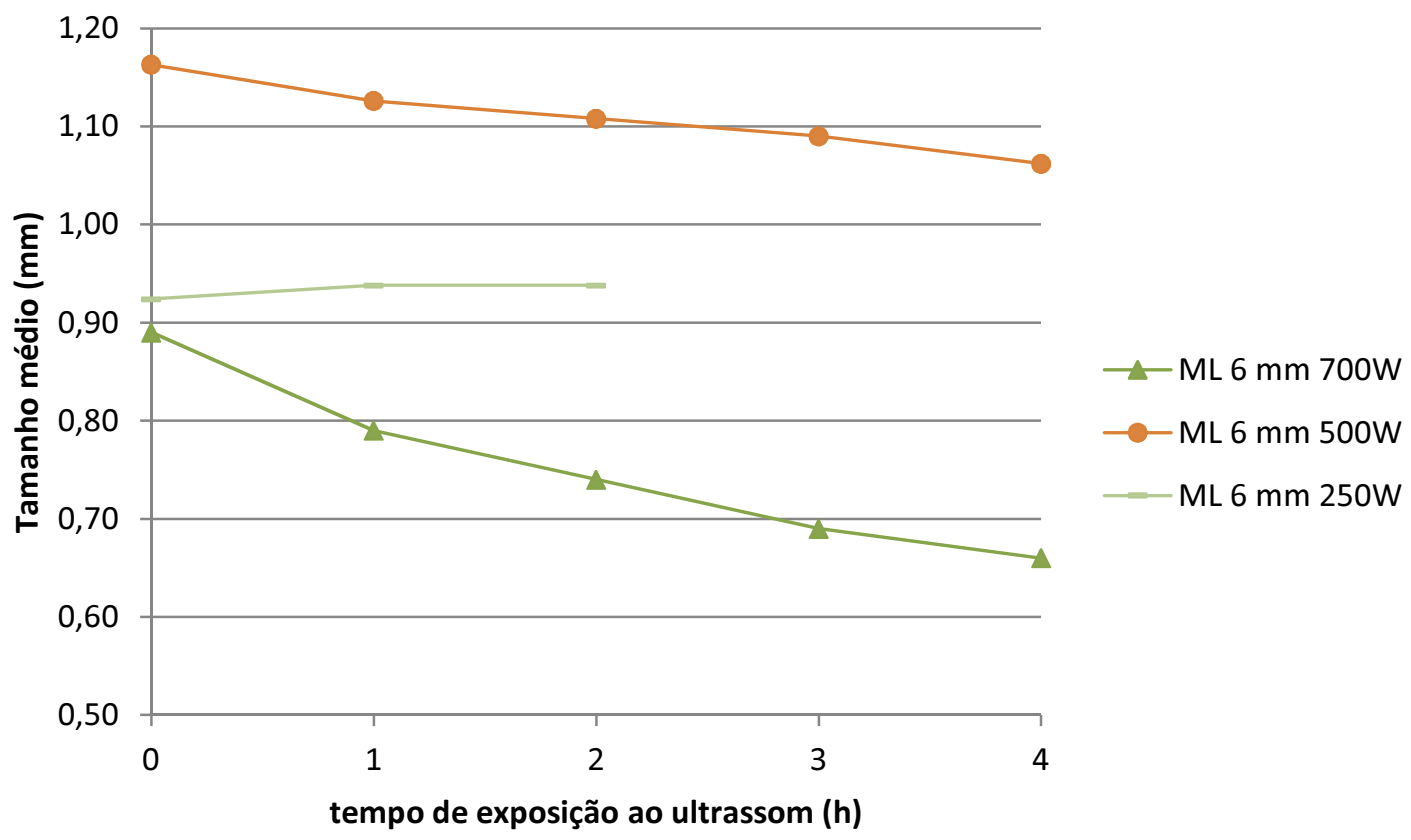

Figura 27. Redução do tamanho médio de partícula: ML $6 \mathrm{~mm}$ em diferentes potências de ultrassom.

Pode-se verificar na Figura 27 a redução do tamanho médio de partícula, sendo mais acentuada na potência de $700 \mathrm{~W}$. Neste caso, houve a redução de $0,89 \mathrm{~mm}$ no ensaio granulométrico inicial para $0,66 \mathrm{~mm}$ após 4 horas de exposição ao ultrassom, rerpesentando uma diminuição de $26 \%$. No ensaio utilizando-se $500 \mathrm{~W}$ de potência, a redução foi de $1,16 \mathrm{~mm}$ para $1,06 \mathrm{~mm}$ $(8,7 \%)$. O ensaio utilizando-se $250 \mathrm{~W}$ foi feito por apenas 2 horas, uma vez que neste período não houve redução do tamanho de partícula.

A Figura 28 contém as curvas de redução do tamanho médio de partícula para a placa ML moída em grelha de $4 \mathrm{~mm}$ sob exposição a diferentes potências de ultrassom. 


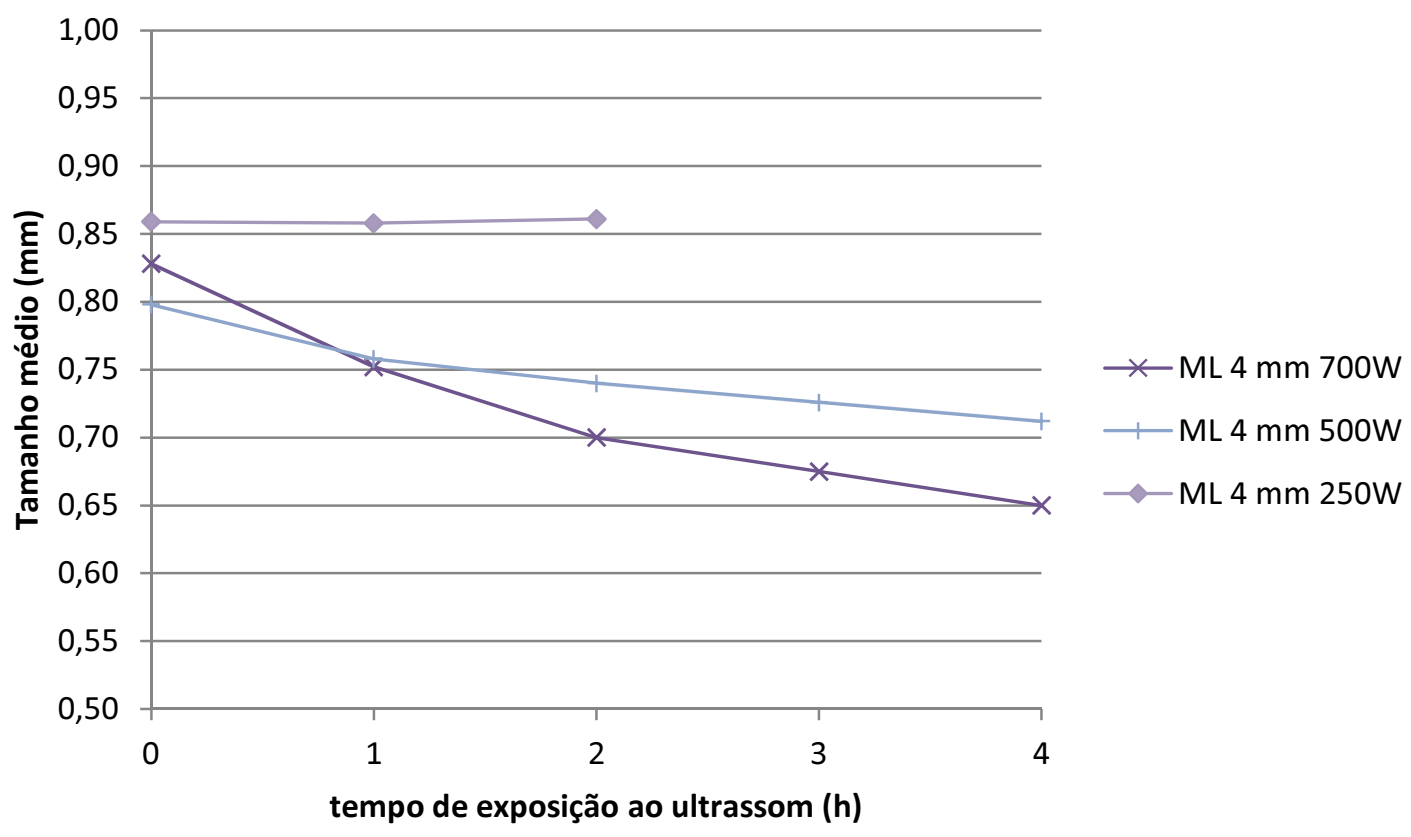

Figura 28. Redução do tamanho médio de partícula: ML $4 \mathrm{~mm}$ em diferentes potências de ultrassom.

A maior redução do tamanho médio da amostra foi observada em potência de $700 \mathrm{~W}$, cujo tamanho médio foi reduzido de $0,83 \mathrm{~mm}$ para $0,65 \mathrm{~mm}$ após 4 horas de exposição ao ultrassom, representando uma diminuição de $21 \%$. A potência de $500 \mathrm{~W}$ reduziu o tamanho médio de $0,80 \mathrm{~mm}$ para $0,71 \mathrm{~mm}$ (11\%). O ensaio utilizando potência de $250 \mathrm{~W}$, após 2 horas de exposição ao ultrassom, não resultou em redução do tamanho médio de partícula.

A Figura 29 traz as curvas de redução de tamanho médio de partícula para a amostra de $2 \mathrm{~mm}$ exposta a diferentes potências de ultrassom. 


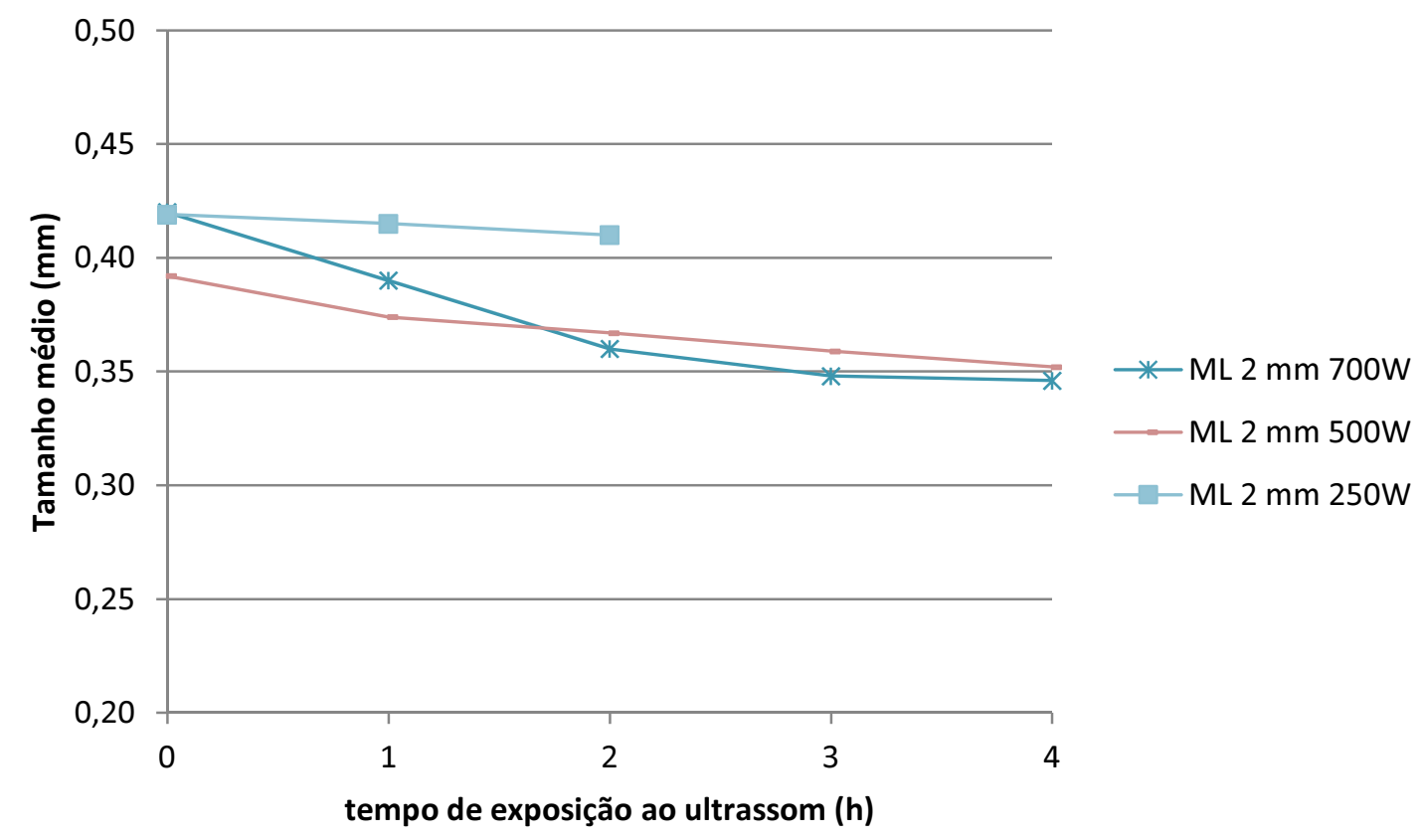

Figura 29. Redução do tamanho médio de partícula: ML $2 \mathrm{~mm}$ em diferentes potências de ultrassom.

Novamente, a potência de $700 \mathrm{~W}$ causou a maior redução, sendo o valor de tamanho médio reduzido de $0,42 \mathrm{~mm}$ para $0,35 \mathrm{~mm}(18 \%)$. O ensaio utilizando-se potência de $500 \mathrm{~W}$ reduziu o tamanho médio de $0,39 \mathrm{~mm}$ para $0,35 \mathrm{~mm}(10 \%)$ e o ensaio com $250 \mathrm{~W}$ causou uma redução de $0,42 \mathrm{~mm}$ para $0,41 \mathrm{~mm}$ em 2 horas de ensaio.

A Figura 30 mostra as curvas de redução de tamanho médio de partícula, para as amostras de placa ML cominuídas em grelha de 6, 4 e $2 \mathrm{~mm}$, expostas à ultrassom em potência de $700 \mathrm{~W}$. 


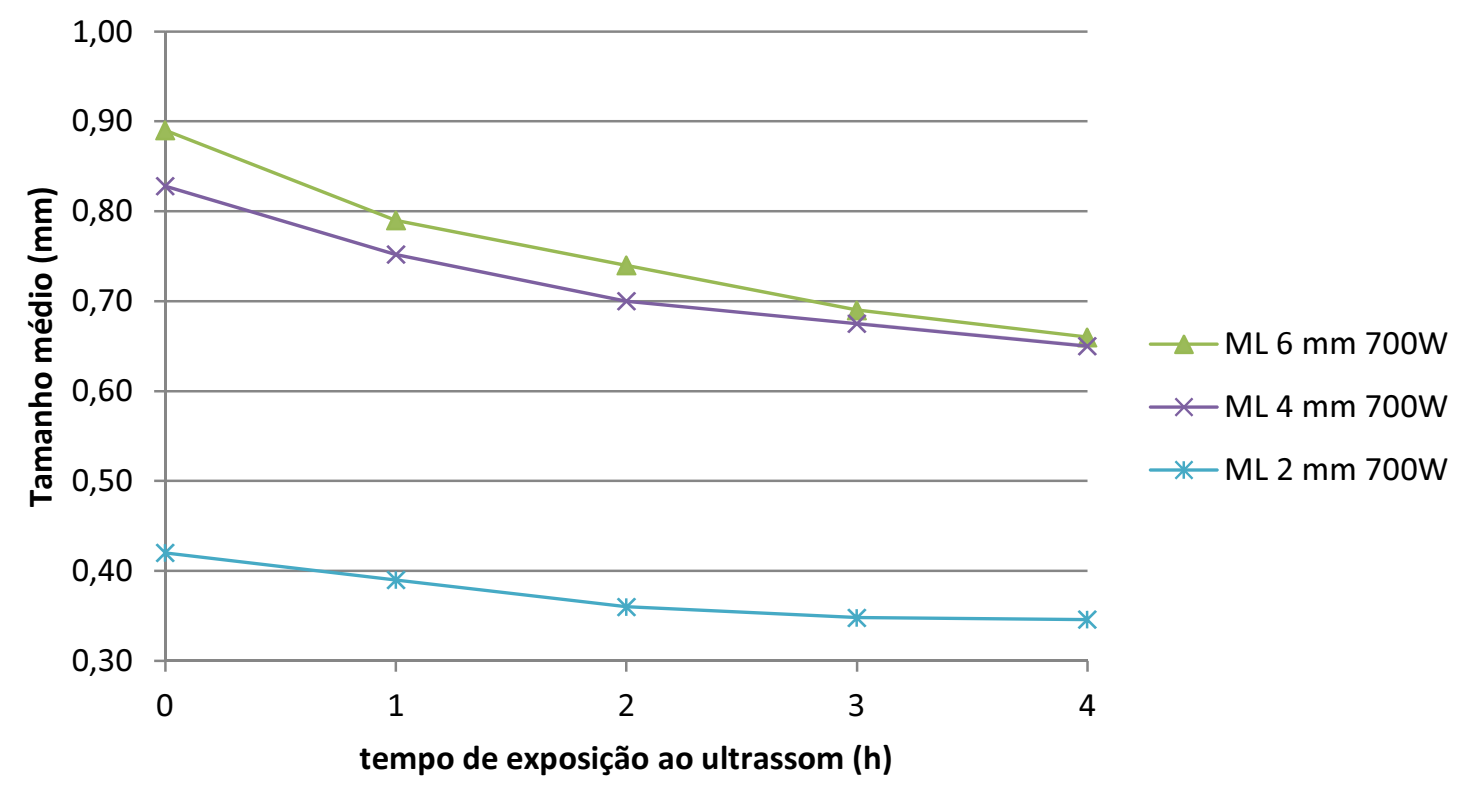

Figura 30. Redução do tamanho médio de partícula: comparação de diferentes tamanhos iniciais de placa ML em potência de $700 \mathrm{~W}$.

Pode-se notar que quanto maior a partícula, maior a redução no tamanho médio de partícula, para uma mesma potência de ultrassom utilizada. Assim, a placa ML de $6 \mathrm{~mm}$ foi reduzida de $0,89 \mathrm{~mm}$ para 0,66 $\mathrm{mm}(26 \%)$, enquanto que a placa de $4 \mathrm{~mm}$ foi reduzida de $0,83 \mathrm{~mm}$ para $0,65 \mathrm{~mm}(21 \%)$, e por último, a placa de $2 \mathrm{~mm}$ teve seu tamanho médio de partícula reduzido de $0,42 \mathrm{~mm}$ para $0,35 \mathrm{~mm}(18 \%)$.

A Figura 31 mostra a influência do tamanho de partícula na redução do tamanho médio de partícula para a potência de $500 \mathrm{~W}$. 


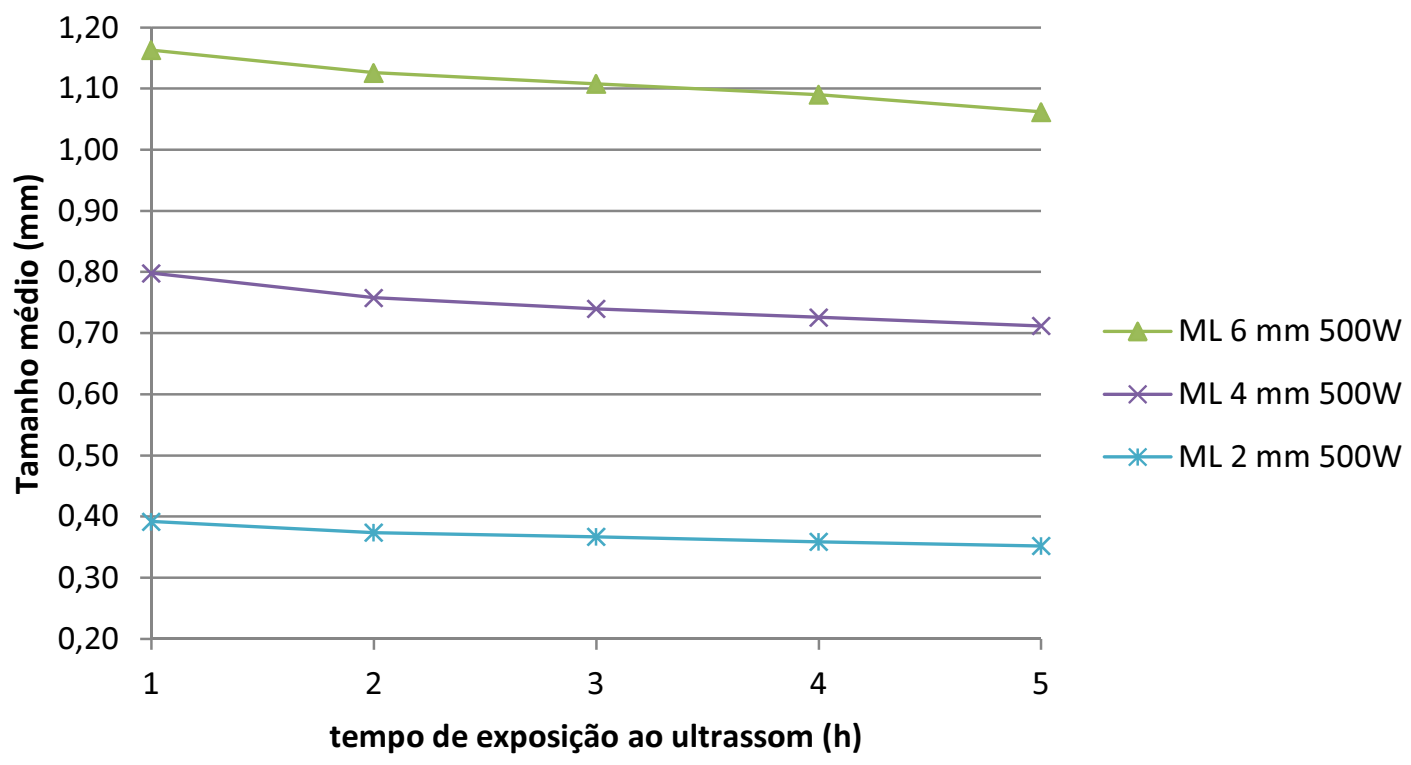

Figura 31. Redução do tamanho médio de partícula: comparação de diferentes tamanhos iniciais de placa ML em potência de $500 \mathrm{~W}$.

A redução do tamanho médio de partícula foi aproximadamente igual nesta potência, sendo a redução das frações de 6,4 e $2 \mathrm{~mm}$ correspondentes à $9 \%, 11 \%$ e $10 \%$, respectivamente.

A Figura 32 apresenta os resultados relativos à redução do tamanho médio de partícula utilizando-se placas $\mathrm{DL}$ em frações de 6,4 e $2 \mathrm{~mm}$ em contato com potência de ultrassom de 700W. 


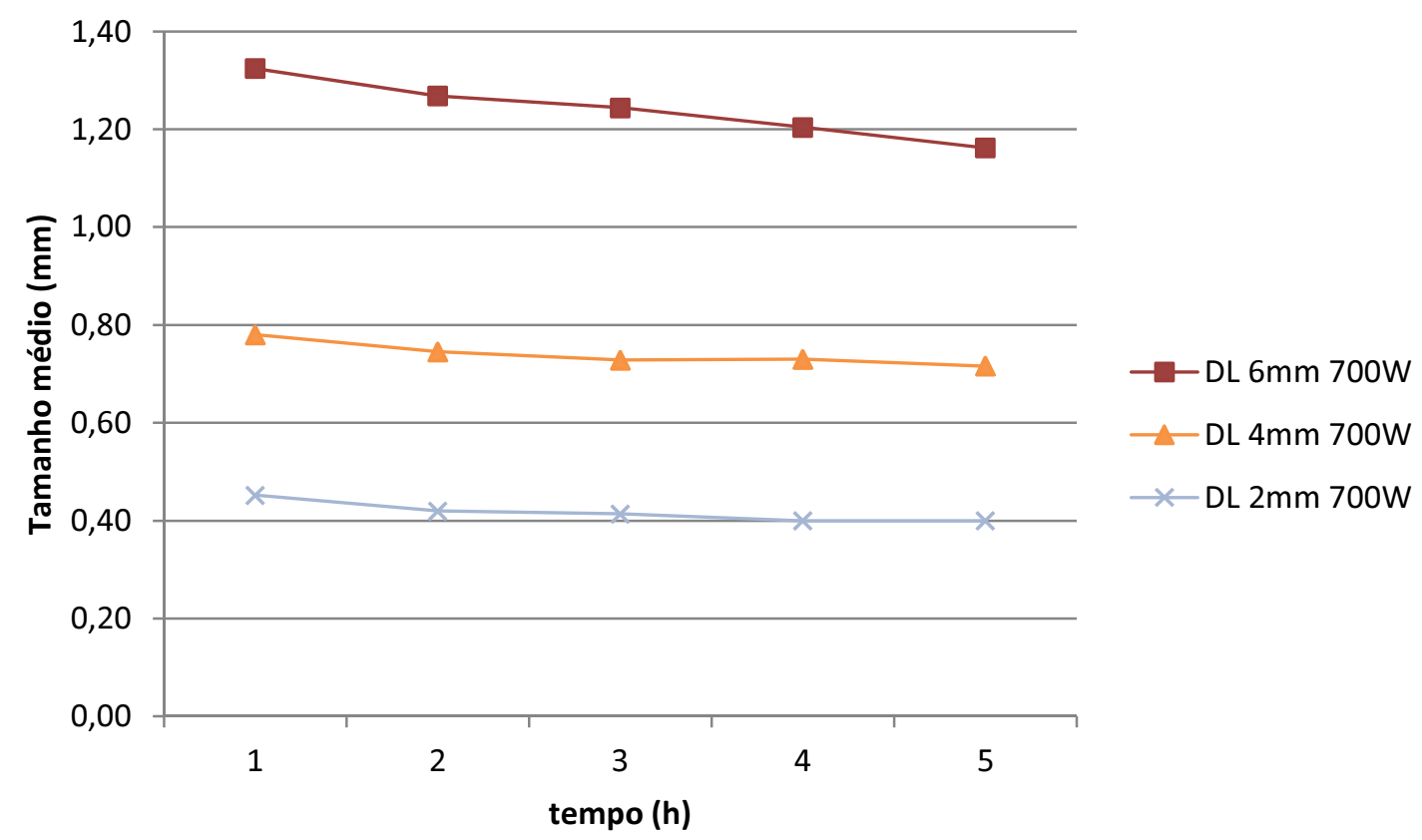

Figura 32. Redução do tamanho médio de partícula: comparação de diferentes tamanhos iniciais de placa DL em potência de $700 \mathrm{~W}$.

A fração DL $6 \mathrm{~mm}$ apresentou redução de 1,32 para $1,16 \mathrm{~mm}$ (12\%) no período de 4 horas. Já a placa DL $4 \mathrm{~mm}$ teve seu tamanho médio reduzido de 0,78 para $0,72 \mathrm{~mm}(8 \%)$ no mesmo intervalo de tempo. A placa DL $2 \mathrm{~mm}$ teve seu tamanho médio de partícula reduzido de 0,45 para $0,40 \mathrm{~mm}(11 \%)$.

A comparação entre a redução relativa de tamanho médio de partícula em função do tipo de placa é apresentado na Tabela 17.

Tabela 17. Percentual de cominuição de $\mathrm{PCl}$ em ultrassom com potência de 700W em 4 horas, em função do tipo de placa: DL e ML.

Material Cominuído em grelha de

Placa DL Placa ML

$\begin{array}{ccc}6 \mathrm{~mm} & 12 \% & 26 \% \\ 4 \mathrm{~mm} & 8 \% & 21 \% \\ 2 \mathrm{~mm} & 11 \% & 18 \%\end{array}$


Para a mesma potência, as placas $\mathrm{ML}$ apresentaram-se mais suscetíveis à cominuição em comparação com as placas DL. A explicação para o resultado observado pode ser feita com base no detalhe construtivo de cada tipo de placa. As placas ML possuem camadas intercaladas de fibra de vidro reforçada por polímero e finas lâminas de cobre, o que torna o desprendimento das camadas mais fácil, principalmente na junção cobre-polímero. Já as placas DL são formadas por placa inteiriça de fibra de vidro reforçada por polímero com cobre somente nas superfícies superior e inferior. Assim, a fragmentação que se tem corresponde à fragmentação da parte polimérica.

A Figura 33 apresenta o compilado dos resultados da cominuição das placas ML, nas diferentes granulometrias iniciais e nas diferentes potências de ultrassom estudadas.

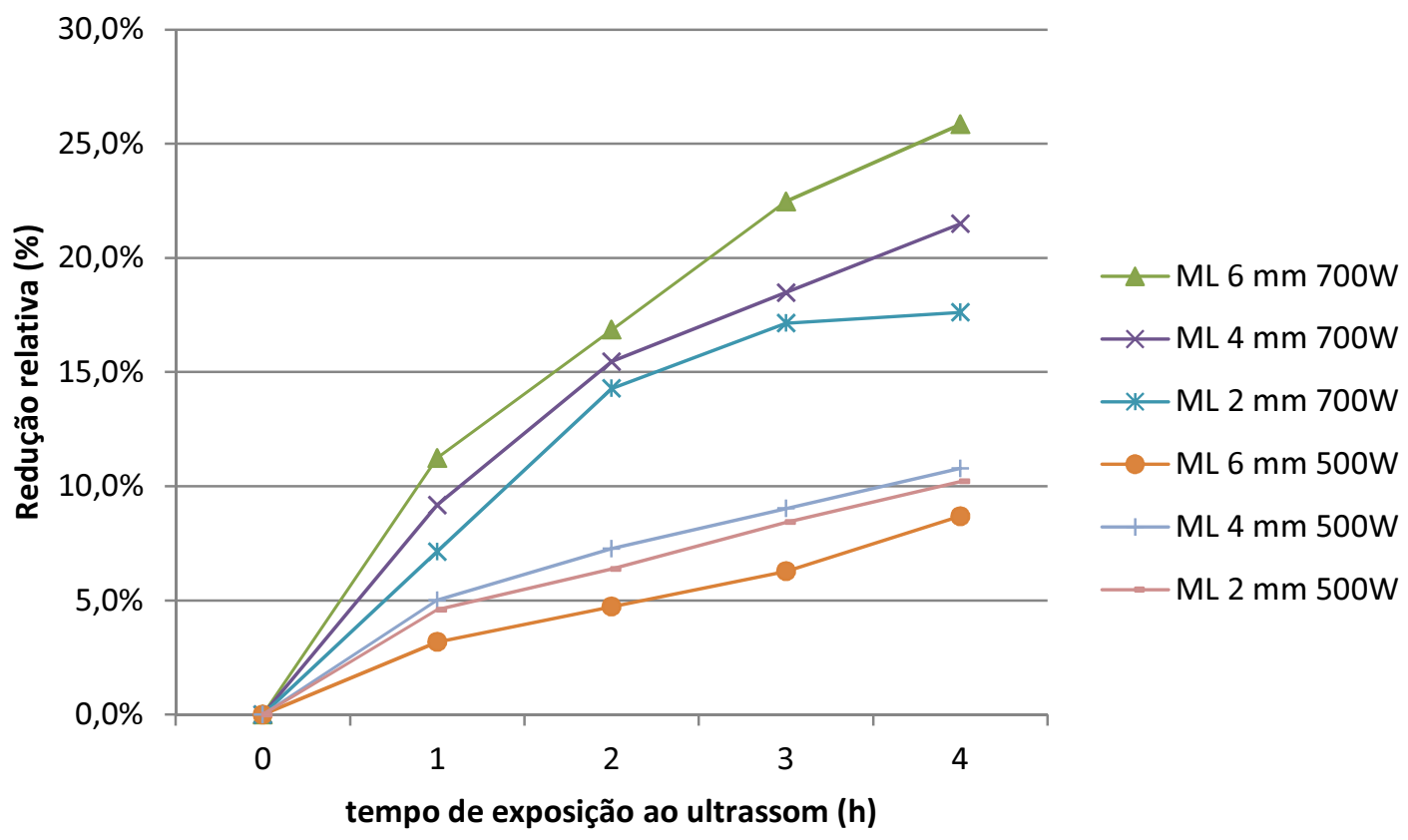

Figura 33. Redução relativa do tamanho médio de partícula em função do tempo de exposição ao ultrassom.

A maior cominuição relativa verificada foi da amostra de $6 \mathrm{~mm}$ no ensaio com potência de $700 \mathrm{~W}$. Contudo, o conjunto de ensaios com potência de $700 \mathrm{~W}$ apresentou maior cominuição nas placas, o que é justificado pela relação da 
potência utilizada com o número de eventos de implosão de bolhas: quanto maior a potência, maior o número de bolhas de cavitação e maior a cominuição do material.

Foram tentados, ainda, dois métodos de verificação da redução do tamanho de partícula: por difração a laser e por isoterma de adsorção BET. No primeiro caso não foi possível realizar a medida de tamanho de partícula, pois a amostra se acumulava ao fundo da célula óptica, dada a densidade das partículas de $\mathrm{PCl}$, o que não permitiu que fosse feita a leitura. No caso da isoterma de adsorção também não foi possível medir, pois a área superficial da amostra estava abaixo do limite de detecção que o equipamento permitia medir. Mesmo colocando-se o máximo de amostra permitida no porta amostras, não foi possível se medir a área superficial.

\subsection{LIXIVIAÇÃO COM ÁCIDO SULFÚRICO}

Neste item, é apresentada a influência dos parâmetros: razão sólidolíquido, concentração de ácido e potência de ultrassom na lixiviação de placas DL com ácido sulfúrico. Para facilitar a interpretação das curvas, os resultados são separados por metal.

\subsubsection{Ferro}

\subsubsection{Influência da razão sólido-líquido}

A influência da razão sólido-líquido na taxa de lixiviação foi investigada nas proporções 1:40, 1:20 e 1:10, com concentração de ácido fixada em 0,5 mol. $\mathrm{L}^{-1}$. Os resultados referentes ao ensaio silencioso podem ser visualizados na Figura 34. 


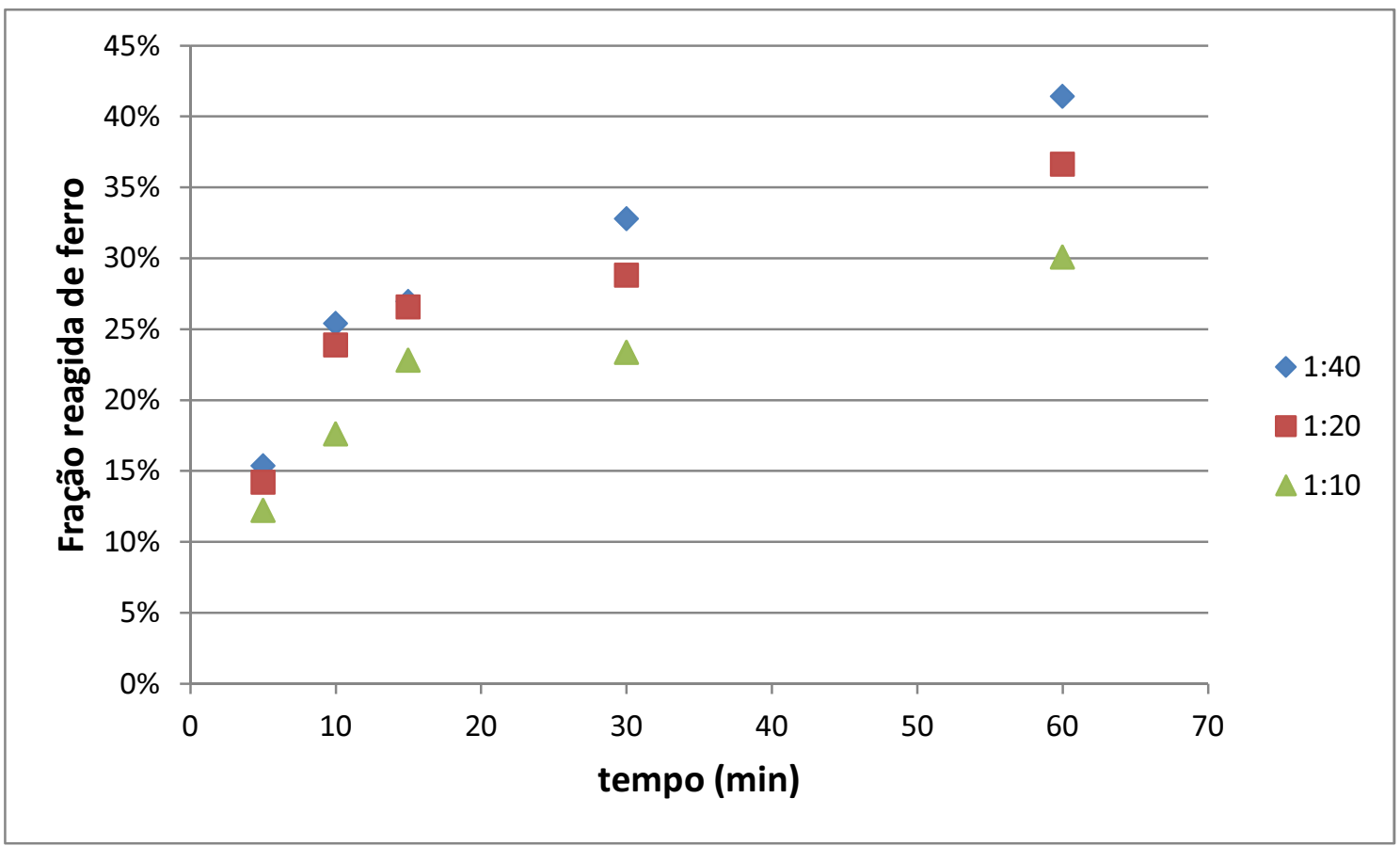

Figura 34. Influência da razão S/L no ensaio silencioso, com concentração de ácido de $0,5 \mathrm{~mol} . \mathrm{L}^{-1}$

Nota-se que os percentuais de extração na razão $S / L$ de 1:40 causou uma extração de $41 \%$, enquanto que a razão $S / L$ de 1:20 resultou em extração de $36 \%$. A razão de 1:10 teve a pior extração de ferro, correspondendo à $30 \%$.

A influência da razão $S / L$ na lixiviação de ferro também foi investigada na presença de ultrassom com potência de $700 \mathrm{~W}$. Na Figura 35 estão os resultados referentes ao ensaio sonicado com potência de $700 \mathrm{~W}$ e concentração de ácido de $0,5 \mathrm{~mol} \cdot \mathrm{L}^{-1}$. 


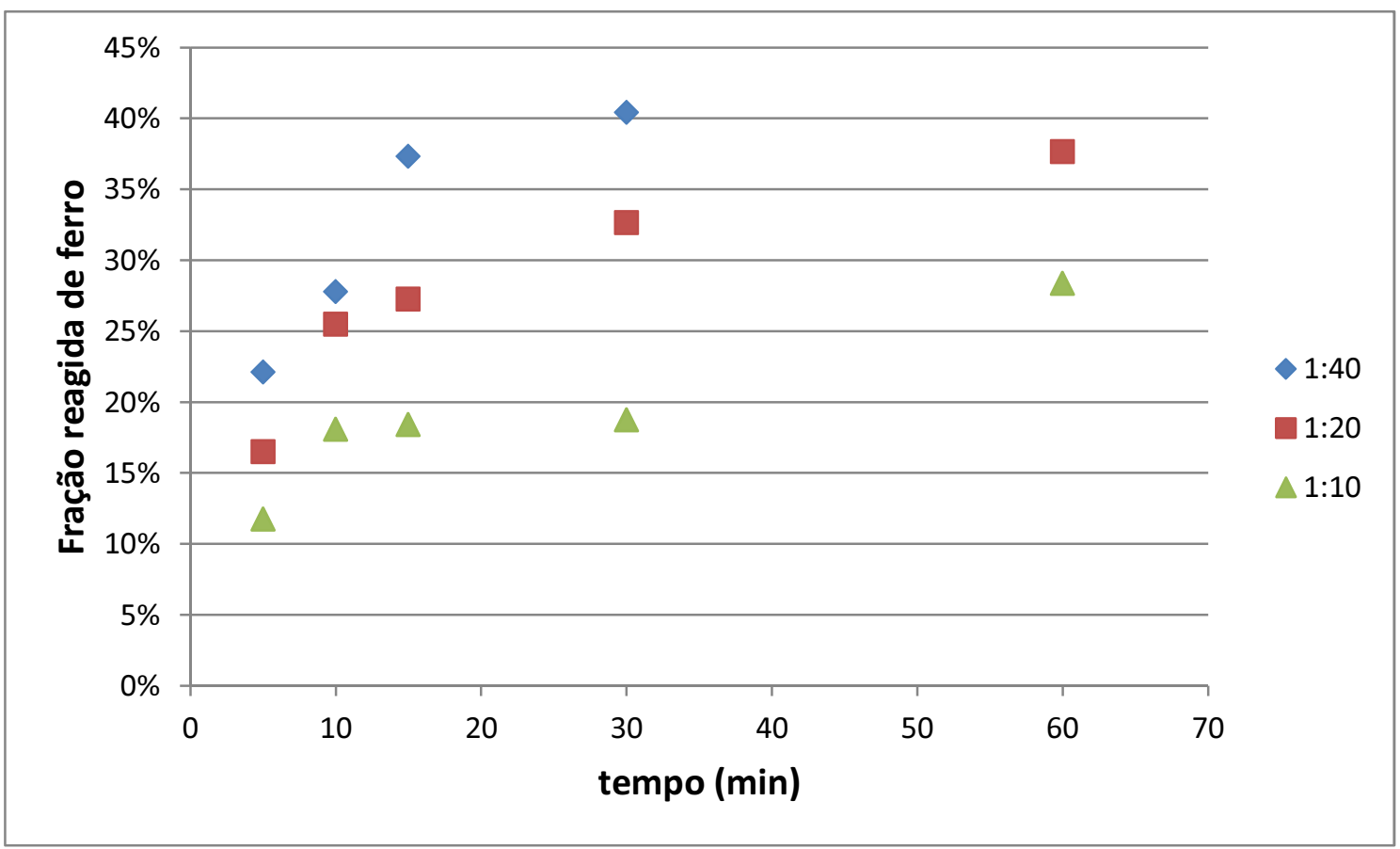

Figura 35. Influência da razão $S / L$ no ensaio sonicado com $700 \mathrm{~W}$, com concentração de ácido de 0,5 mol.. ${ }^{-1}$

Em 30 minutos de ensaio, a razão $S / L$ de $1: 40$ removeu $40 \%$ de ferro, enquanto que o ensaio com razão $S / L$ de $1: 20$ removeu $33 \%$ no mesmo tempo. O ensaio com razão $S / L$ de 1:10 provocou a remoção de apenas $19 \%$ em 30 minutos, obtendo a pior extração deste conjunto.

Ao se considerar as Figura 34 e Figura 35, nota-se que a tendência é que haja maior extração quanto menor for a razão S/L.

\subsubsection{Influência da concentração de ácido}

A influência da concentração de ácido foi investigada na razão $S / L$ de 1:20. Os resultados referentes ao ensaio silencioso são reportados na Figura 36. 


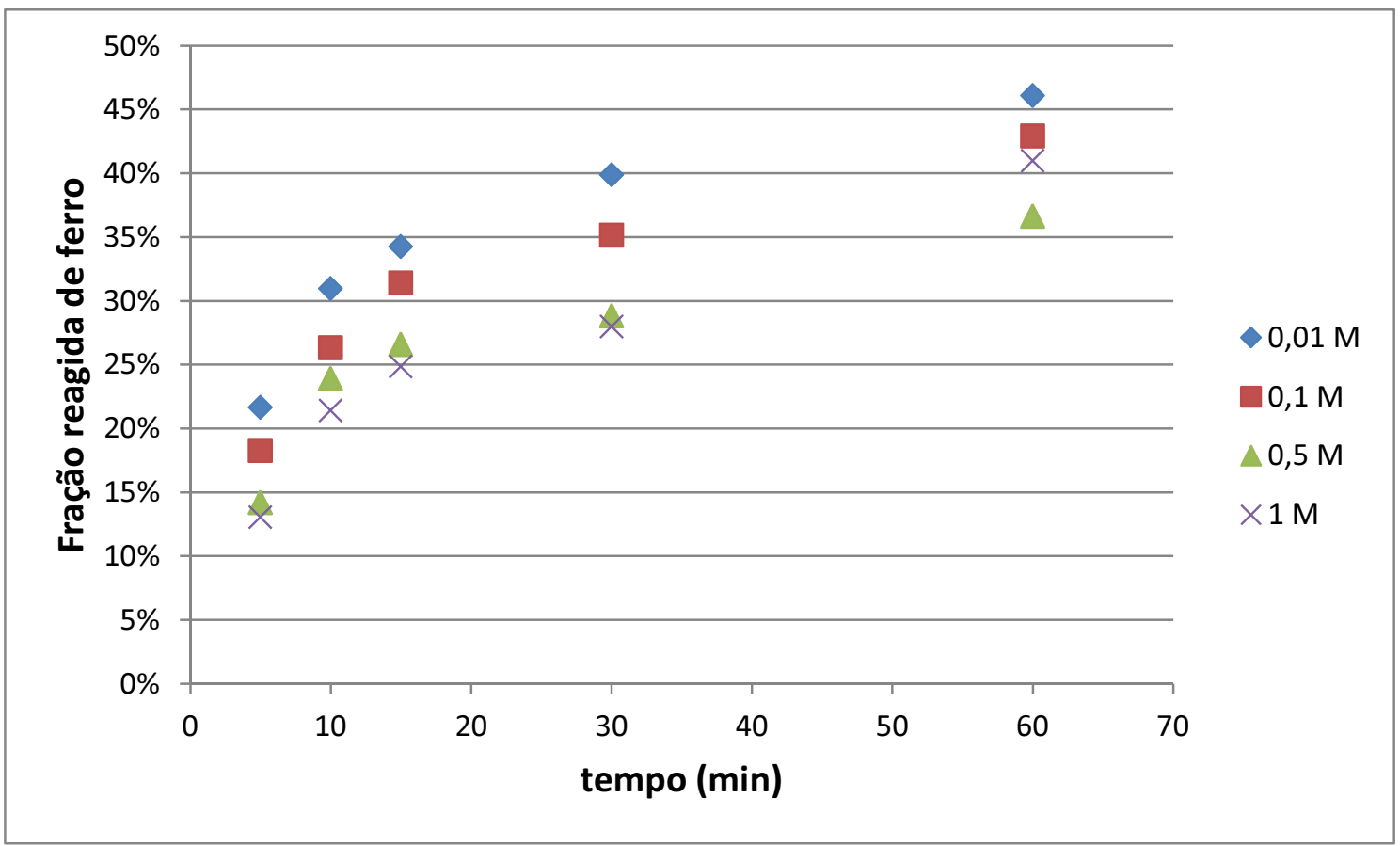

Figura 36. Influência da concentração de ácido no ensaio silencioso, com razão S/L de 1:20.

Os valores de extração no tempo de 60 minutos corresponderam à $46 \%$ no ensaio com 0,01 mol. $\mathrm{L}^{-1}, 43 \%$ com 0,1 mol. $\mathrm{L}^{-1}, 37 \%$ quando a concentração de ácido foi de $0,5 \mathrm{~mol} . \mathrm{L}^{-1}$ e de $41 \%$ com concentração de 1 mol.L $\mathrm{L}^{-1}$. Nota-se que a concentração de 0,01 mol. $L^{-1}$ obteve o maior percentual de extração.

Na Figura 37 são apresentados os resultados da análise da influência da concentração de ácido sulfúrico no ensaio sonicado a $700 \mathrm{~W}$. 


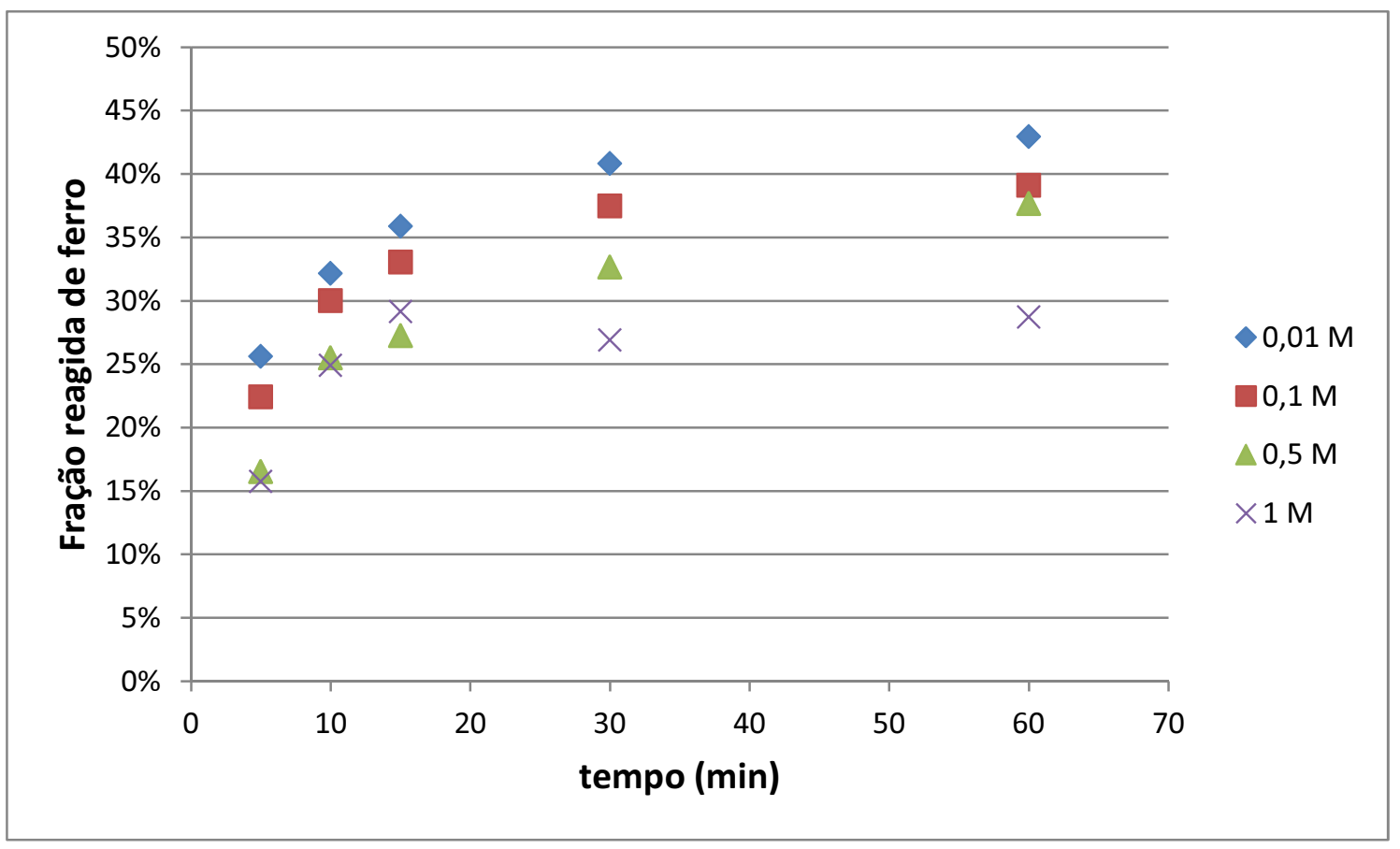

Figura 37. Influência da concentração de ácido no ensaio sonicado com potência de $700 \mathrm{~W}$, com razão S/L de 1:20.

Ao se analisar as Figura 36 e Figura 37, nota-se que a maior extração de ferro ocorreu nos ensaios contendo a menor concentração de ácido, o que sugere uma ordem de reação negativa com relação ao ácido. Uma possível explicação para este fenômeno é reportada por Epelboin e colaboradores (110): $\mathrm{o}^{+}$se adsorve fortemente nos sítios de ferro, formando a espécie $(\mathrm{FeH})_{\text {ads, }}$ que possui uma estabilidade relativamente alta. Desta forma, o aumento da concentração de $\mathrm{H}^{+}$causa uma saturação dos sítios ativos de ferro, ocasionada pelo aumento da quantidade de $(\mathrm{FeH})_{\text {ads. }}$.

No entanto, ao se reduzir a concentração de ácido tentando priorizar a velocidade de reação, perde-se a relação estequiométrica e a remoção total do ferro fica comprometida pelo esgotamento de ácido no final da reação. Assim, pode-se sugerir que a concentração de ácido inicial seja baixa (da ordem de 0,1 mol. $\mathrm{L}^{-1}$ ) e que seja adicionado ácido no decorrer da reação. 


\subsubsection{Influência da potência de ultrassom}

Os dados relativos à investigação da influência da potência de ultrassom sobre a lixiviação são apresentados na Figura 38. As condições fixadas neste conjunto de ensaios foram: razão $S / L$ de 1:20 e concentração de ácido de 0,5 mol. $\mathrm{L}^{-1}$.

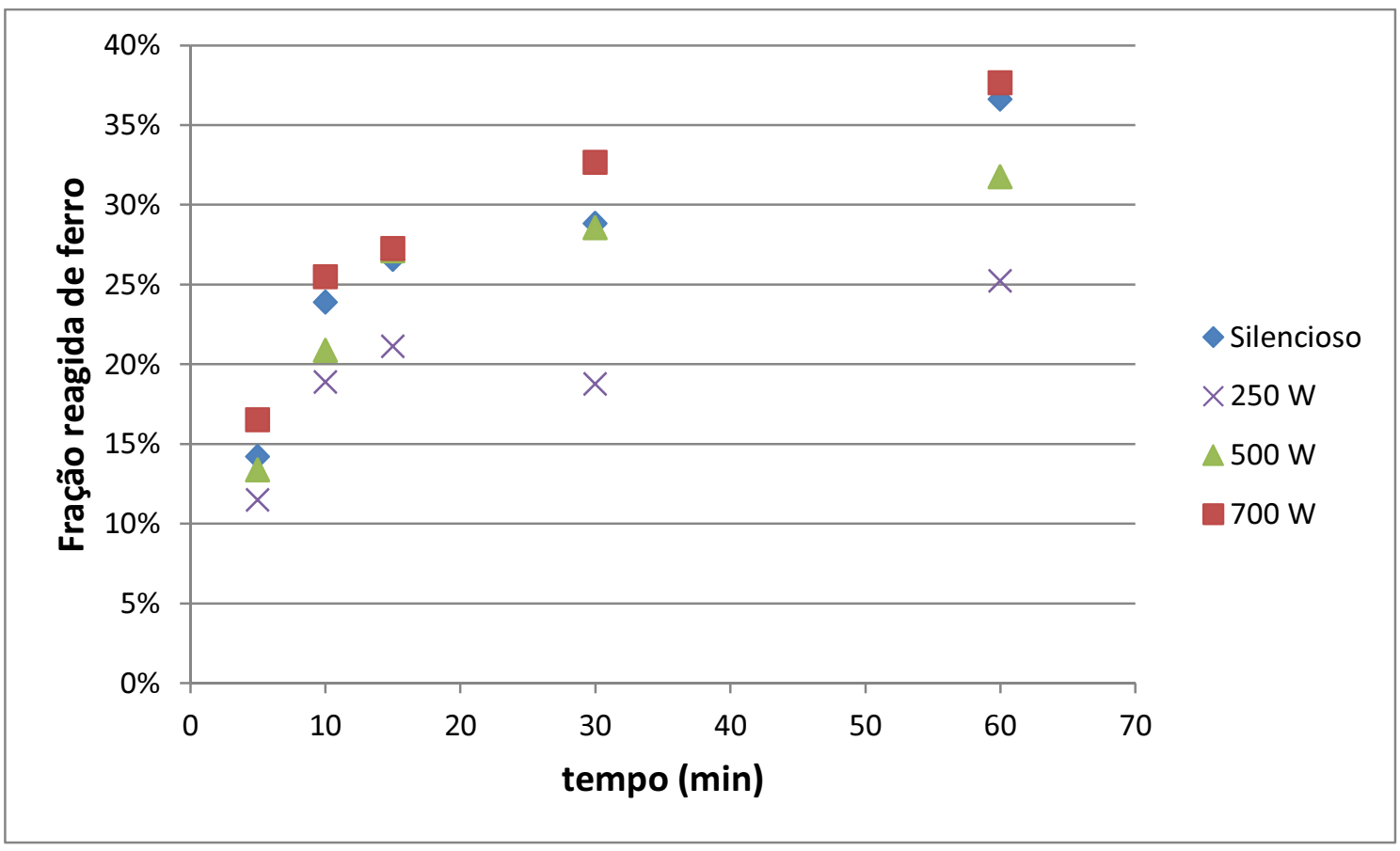

Figura 38. Influência da potência de ultrassom, com razão $S / L$ de 1:20 e concentração de ácido de $0,5 \mathrm{~mol} \cdot \mathrm{L}^{-1}$.

Neste conjunto de ensaios, o percentual de extração de ferro foi próximo quando comparados os ensaios silencioso e sonicado com $700 \mathrm{~W}$, sendo os valores $37 \%$ e $38 \%$ respectivamente. Os ensaios nos quais foram empregadas potências de 250 e $500 \mathrm{~W}$ resultaram em extração de $25 \%$ e $32 \%$ respectivamente.

Os ensaios sonicados não aumentaram a taxa de lixiviação de ferro em relação ao ensaio silencioso. As potências de 250 e 500W apresentaram taxa de extração menor que os outros ensaios pois a menor potência causa menor agitação da solução, sendo possivelmente criados gradientes de concentração de ácido pela falta de homogeneidade. 


\subsubsection{Alumínio}

\subsubsection{Influência da Razão S/L}

A influência da razão $S / L$ para a extração de alumínio com ácido sulfúrico no ensaio silencioso foi investigada, e seus resultados estão na Figura 39. A concentração de ácido utilizada foi de $0,5 \mathrm{~mol} \cdot \mathrm{L}^{-1}$.

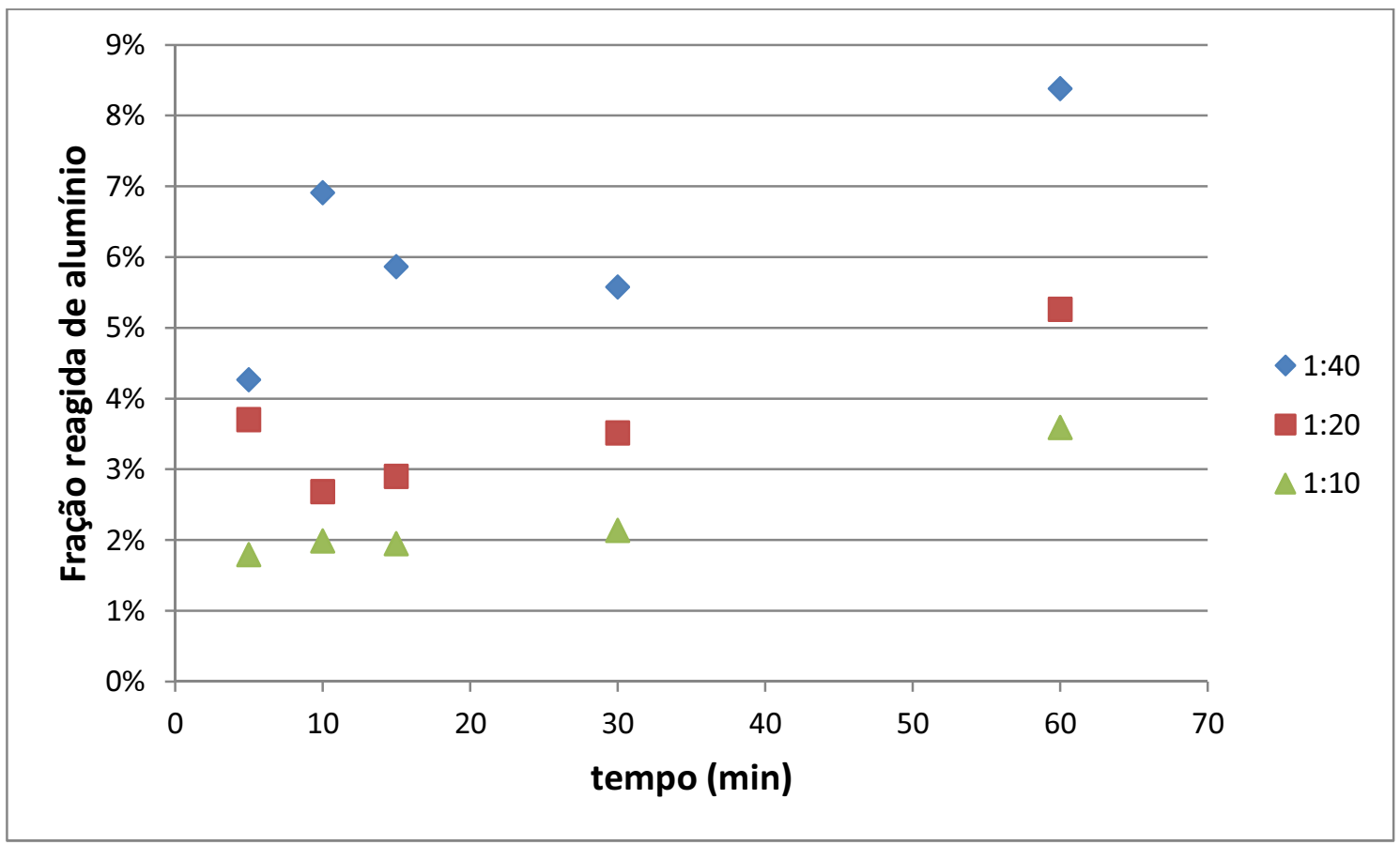

Figura 39. Influência da razão $S / L$ no ensaio silencioso, com concentração de ácido de $0,1 \mathrm{~mol} \cdot \mathrm{L}^{-1}$.

A maior extração de alumínio pode ser verificada no ensaio com razão $S / L$ de $1: 40$, correspondendo a $4,8 \%$ de remoção de alumínio. $O$ ensaio com razão $S / L$ 1:20 resultou em $2,7 \%$ de extração e o ensaio 1:10 removeu apenas $1,9 \%$.

A influência da razão $S / L$ também foi investigada para o ensaio sonicado com potência de $700 \mathrm{~W}$. Os resultados são reportados na Figura 40. Nesta caso, a concentração de ácido foi fixada em $0,1 \mathrm{~mol} \cdot \mathrm{L}^{-1}$. 


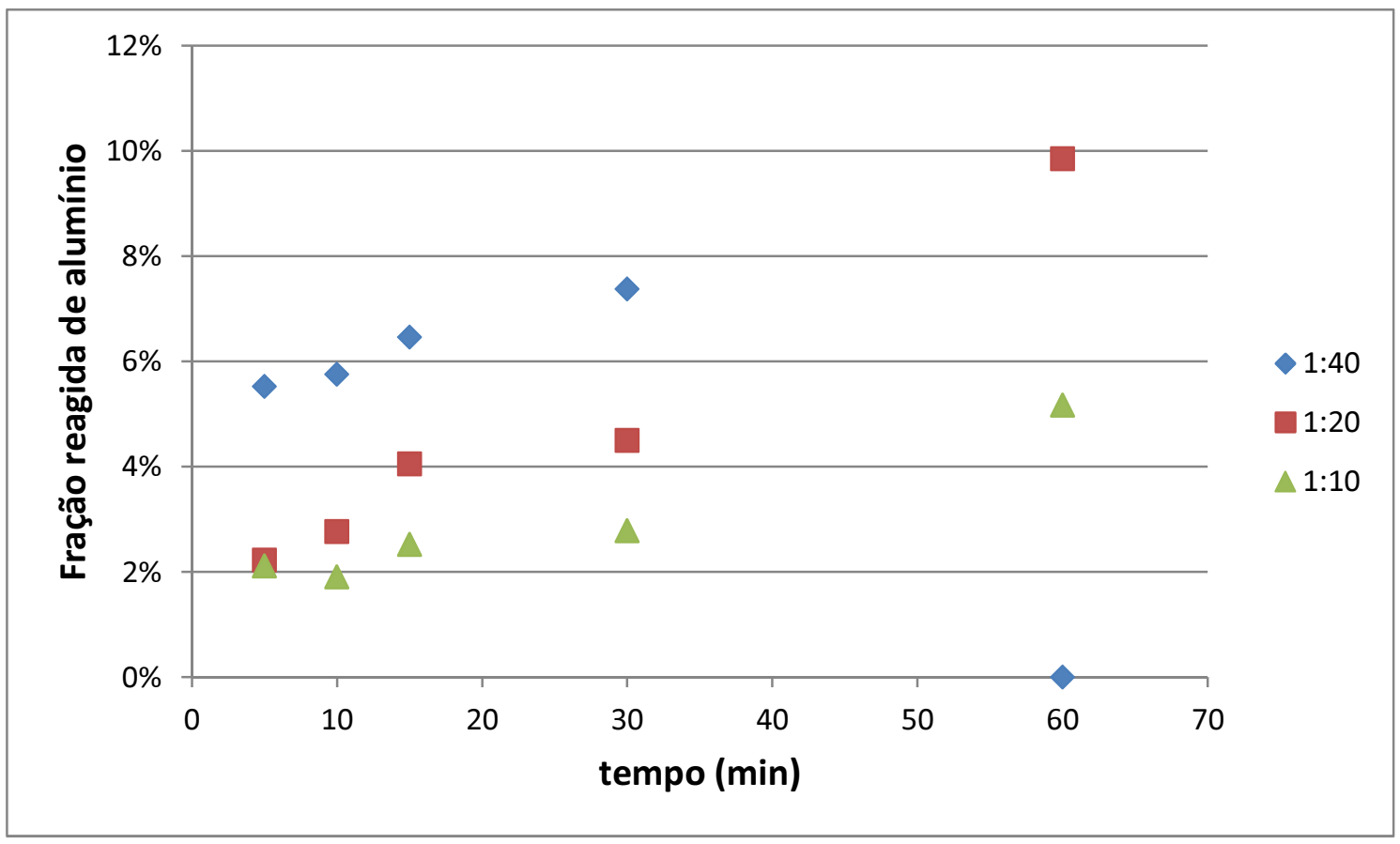

Figura 40. Influência da razão S/L no ensaio sonicado com potência de $700 \mathrm{~W}$, com concentração de ácido de $0,1 \mathrm{~mol}^{-\mathrm{L}^{-1}}$.

O ensaio de razão S/L 1:40 apresentou maior extração de alumínio, removendo $7,4 \%$. O ensaio com razão $S / L$ de $1: 20$ removeu $4,5 \%$ e o ensaio com razão $S / L$ de 1:10 apresentou extração de 2,8\%.

Em ambos os ensaios (sonicado e silencioso), a extração foi maior com a menor razão $\mathrm{S} / \mathrm{L}$, demonstrando que quando há mais ácido em relação ao metal, a lixiviação é mais acentuada.

\subsubsection{Influência da concentração de ácido}

A influência da concentração de ácido sulfúrico no ensaio silencioso foi realizada e os dados são apresentados na Figura 41. Neste conjunto de ensaios, foi utilizada razão $S / L$ de 1:20. 


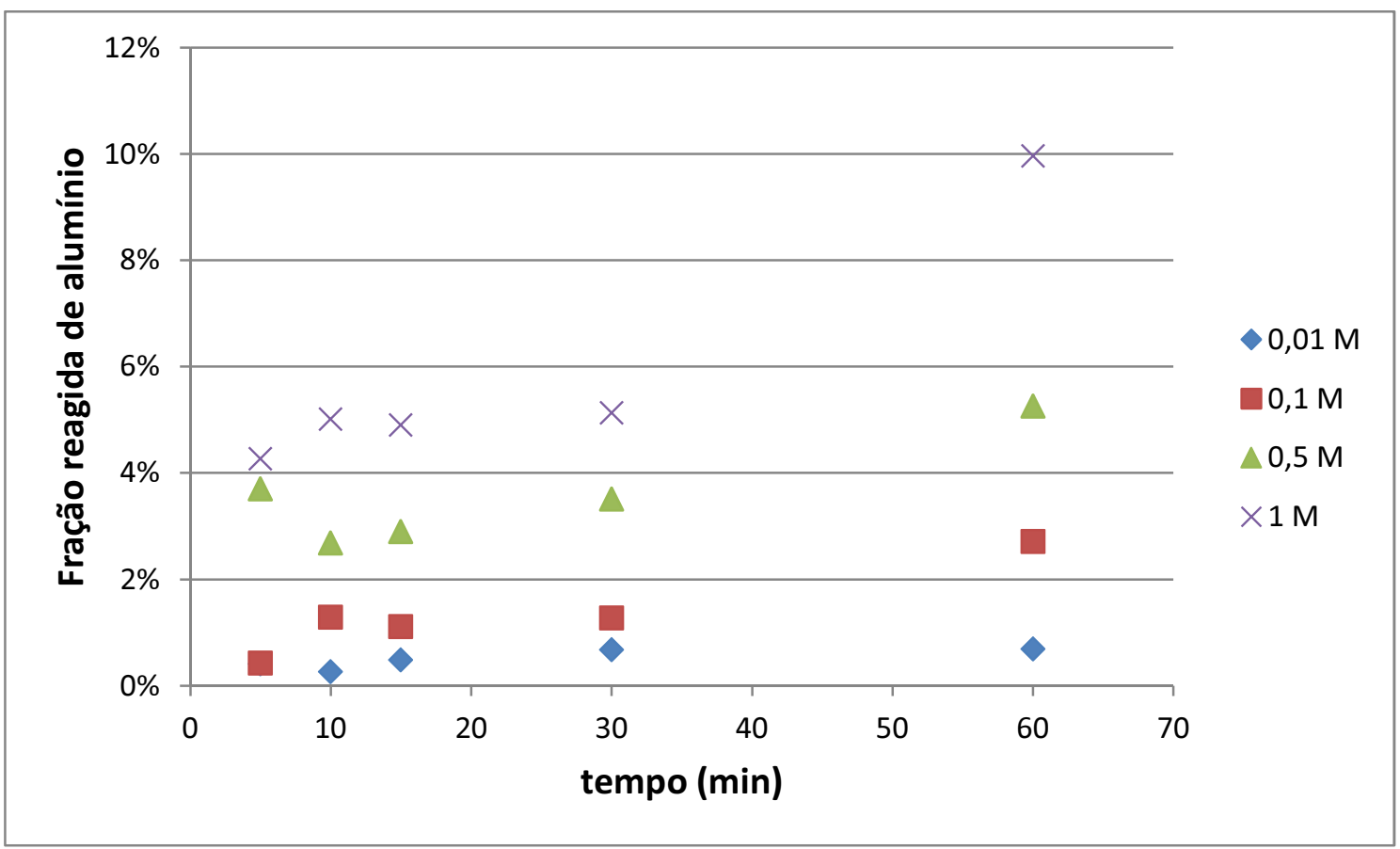

Figura 41. Influência da concentração de ácido no ensaio silencioso, com razão S/L de 1:20.

Como pode ser observado na Figura 41 , a concentração de 1 mol. L $^{-1}$ de ácido sulfúrico ocasionou a maior extração de alumínio, cujo percentual corresponde a $10 \%$. O ensaio com $0,5 \mathrm{~mol}^{-\mathrm{L}^{-1}}$ resultou em extração de $5,3 \%$ de alumínio. $O$ ensaio utilizando-se concentração de ácido de $0,1 \mathrm{~mol} . \mathrm{L}^{-1}$ extraiu $2,7 \%$ e o ensaio que foi realizado utilizando-se concentração de $0,01 \mathrm{~mol}^{-L^{-1}}$ extraiu apenas $0,7 \%$ do alumínio presente nas placas.

Na Figura 42 podem ser vistos os resultados referentes aos ensaios que visaram investigar a influência da concentração de ácido em presença de ultrassom com potência de $700 \mathrm{~W}$. Neste conjunto, a razão $\mathrm{S} / \mathrm{L}$ foi fixada em 1:20. 


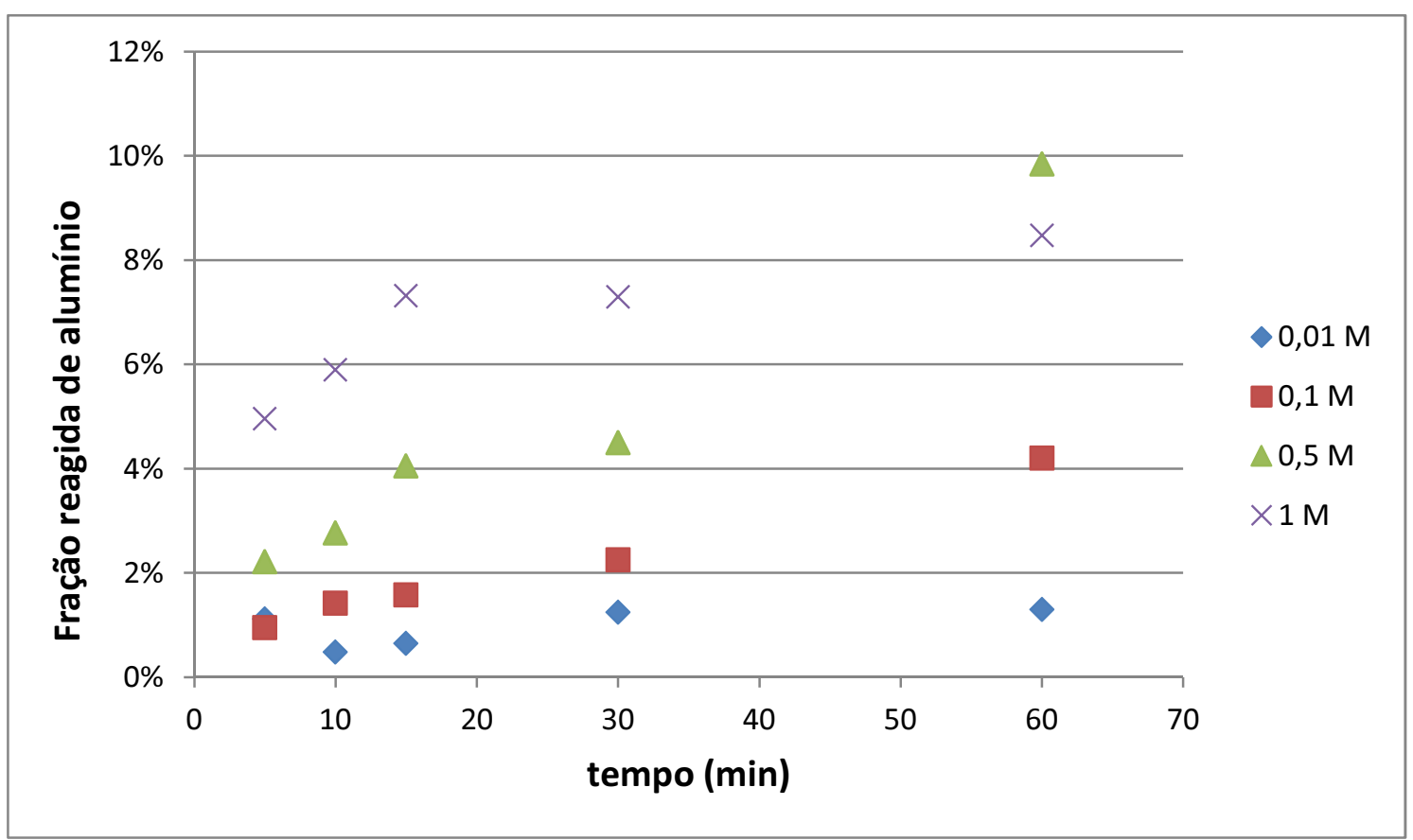

Figura 42. Influência da concentração de ácido no ensaio sonicado com potência de $700 \mathrm{~W}$, com razão S/L de 1:20.

$\mathrm{Na}$ Figura 42, nota-se que a concentração de 1 mol.L $\mathrm{L}^{-1}$ extraiu 8,5\%. A concentração de 0,5 mol. $\mathrm{L}^{-1}$ resultou em uma lixiviação de $9,8 \%$ de alumínio. $A$ concentração de 0,1 mol.L $L^{-1}$ promoveu extração de $4,2 \%$ e a concentração de 0,01 mol. $L^{-1}$ promoveu a menor extração do conjunto de ensaios, com valor de $1,3 \%$. Os valores de extração correspondentes às concentrações de 0,5 e $1 \mathrm{~mol} . \mathrm{L}^{-1}$ promoveram praticamente a mesma extração, sendo a curva de extração para $1 \mathrm{~mol} . \mathrm{L}^{-1}$ mostrando extração superior às outras curvas para tempos menores que 30 minutos. Somente no ponto correspondente a 60 minutos de reação em que a extração da concentração de $0,5 \mathrm{~mol} . \mathrm{L}^{-1}$ foi maior que a de $1 \mathrm{~mol} . \mathrm{L}^{-1}$. Considerando que o aumento da concentração de alumínio do tempo 30 minutos para o tempo 60 minutos foi brusco, pode-se sugerir que houve algum erro aleatório de análise química. 


\subsubsection{Influência da potência de ultrassom}

Os resultados da investigação da influência da potência de ultrassom na lixiviação de alumínio por ácido sulfúrico são apresentados na Figura 43. Nestes ensaios a concentração de ácido foi fixada em $0,5 \mathrm{~mol}^{-L^{-1}}$ e a razão $\mathrm{S} / \mathrm{L}$ utilizada foi 1:20.

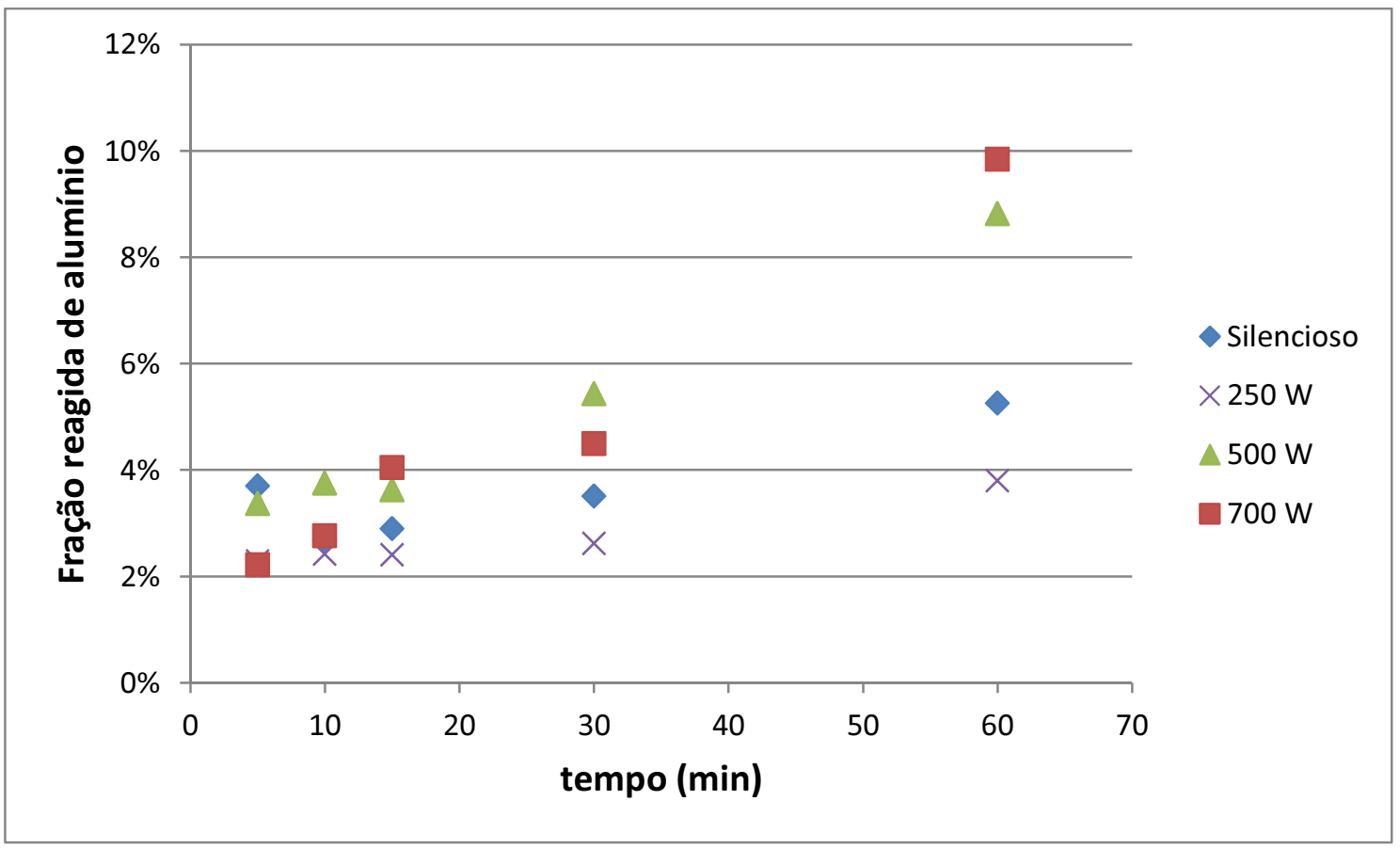

Figura 43. Influência da potência de ultrassom, com razão $S / L$ de 1:20 e concentração de ácido sulfúrico de $0,5 \mathrm{~mol} \cdot \mathrm{L}^{-1}$.

Ao se analisar os resultados, vê-se que a lixiviação utilizando-se potência de ultrassom de $700 \mathrm{~W}$ obteve o maior percentual de extração em relação à outras condições, sendo removido $9,8 \%$ do alumínio presente. $O$ efeito de limpeza da superfície, causada pela implosão assimétrica das bolhas pode ser o motivo do aumento da taxa de extração do alumínio. 


\subsubsection{Níquel}

\subsubsection{Influência da Razão S/L}

A influência da razão $S / L$ na remoção de níquel por acido sulfúrico foi investigada, e os resultados experimentais dos ensaios são apresentados na Figura 44. A concentração de ácido utilizada foi de $0,5 \mathrm{~mol} \cdot \mathrm{L}^{-1}$.

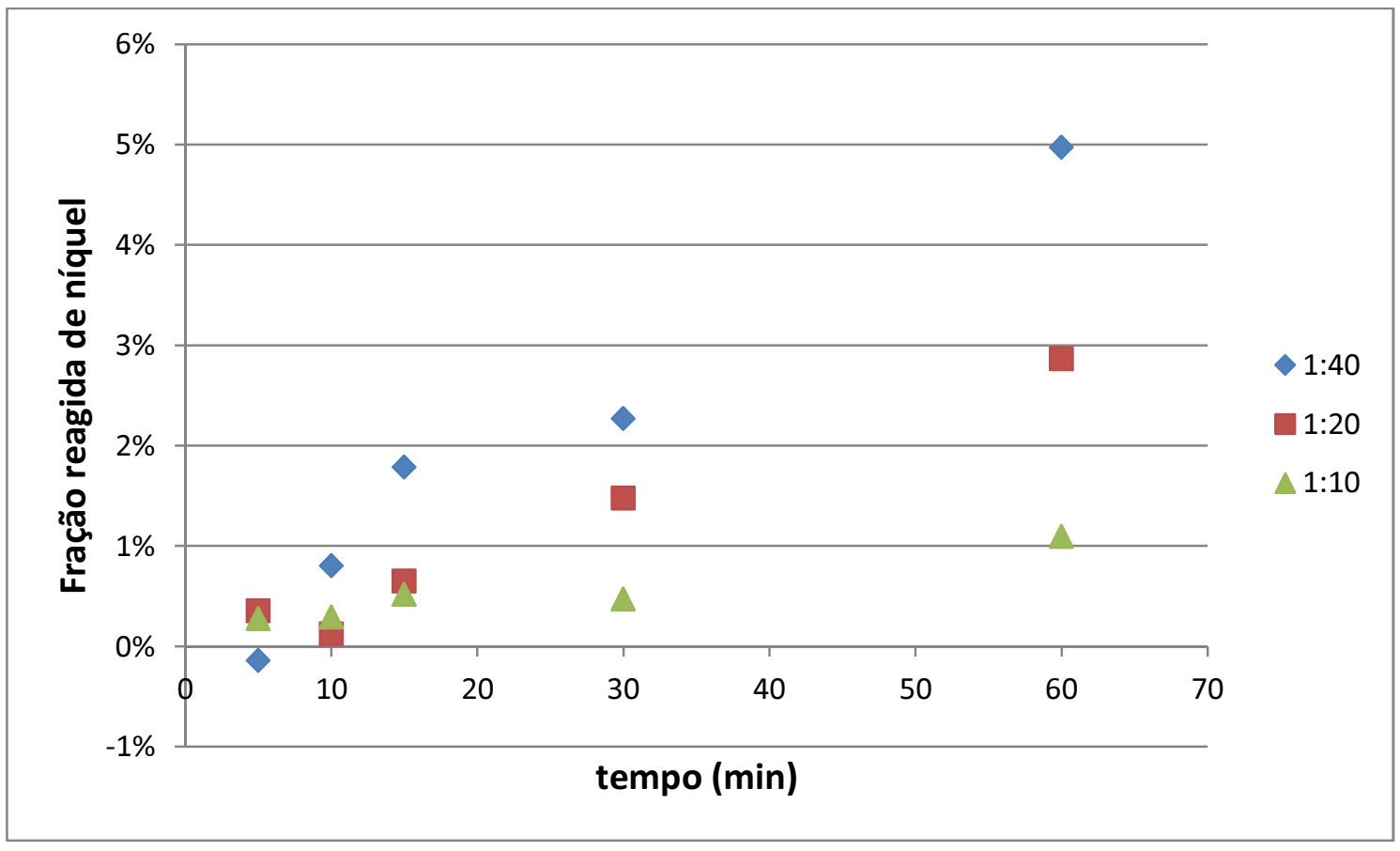

Figura 44. Influência da razão S/L no ensaio silencioso, com concentração de ácido de $0,5 \mathrm{~mol} . \mathrm{L}^{-1}$.

Novamente, o ensaio que resultou na maior extração foi aquele com razão $S / L$ de 1:40, neste caso do níquel, removendo 5,0\%. O ensaio de 1:20 removeu $2,9 \%$ e o ensaio com razão $S / L$ de $1: 10$ removeu apenas $1,1 \%$.

A influência da razão S/L também foi investigada no ensaio sonicado com potência de $700 \mathrm{~W}$. Os resultados são apresentados na Figura 45. A concentração de ácido sulfúrico foi fixada em 0,5 mol. $\mathrm{L}^{-1}$ neste conjunto de ensaios. 


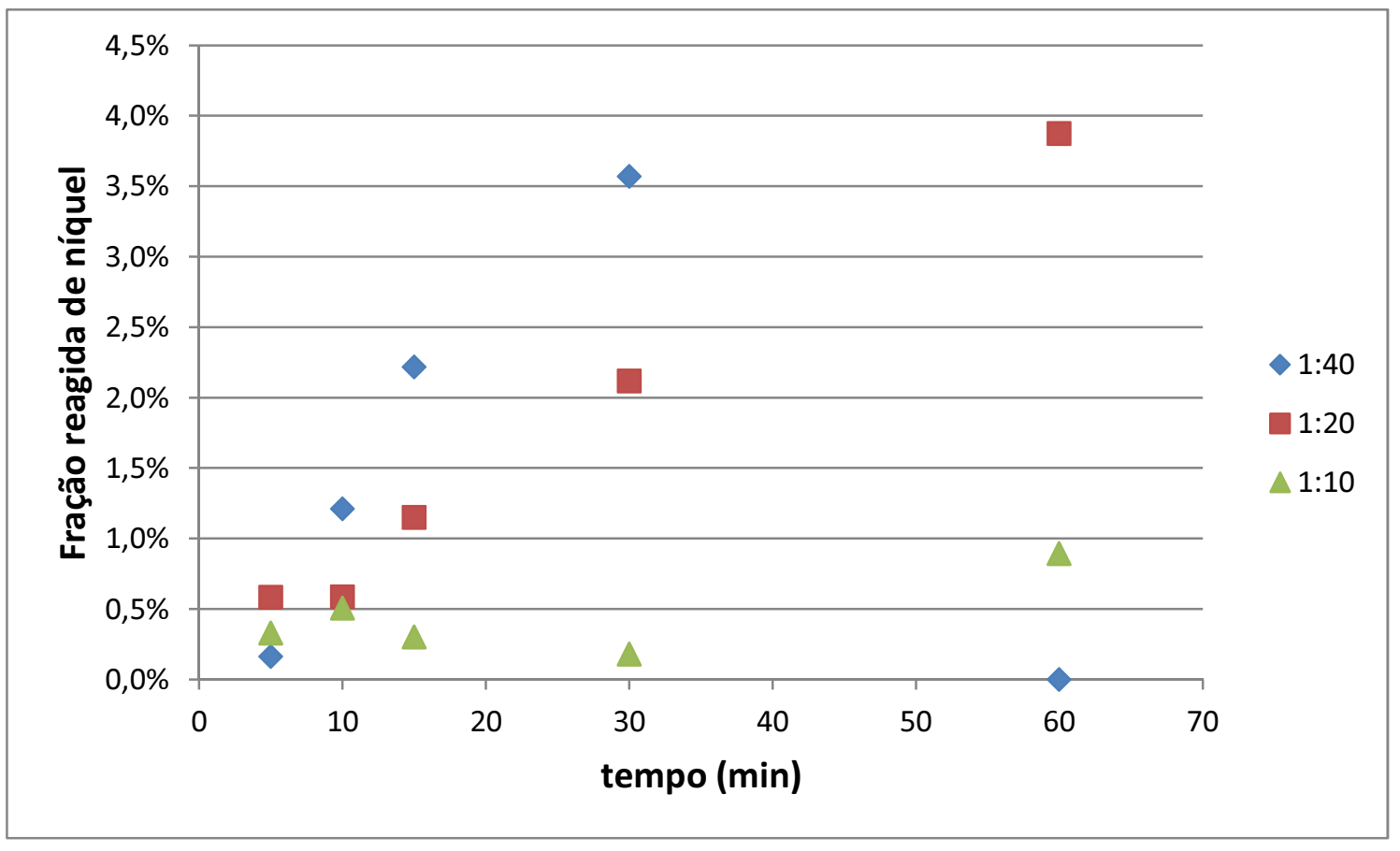

Figura 45. Influência da razão $S / L$ no ensaio sonicado com potência de $700 \mathrm{~W}$, com concentração de ácido de $0,5 \mathrm{~mol} . \mathrm{L}^{-1}$.

É possível se notar a diferença entre a extração correspondente à razão $S / L$ de 1:40 em comparação às de 1:20 e 1:10 para tempos até 30 minutos. $A$ razão $S / L$ de $1: 40$, no tempo de 30 minutos, havia extraído $3,6 \%$ de níquel. $A$ razão $S / L$ de $1: 20$ removeu $2,1 \%$ e a de $1: 10,0,2 \%$. Assim, a extração de níquel segue a mesma tendência dos outros metais, sofrendo maior extração com a maior disponibilidade de ácido, promovida pela menor razão S/L.

\subsubsection{Influência da concentração de ácido}

A influência da concentração de ácido sulfúrico na lixiviação de níquel da placa DL foi investigada no ensaio silencioso, cujos resultados são apresentados na Figura 46. A razão S/L utilizada foi fixada em 1:20 nestes ensaios. 


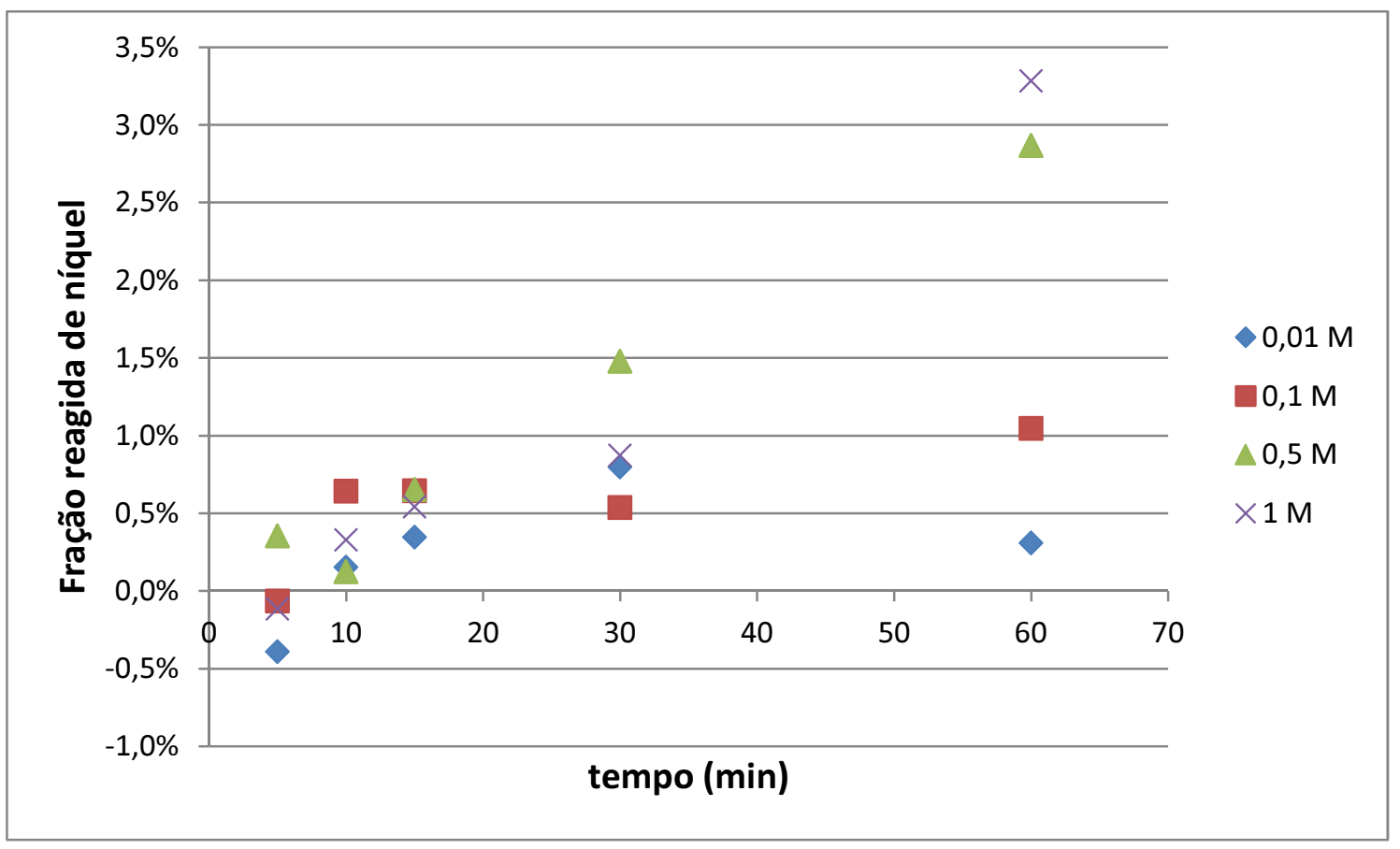

Figura 46. Influência da concentração de ácido no ensaio silencioso, com razão S/L de 1:20.

A concentração de 1 mol.L-1 resultou na maior extração, de $3,3 \%$. As

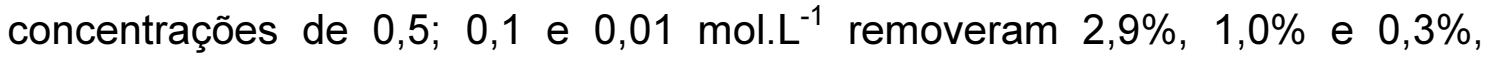
respectivamente. A maior extração foi promovida pela maior concentração de ácido no tempo de 60 minutos.

A investigação da influência da concentração de ácido sobre a lixiviação de níquel também foi realizada para o ensaio sonicado com potência de $700 \mathrm{~W}$, e seus resultados estão na Figura 47. A razão S/L utilizada foi de 1:20. 


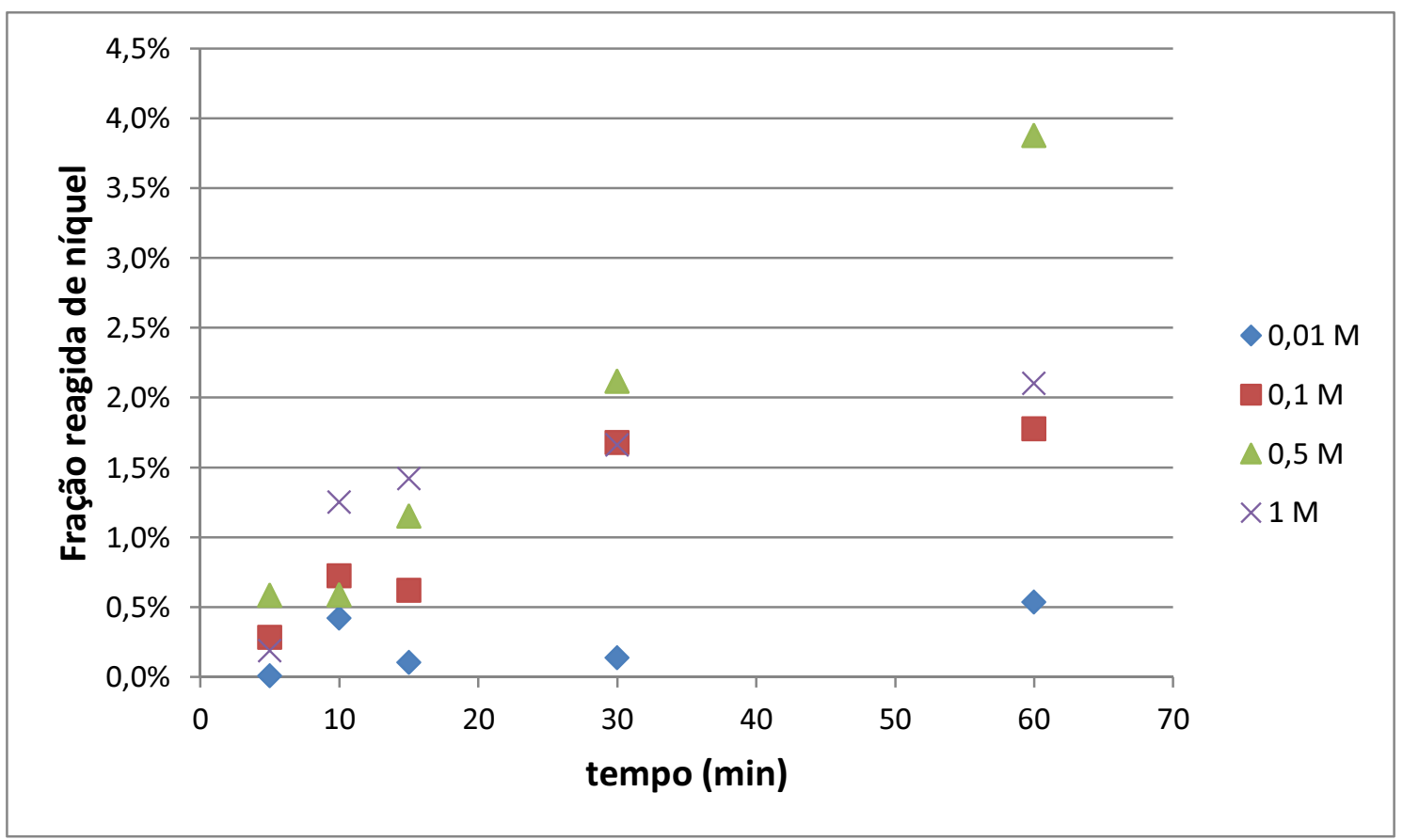

Figura 47. Influência da concentração de ácido no ensaio sonicado com potência de $700 \mathrm{~W}$, com razão S/L de 1:20.

Nesta figura houve uma inversão na taxa de extração, que correspondeu à concentração de $0,5 \mathrm{~mol} \cdot \mathrm{L}^{-1}$. No entanto, analisando-se a tendência das outras concentrações, nota-se que há um aumento na extração com o aumento na concentração. Assim, pode-se afirmar que houve um erro aleatório.

5.4.3.3 Influência da potência de ultrassom

A influência da potência de ultrassom na lixiviação de níquel foi investigada, utilizando-se razão $S / L$ de 1:20 e concentração de ácido de 0,5 mol. $\mathrm{L}^{-1}$. Os resultados são apresentados na Figura 48. 


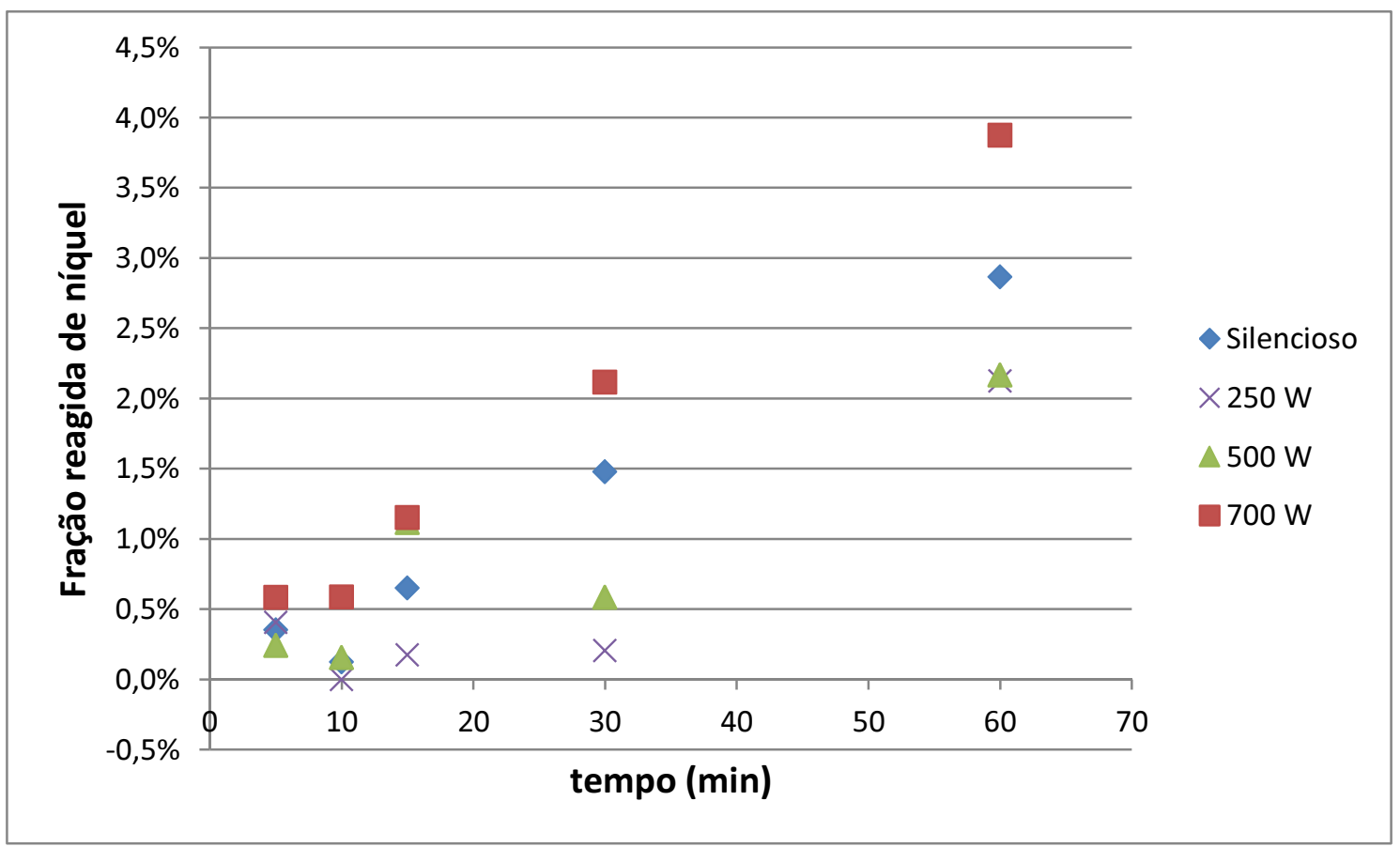

Figura 48. Influência da potência de ultrassom na lixiviação de níquel, com razão $S / L$ de 1:20 e concentração de ácido de 0,5 mol. $\mathrm{L}^{-1}$.

O ensaio sonicado com potência de $700 \mathrm{~W}$ apresentou melhor percentual de extração, alcançando o valor de 3,9\%. O ensaio silencioso foi capaz de remover $2,9 \%$. Os ensaios sonicados com potências de 250 e $500 \mathrm{~W}$ apresentaram extração aquém do ensaio silencioso, e removeram $2,2 \%$ ambos.

\subsection{LIXIVIAÇÃO POR ÁCIDO SULFÚRICO COM MEIO OXIDANTE}

Os ensaios realizados com ácido sulfúrico em meio oxidante são apresentados. Analogamente ao capítulo anterior, cada metal é discutido separadamente.

\subsubsection{Ferro}

As curvas de extração do ferro obtidas são apresentadas na Figura 49. As condições utilizadas neste ensaio foram razão S/L de 1:40, concentração de 
ácido sulfúrico de $0,5 \mathrm{~mol} \cdot \mathrm{L}^{-1}$ e oxigênio borbulhado no meio reacional a $100 \mathrm{~mL} \cdot \mathrm{min}^{-1}$.

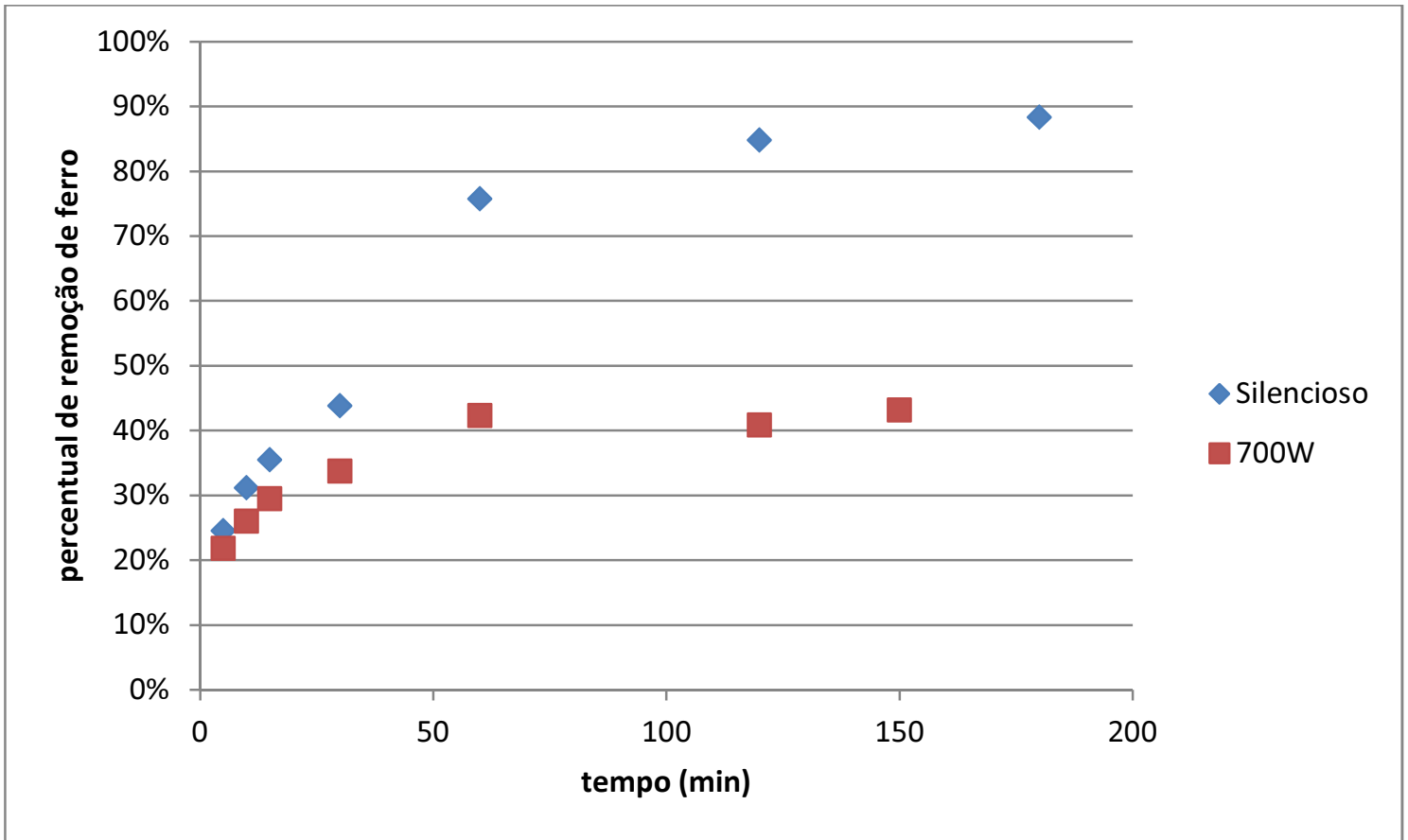

Figura 49. Extração de ferro em meio oxidante em diferentes potências de ultrassom. Condições: Razão S/L 1:40, concentração de ácido sulfúrico 0,5 mol. $\mathrm{L}^{-1}$ e oxigênio borbulhado a $100 \mathrm{~mL} \cdot \mathrm{min}^{-1}$.

O ensaio silencioso, após $180 \mathrm{~min}$ de ensaio extraiu $88 \%$ de ferro, enquanto que o ensaio sonicado com $700 \mathrm{~W}$, após 150 minutos removeu apenas $43 \%$. Assim, a lixiviação com meio oxidante não se mostrou favorecida com a presença do ultrassom. Provavelmente as bolhas formadas pela inserção de oxigênio no meio reativo podem ter reduzido a eficiência da ação das bolhas de cavitação sobre o sólido disperso no meio, reduzindo, assim, a extração de metal.

\subsubsection{Alumínio}

Os resultados de extração de alumínio por ácido sulfúrico em meio oxidante podem ser vistos na Figura 50. As condições utilizadas neste ensaio 
foram razão $S / L$ de 1:40, concentração de ácido sulfúrico de 0,5 mol. $\mathrm{L}^{-1} \mathrm{e}$ oxigênio borbulhado no meio reacional a $100 \mathrm{~mL} \cdot \mathrm{min}^{-1}$.

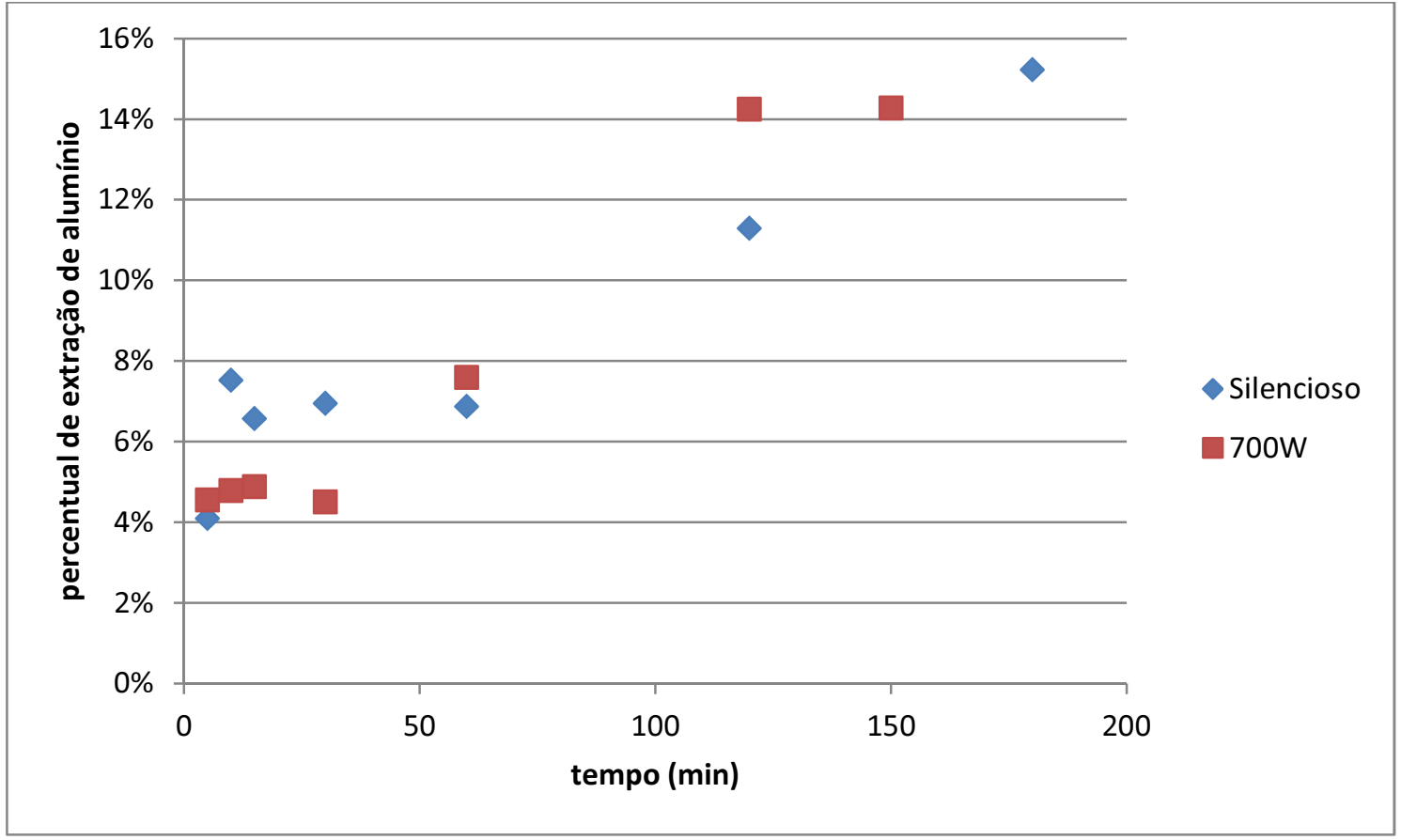

Figura 50. Extração de alumínio em meio oxidante em diferentes potências de ultrassom. Condições: Razão S/L 1:40, concentração de ácido sulfúrico 0,5 mol. L ${ }^{-1}$ e oxigênio borbulhado a $100 \mathrm{~mL} \cdot \mathrm{min}^{-1}$.

O percentual de extração de alumínio foi aproximadamente o mesmo nos três ensaios realizados. Houve remoção de 15,2\% em 180 minutos no ensaio silencioso. No ensaio sonicado com potência de $700 \mathrm{~W}$, houve remoção de $14,3 \%$ de alumínio em 150 minutos. Assim, quando comparados os ensaios silencioso e sonicado a $700 \mathrm{~W}$, a extração de alumínio mostrou-se insensível à presença de ultrassom. Uma possível explicação para o fato pode ser a formação de uma camada de passivação de alumina sobre as partículas de alumínio, formação esta favorecida pela presença de oxigênio em solução, o que dificulta a lixiviação deste metal. 


\subsubsection{Níquel}

Os resultados referentes aos ensaios de lixiviação de níquel por ácido sulfúrico em meio oxidante pode ser vistos na Figura 51.

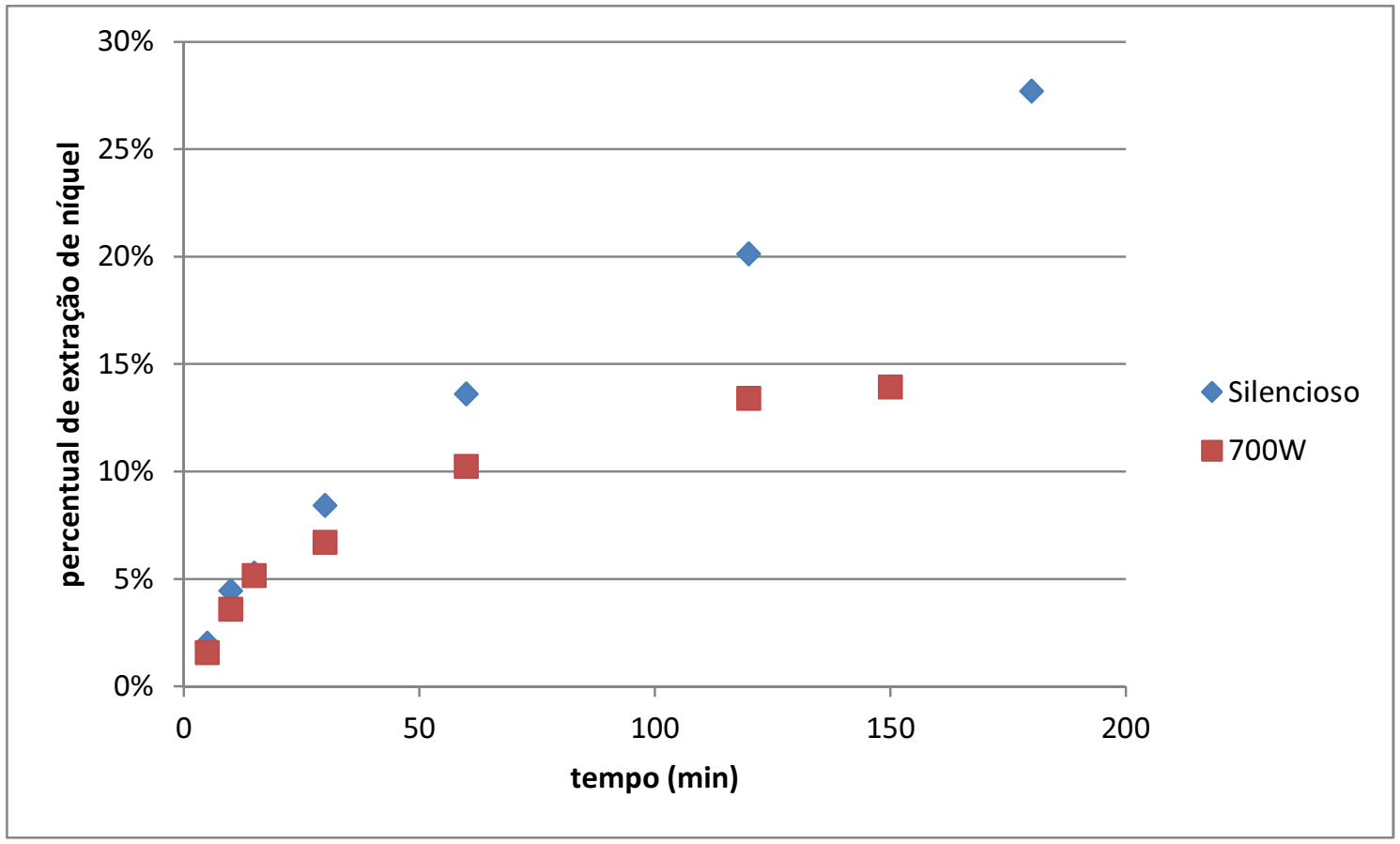

Figura 51. Extração de níquel em meio oxidante em diferentes potências de ultrassom. Condições: Razão S/L 1:40, concentração de ácido sulfúrico 0,5 mol. $\mathrm{L}^{-1}$ e oxigênio borbulhado a $100 \mathrm{~mL} \cdot \mathrm{min}^{-1}$.

O ensaio silencioso incorreu em extração de 27,7\%, em 180 minutos de reação. O ensaio sonicado com potência de $700 \mathrm{~W}$ ocasionou a extração de 13,9\% em 150 minutos de reação. Para o caso do níquel, o ensaio silencioso se mostrou melhor para a extração em relação ao ensaio sonicado. O fato pode ser explicado pela presença de bolhas de oxigênio no meio reacional, que podem atenuar a cavitação e a agitação da solução, e impedir que a implosão das bolhas de cavitação atinjam as partículas. Há também de ser considerada a possível formação de uma camada passiva no $\mathrm{Ni}$, facilitada pela presença de oxigênio. Assim, com a passivação, o metal se torna menos suscetível ao ataque do ácido, reduzindo seu percentual de lixiviação. 


\subsection{COMPARAÇÃO ENTRE LIXIVIAÇÃO COM ÁCIDO SULFÚRICO NA AUSÊNCIA E PRESENÇA DE MEIO OXIDANTE}

A comparação é realizada utilizando-se os ensaios do tipo silencioso.

\subsubsection{Ferro}

A comparação do percentual de lixiviação de ferro com e sem ácido sulfúrico, no ensaio silencioso, está apresentada na Figura 52 . A concentração de ácido utilizada foi de $0,5 \mathrm{~mol} . \mathrm{L}^{-1}$ e a razão $S / L$ foi de $1: 40$. No ensaio com meio oxidante, oxigênio gasoso foi fornecido ao sistema a uma taxa de $100 \mathrm{~mL} \cdot \mathrm{min}^{-1}$.

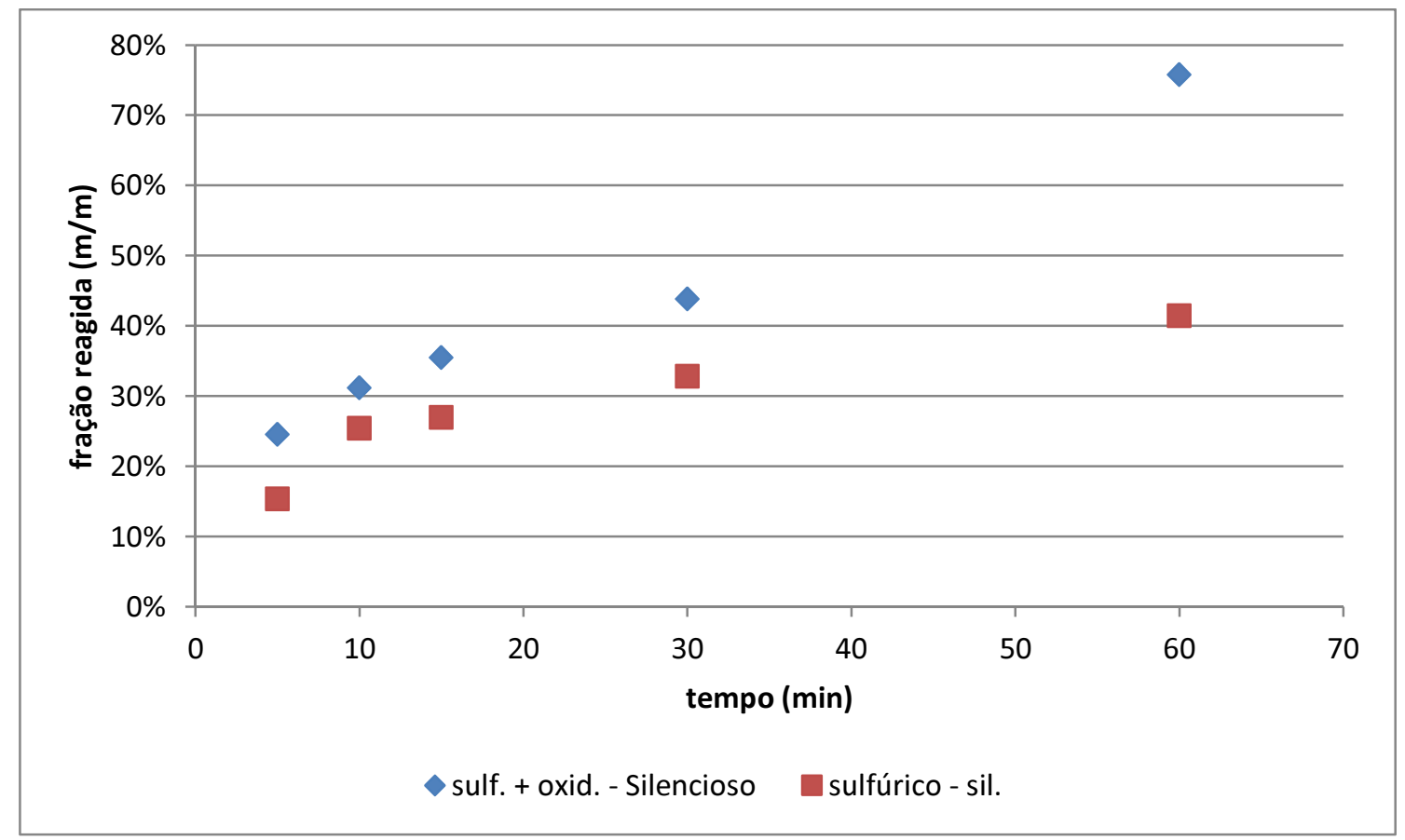

Figura 52. Extração de ferro com ácido sulfúrico e ácido sulfúrico em meio oxidante, no ensaio silencioso. Condições: concentração de ácido: $0,5 \mathrm{~mol}^{-\mathrm{L}^{-1} \mathrm{e}}$ razão S/L 1:40. 
O ensaio no qual foi utilizado meio oxidante removeu $76 \%$ de ferro, enquanto que o ensaio empregando somente ácido sulfúrico removeu $41 \%$. Neste caso, o meio oxidante auxiliou na extração de ferro em um fator de 2 vezes em comparação ao ensaio sem meio oxidante. Como o Fe não forma camada passiva na presença de oxigênio, o metal teve sua extração favorecida pela presença de agente oxidante.

\subsubsection{Alumínio}

A Figura 53 contém as curvas relativas à comparação da extração de alumínio por ácido sulfúrico somente e ácido sulfúrico em meio oxidante no ensaio silencioso. A concentração de ácido utilizada em ambos experimentos foi de $0,5 \mathrm{~mol}^{-L^{-1}}$ e a razão $S / L$ foi de 1:40. No ensaio com meio oxidante, oxigênio gasoso foi fornecido ao sistema a uma taxa de $100 \mathrm{~mL} \cdot \mathrm{min}^{-1}$.

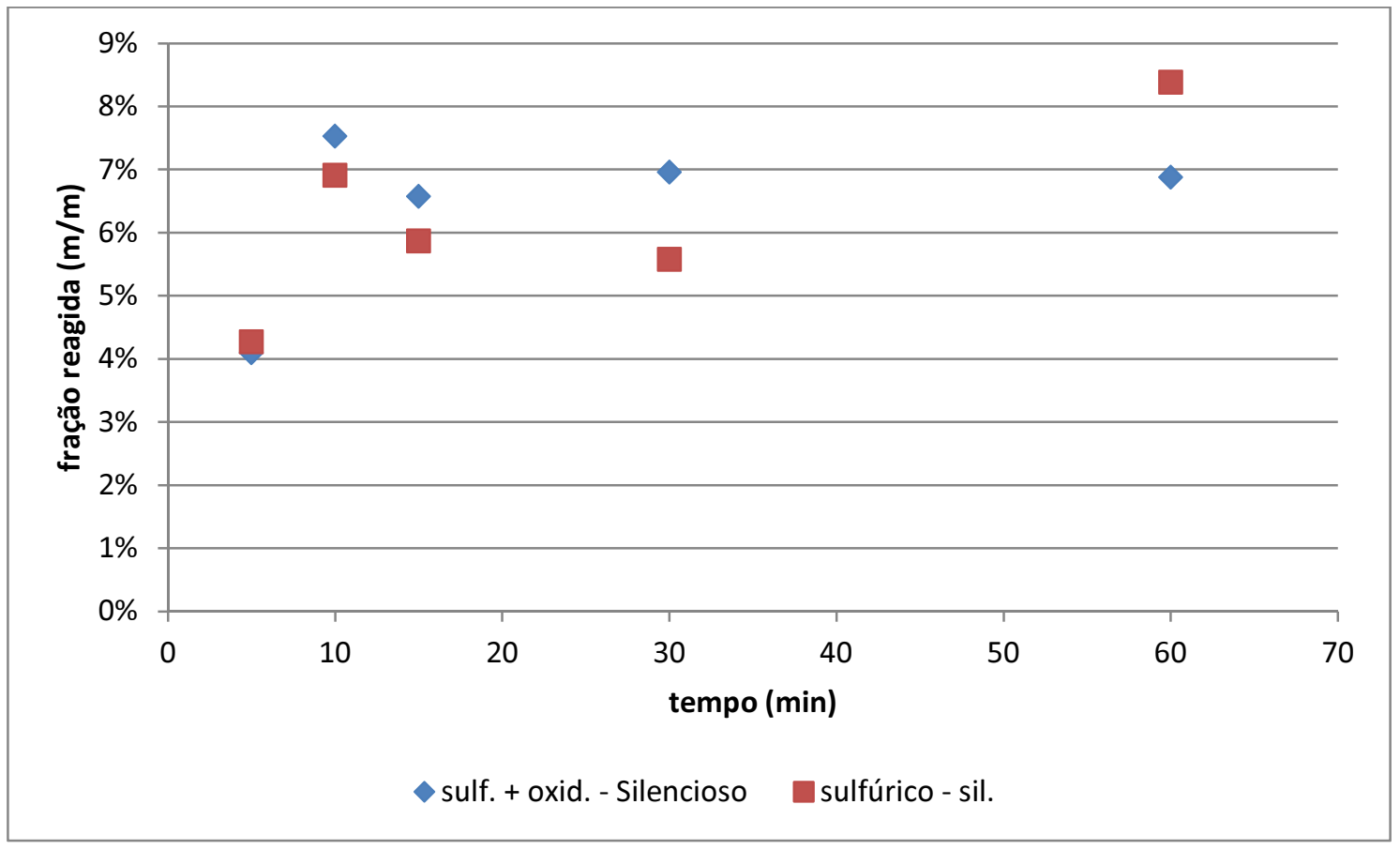

Figura 53. Extração de alumínio com ácido sulfúrico e ácido sulfúrico em meio oxidante, no ensaio silencioso. Condições: concentração de ácido: $0,5 \mathrm{~mol} . \mathrm{L}^{-1} \mathrm{e}$ razão S/L 1:40. 
Ao final de 60 minutos, a extração obtida pelo ensaio sem meio oxidante, foi de $8,4 \%$. O ensaio com meio oxidante promoveu extração de 6,9\%. No entando, apesar de a extração sem meio oxidante ter sido maior no final do experimento, as amostras relativas aos tempos de 10, 15 e 30 minutos mostram a concentração de alumínio presente na solução no ensaio com meio oxidante maior que a concentração do ensaio sem meio oxidante. Assim, podese afirmar que o ensaio com meio oxidante não promoveu um aumento na extração de alumínio possivelmente pela formação de alumina na superfície do alumínio, favorecida pela presença de oxigênio no meio reacional.

\subsubsection{Níquel}

A comparação entre a extração de níquel somente com ácido sulfúrico e com ácido sulfúrico na presença de meio oxidante está reportada na Figura 54. As condições utilizadas foram: concentração de ácido sulfúrico com concentração de $0,5 \mathrm{~mol}^{-L^{-1}}$ e razão $\mathrm{S} / \mathrm{L}$ de 1:40. No ensaio com meio oxidante, oxigênio gasoso foi fornecido ao sistema a uma taxa de $100 \mathrm{~mL} \cdot \mathrm{min}^{-1}$. 


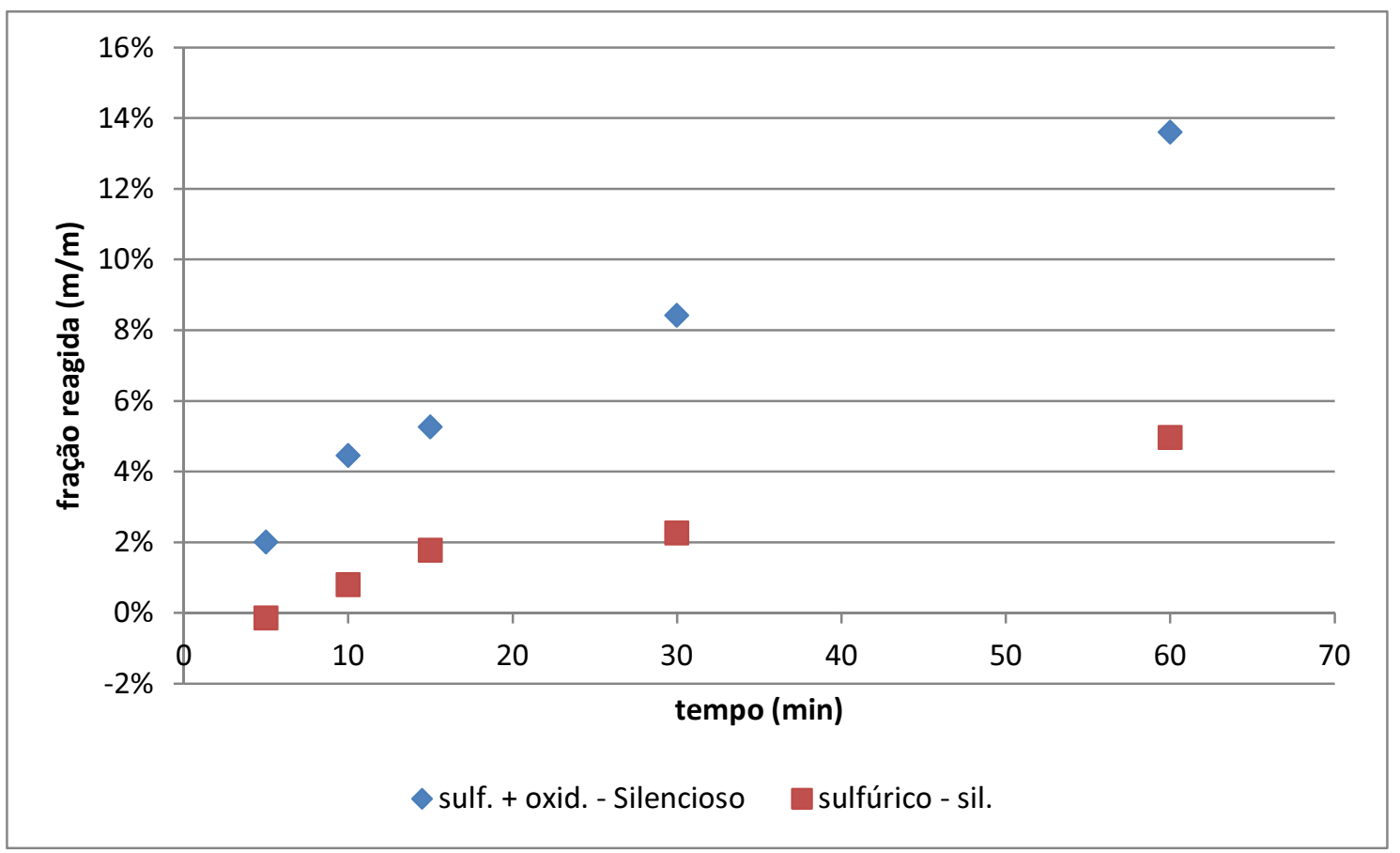

Figura 54. Extração de níquel com ácido sulfúrico e ácido sulfúrico em meio oxidante, no ensaio silencioso. Condições: concentração de ácido: $0,5 \mathrm{~mol}^{-1} \mathrm{~L}^{-1} \mathrm{e}$ razão S/L 1:40.

O resultado com meio oxidante apresentou melhor extração, sendo removidos $14 \%$ de níquel. O ensaio realizado somente com ácido sulfúrico apresentou extração de $5 \%$. Neste caso, a extração de níquel foi aumentada por um fator de 3 vezes quando foi utilizado oxigênio como meio oxidante, pois presença deste agente aumenta o potencial de oxidação do meio reacional e favorece a lixiviação deste metal.

\subsubsection{Cobre}

A Figura 55 mostra as curvas do percentual de extração do cobre utilizando ácido sulfúrico e o mesmo ácido em meio oxidante. A concentração de ácido utilizada em ambos experimentos foi de $0,5 \mathrm{~mol} . \mathrm{L}^{-1}$ e a razão $\mathrm{S} / \mathrm{L}$ foi de 1:40. No ensaio com meio oxidante, oxigênio gasoso foi fornecido ao sistema a uma taxa de $100 \mathrm{~mL} \cdot \mathrm{min}^{-1}$. 


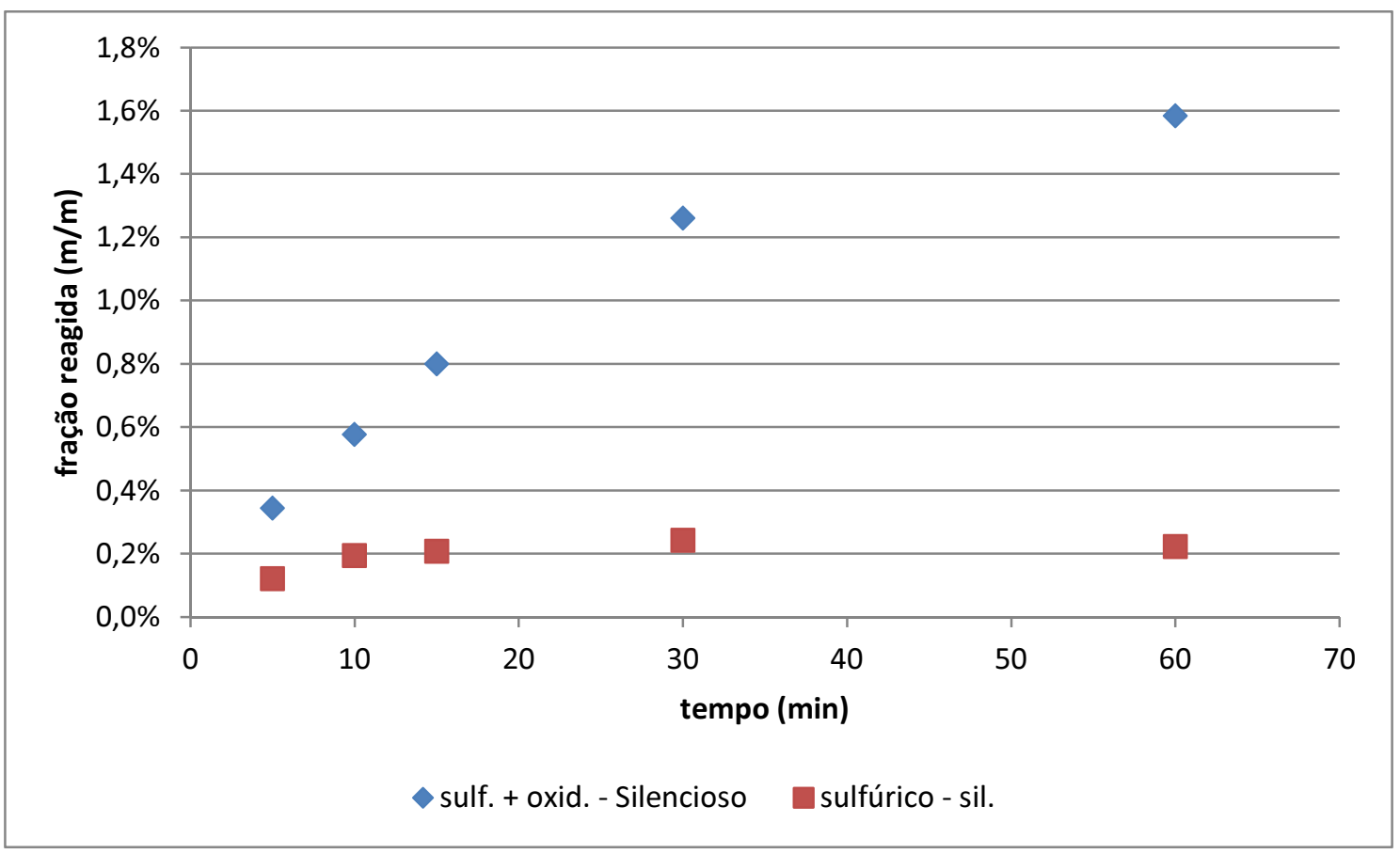

Figura 55. Extração de cobre com ácido sulfúrico e ácido sulfúrico em meio oxidante, no ensaio silencioso. Condições: concentração de ácido: $0,5 \mathrm{~mol}^{-1} \mathrm{e}$ razão S/L 1:40.

O percentual de remoção de cobre utilizando-se meio oxidante foi de $1,6 \%$, enquanto que a extração no ensaio que foi utilizado somente ácido sulfúrico foi de $0,2 \%$. O aumento na remoção de cobre promovido pela utilização de oxigênio como meio oxidante foi de 8 vezes. O $\mathrm{Cu}$ não é deslocado para a solução em meio sulfúrico apenas. Para que este se solubilize é necessário um agente oxidante, que, neste caso, foi empregado o oxigênio, que causou este aumento significativo em sua extração. No entanto, o percentual de extração de cobre está muito pequeno se comparado ao ferro, por exemplo.

A extração de cobre não foi apresentada na seção de lixiviação com ácido sulfúrico, pois, em todos os ensaios realizados sem um agente oxidante, a extração de cobre foi inferior a $0,1 \%$. 


\subsection{ANÁLISE CINÉTICA}

O modelamento cinético foi feto com intuito de se obter informações sobre o tipo de controle que a reação de lixiviação apresenta. Para tal, foram utilizados somente os dados referentes à lixiviação de ferro, pois este foi o metal que apresentou maior percentual de extração e assim a fração reagida se aproximou mais do valor unitário. Foram considerados dois possíveis controles da reação: por reação química e por difusão. A análise foi realizada para o ensaio silencioso e para o ensaio sonicado com potência de $700 \mathrm{~W}$. As condições dos experimentos cujos resultados foram utilizados no modelamento foram: razão $S / L$ 1:20, concentração de ácido de 0,5 mol. $L^{-1}$, condições estas escolhidas dada a maior extração percentual de metal.

O ajuste dos dados experimentais nos modelos foi realizado utilizandose as equações 12 e 18 do capítulo de Introdução. Na Figura 56 é apresentado o ajuste dos ensaios silencioso e sonicado com potência de $700 \mathrm{~W}$. O resultado referente ao tempo de 5 minutos não foi considerado no ajuste linear, pois estava muito distante da reta e pode se tratar de um erro experimental aleatório.

\section{Controle por difusão}

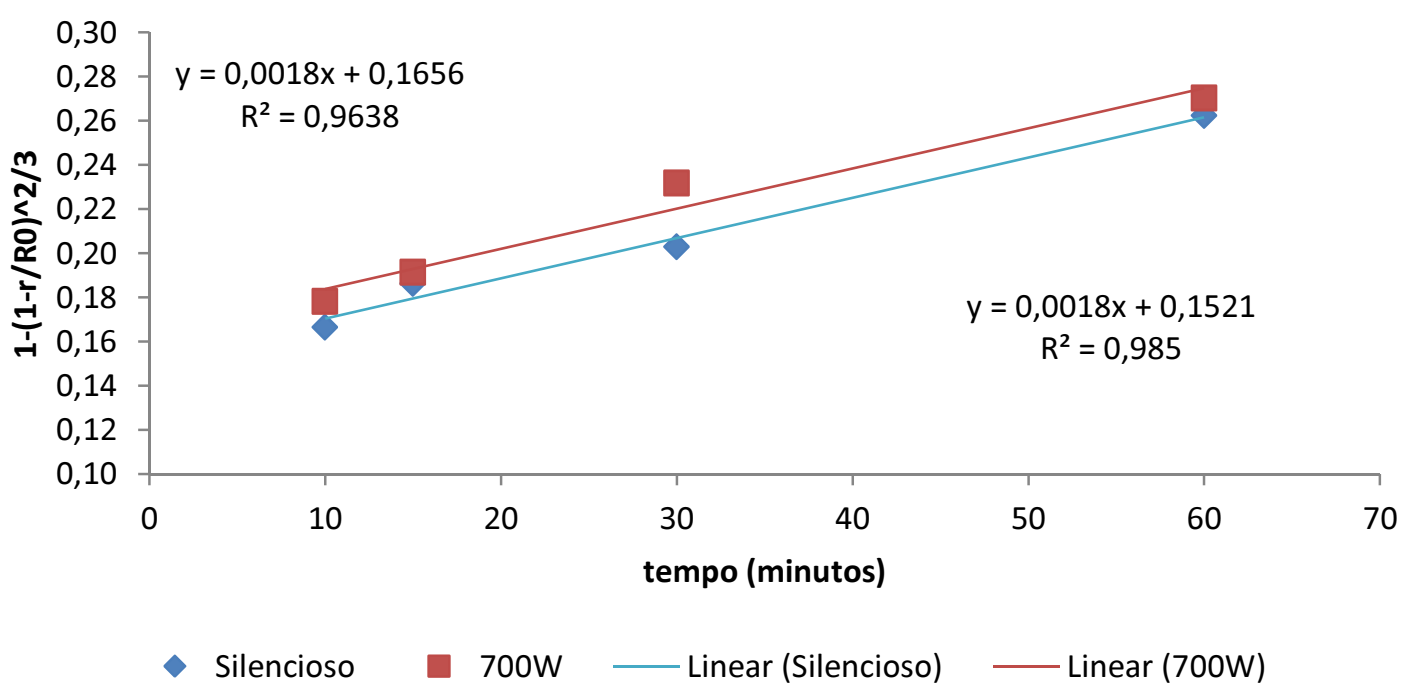

Figura 56. Ajuste da lixiviação por controle por difusão do ensaio silencioso e sonicado com potência de $700 \mathrm{~W}$. 
O ajuste da curva do ensaio silencioso resultou em um valor de $r^{2}$ de 0,9638 , enquanto que para o ajuste da curva referente ao ensaio sonicado foi obtido um valor de $r^{2}$ de 0,985 , ambos considerados bons valores.

A Figura 57 reporta o ajuste dos mesmos dados experimentais frente ao modelo que considera o controle da reação por reação química. $O$ resultado referente ao tempo de 5 minutos não foi considerado no ajuste linear, pois estava muito distante da reta e pode se tratar de um erro experimental aleatório.

\section{Controle por reação química}

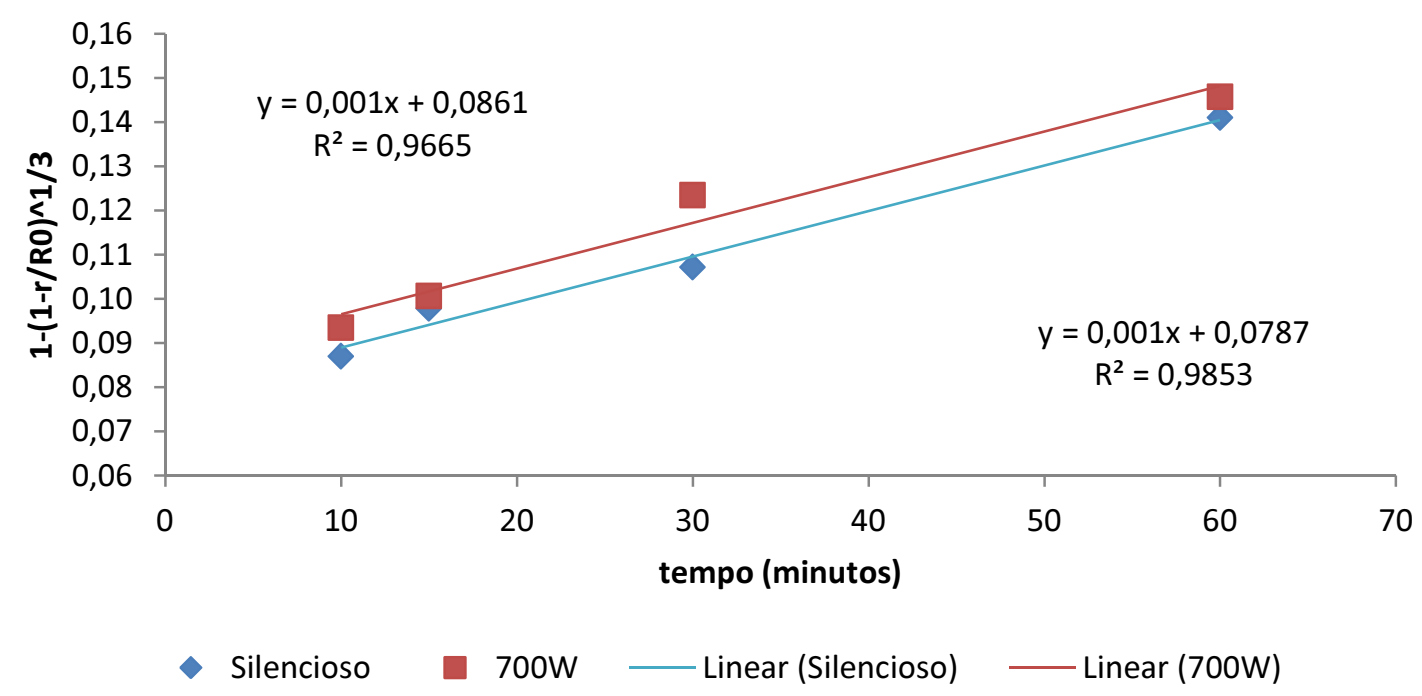

Figura 57. Ajuste da lixiviação por controle por reação química do ensaio silencioso e sonicado com potência de $700 \mathrm{~W}$.

O ajuste da curva referente ao ensaio silencioso resultou em um valor de $r^{2}$ de 0,9665 . A curva experimental do ensaio sonicado com potência de $700 \mathrm{~W}$ obteve um valor de $r^{2}$ de 0,9853 . Ambos valores são considerados bons, pois se aproximam do valor unitário.

No entanto, como ambos ajustes obtidos são considerados bons, não é possível se concluir qual é o controle que se tem na reação, com base no conjunto de experimentos que foi realizado. 
Uma vez que o simples ajuste das curvas experimentais foi inconclusivo, optou-se por utilizar o método do tempo reduzido, objetivando elucidar o mecanismo controlador.

A partir dos resultados experimentais para os ensaios de lixiviação do ferro, com razão $S / L$ 1:40 e concentração $0,5 \mathrm{~mol}^{-L^{-1}}$, aplicou-se o método do tempo reduzido, descrito na seção 4.8. Foi adotada esta razão $S / L$ pois foi a que a apresentou maior extração de ferro; já a concentração de $0,5 \mathrm{~mol} / \mathrm{L}$ foi escolhida por ser a intermediária entre as concentrações utilizadas neste trabalho (entre 0,01 e 1,0 mol. $\mathrm{L}^{-1}$ ).

A Figura 58 apresenta a fração reagida em função do tempo reduzido para o ensaio silencioso sem adição de oxidante (oxigênio). Os dados de fração reagida em função do tempo para este caso foram obtidos a partir da Figura 34.

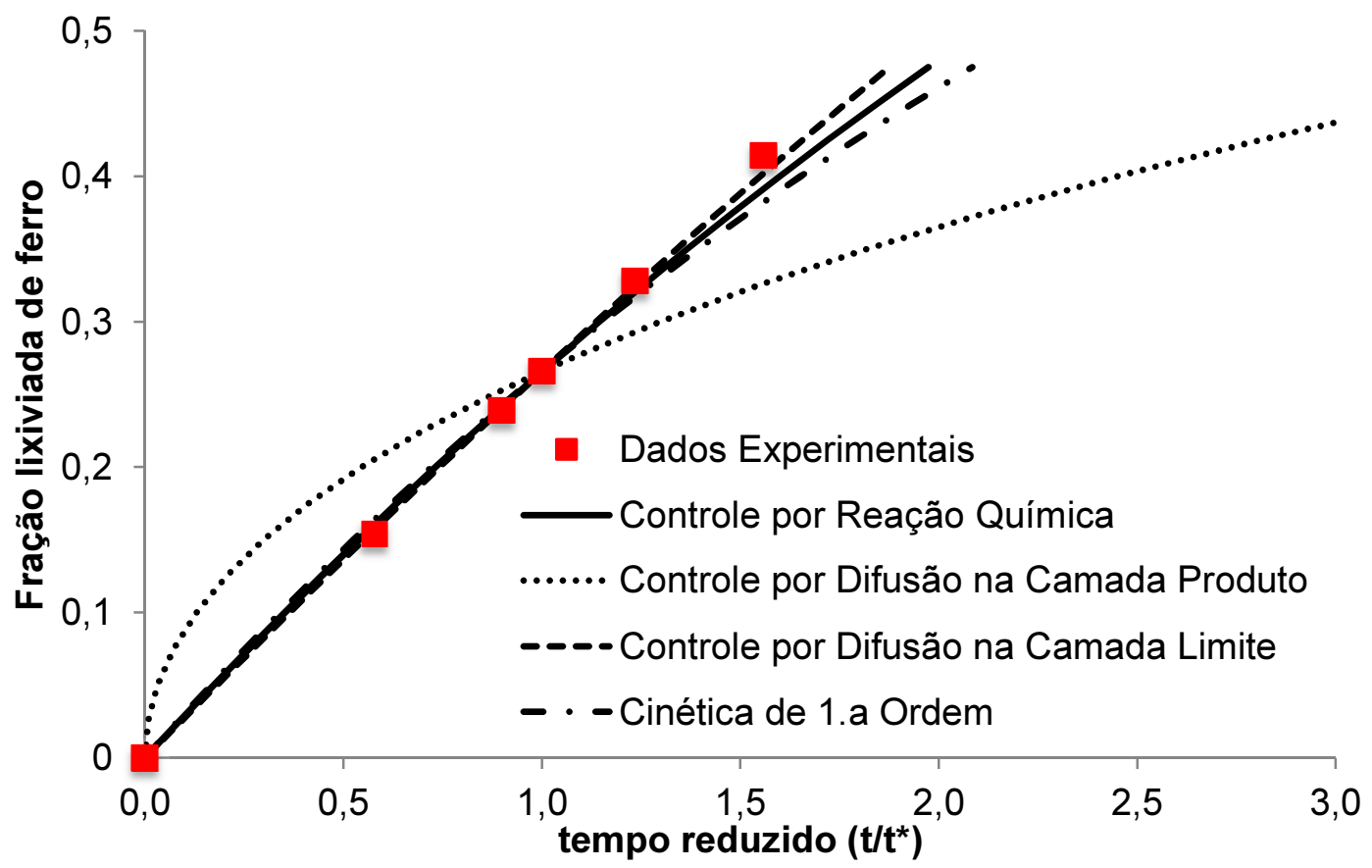

Figura 58. Fração reagida de ferro em função do tempo reduzido para o ensaio silencioso na ausência de oxidante e com razão $S / L$ 1:40 e concentração de ácido $0,5 \mathrm{~mol} . \mathrm{L}^{-1}$. 
Como pode ser visto na Figura 58 , os modelos cinéticos associados aos controles por reação química, por difusão na camada limite e à cinética de $1^{\text {a }}$ ordem apresentam equações muito próximas para frações reagidas inferiores a 0,5 (50\%). Em virtude disso, a identificação do controle cinético torna-se inconclusivo para este caso.

As Figura 59 e Figura 60 apresentam, respectivamente, a análise cinética para o ensaio sonicado com potência de $700 \mathrm{~W}$ e para o ensaio silencioso com adição de oxidante.

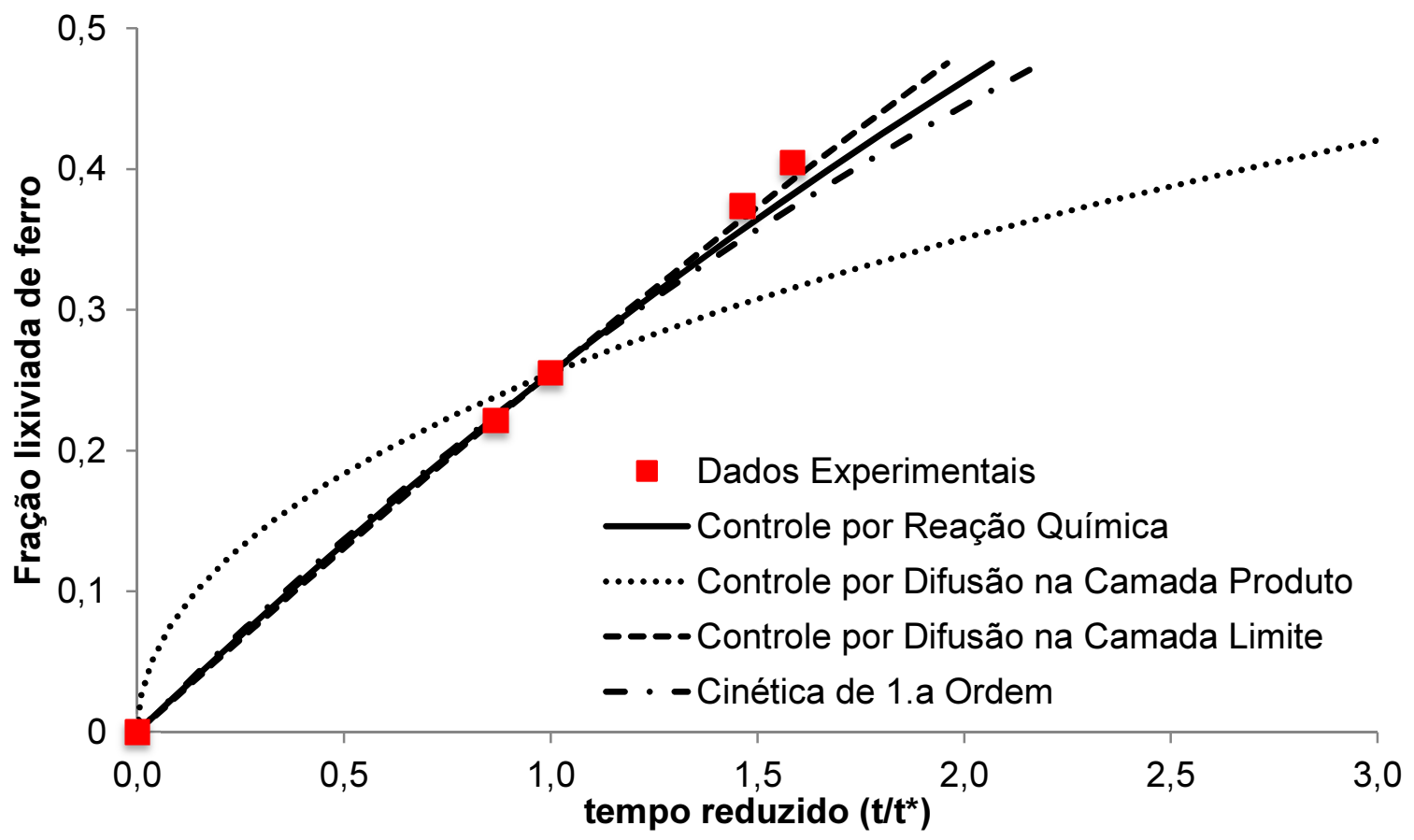

Figura 59. Fração reagida de ferro em função do tempo reduzido para o ensaio sonicado com potência de $700 \mathrm{~W}$ (na ausência de oxidante) e com razão S/L $1: 40$ e concentração de ácido $0,5 \mathrm{~mol} \cdot \mathrm{L}^{-1}$. 


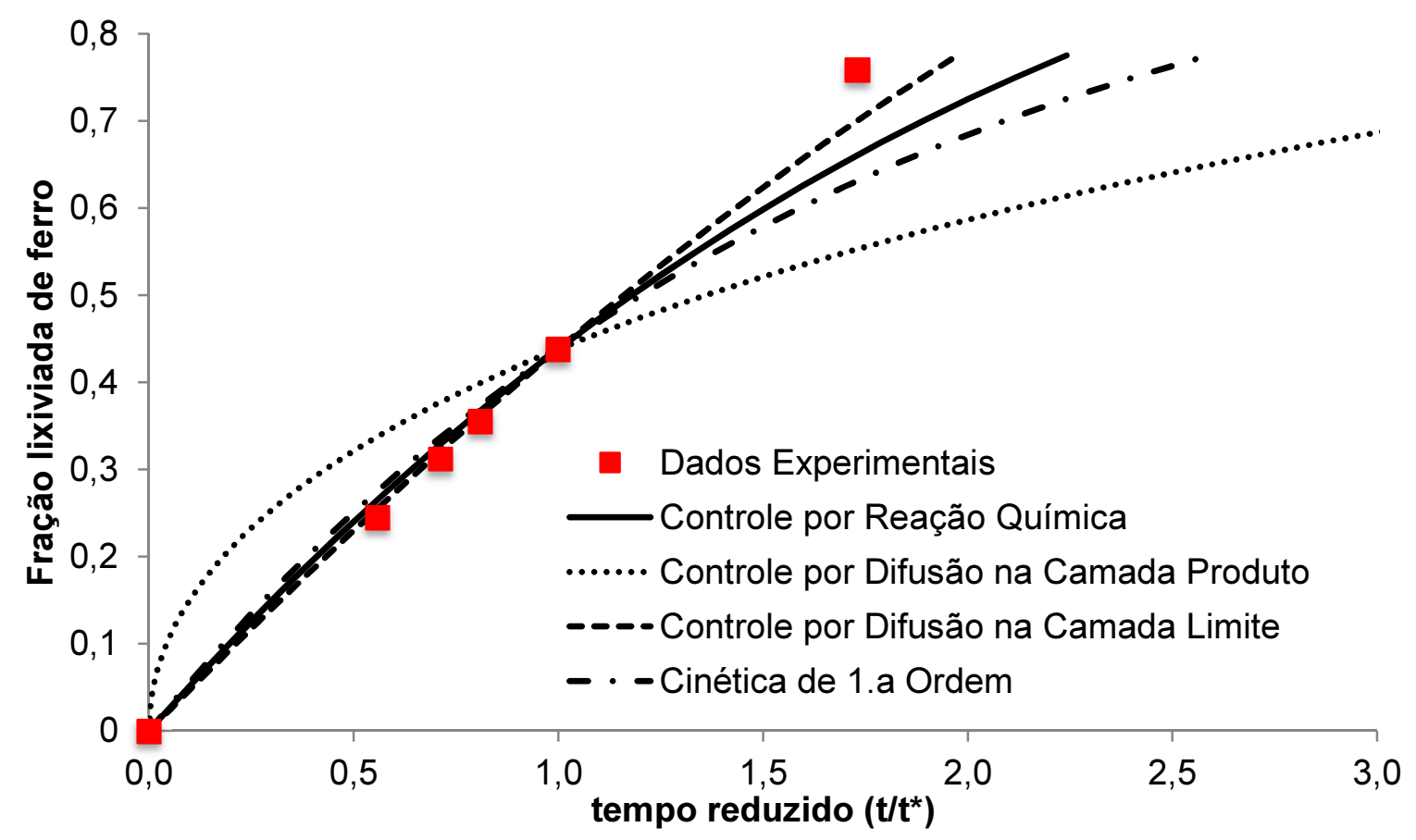

Figura 60. Fração reagida de ferro em função do tempo reduzido para o ensaio silencioso na presença de oxidante e com razão S/L 1:40 e concentração de ácido $0,5 \mathrm{~mol} . \mathrm{L}^{-1}$.

No caso do ensaio sonicado (Figura 59), a identificação do modelo cinético torna-se inconclusivo pelos mesmos motivos do caso anterior: a extração inferior à $50 \%$ dificulta a separação das curvas relacionadas aos modelos mencionados anteriormente. Apesar disso, pode-se inferir que o comportamento cinético não foi alterado com a utilização do ultrassom, dado que as curvas relacionadas aos dados experimentais (pontos vermelhos nas Figura 58 e Figura 59) não sofreram alterações de inclinação. Este comportamento pode significar que, em ambos os casos, o mecanismo controlador é o mesmo (controle químico ou controle por difusão na camada limite), porém não é possível distinguir qual.

Já com a adição de oxidante, a extração de ferro atingiu valores próximos a $80 \%$, como pode ser visto na Figura 60 . Existe, nesta figura, uma tendência dos pontos experimentais se aproximarem da curva que representa $o$ controle por difusão na camada limite. Contudo, em virtude da adição de mais um reagente no sistema (oxigênio), não é possível afirmar que este controle também é válido para os dois casos anteriores. Se este for o caso, a agitação 
da solução com a utilização do ultrassom, e consequente redução da espessura da camada limite, não seria suficiente para alterar o controle por difusão para controle por reação química, isso pode estar associado ao fato da etapa química de lixiviação de ferro já mais rápida que a difusão dos reagentes e produtos, independente do equipamento utilizado para agitação.

O procedimento descrito foi aplicado para os dados experimentais associados às lixiviações dos demais metais: alumínio, níquel e cobre. Contudo, em virtude da extração relativamente baixa: 6,9\%, 13,6\% e 1,6\% para o ensaio silencioso com oxidante para alumínio, níquel e cobre, respectivamente, a identificação do mecanismo controlador é prejudicada. As Figura 61 e Figura 62 apresentam a análise cinética da fração lixiviada de níquel e cobre em função do tempo reduzido e exemplificam as difuldades em determinar o modelo cinético. As condições dos experimentos foram as mesmas dos ensaios relacionados ao ferro: razão S/L 1:40 e concentração de ácido $0,5 \mathrm{~mol} \cdot \mathrm{L}^{-1}$.

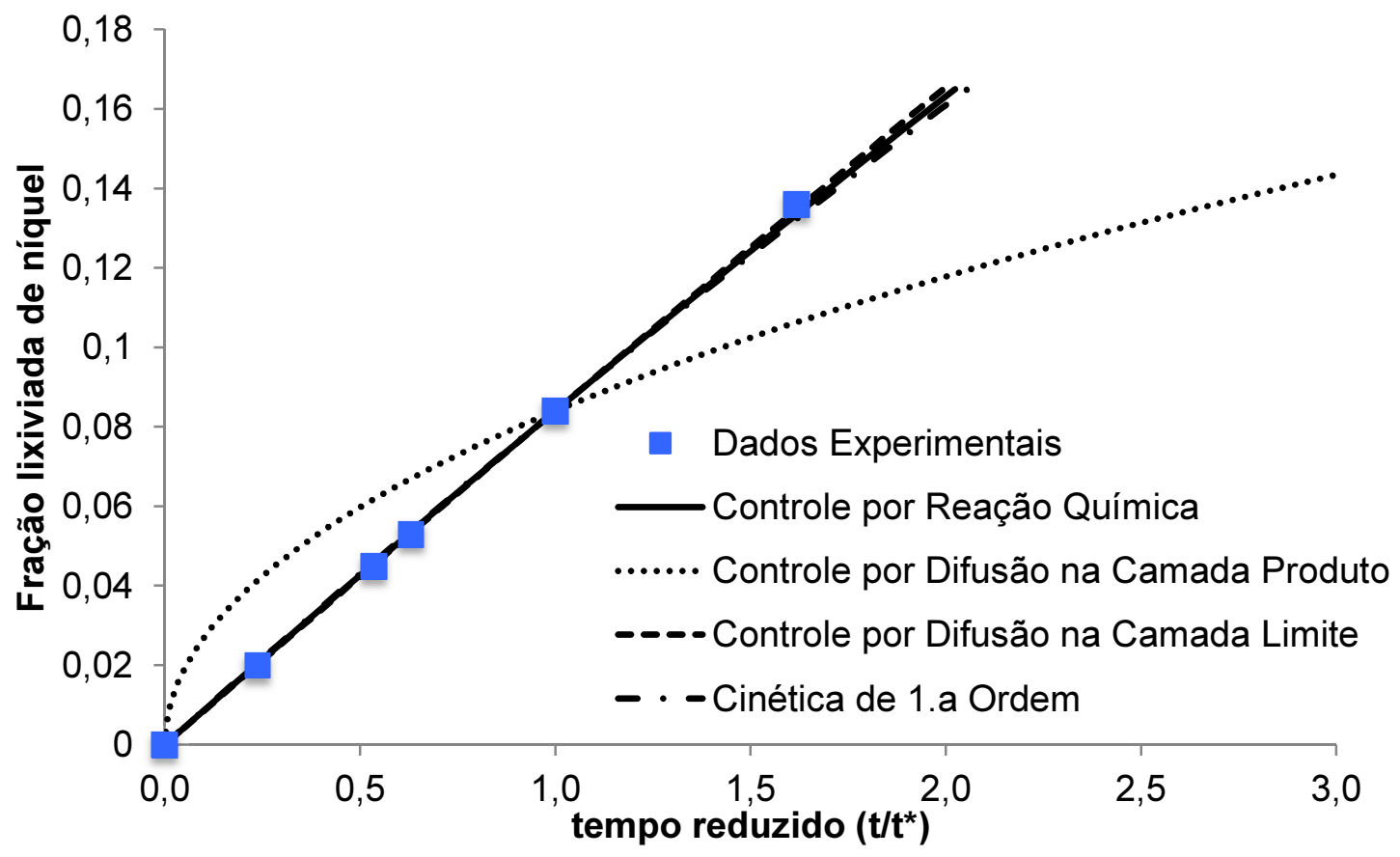

Figura 61. Fração reagida de níquel em função do tempo reduzido para o ensaio silencioso na presença de oxidante e com razão S/L 1:40 e concentração de ácido $0,5 \mathrm{~mol} \cdot \mathrm{L}^{-1}$. 


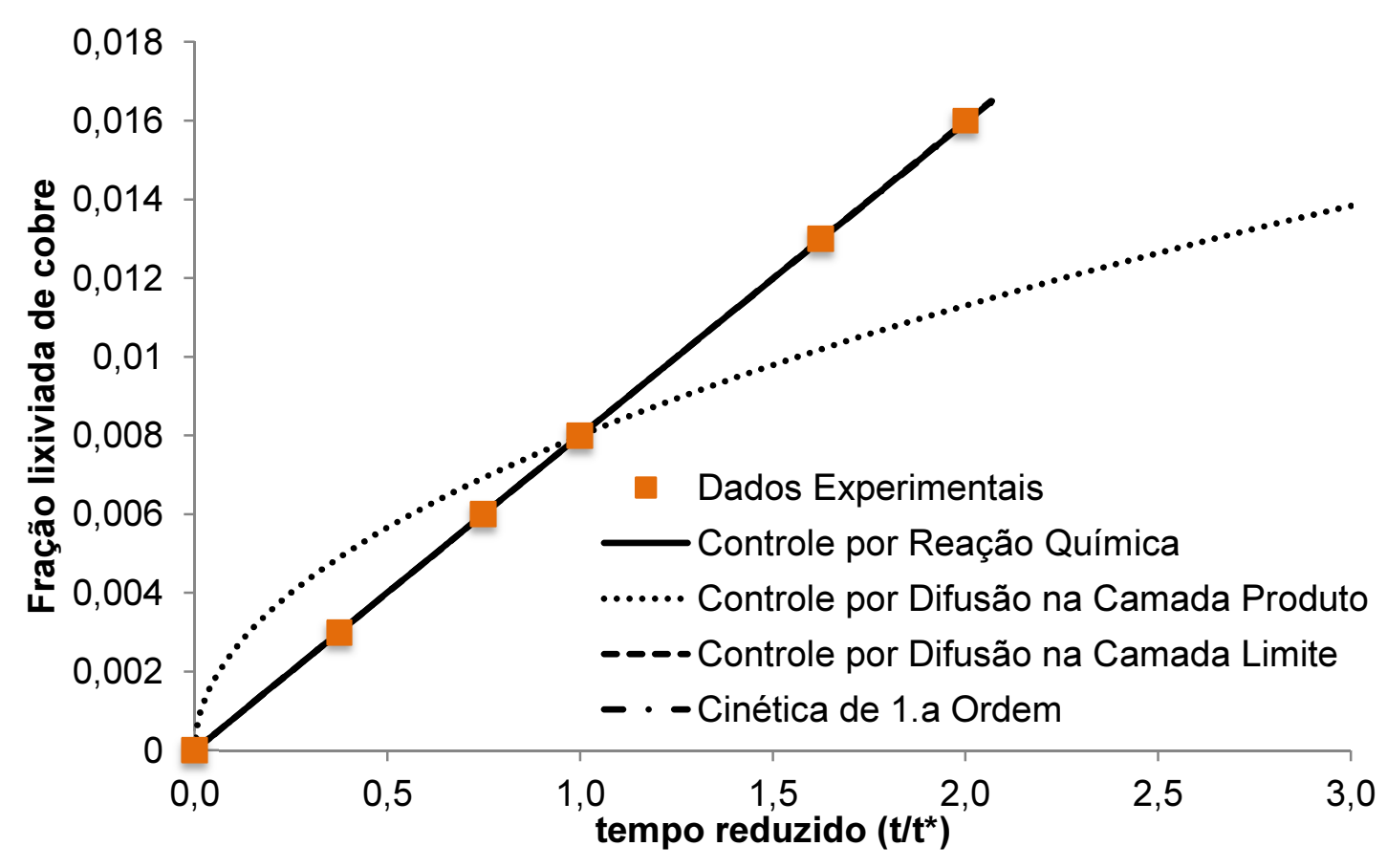

Figura 62. Fração reagida de cobre em função do tempo reduzido para o ensaio silencioso na presença de oxidante e com razão $S / L$ 1:40 e concentração de ácido $0,5 \mathrm{~mol} \cdot \mathrm{L}^{-1}$.

A dificuldade em determinar a melhor equação cinética está associada a características do método do tempo reduzido. Quando a extração é inferior a $60-70 \%$, valores estes considerados baixos, a fração reagida de referência $X^{*}$ escolhida, e consequentemente o tempo $t^{*}$, deve ser menor do que $0,3-0,4,0$ implica em uma aproximação das curvas, como pode ser verificado ao se comparar as Figura 63 e Figura 64, que representam a aplicação do método do tempo reduzido adotando-se $X^{*}$ igual a 0,5 e a 0,15 , respectivamente. 


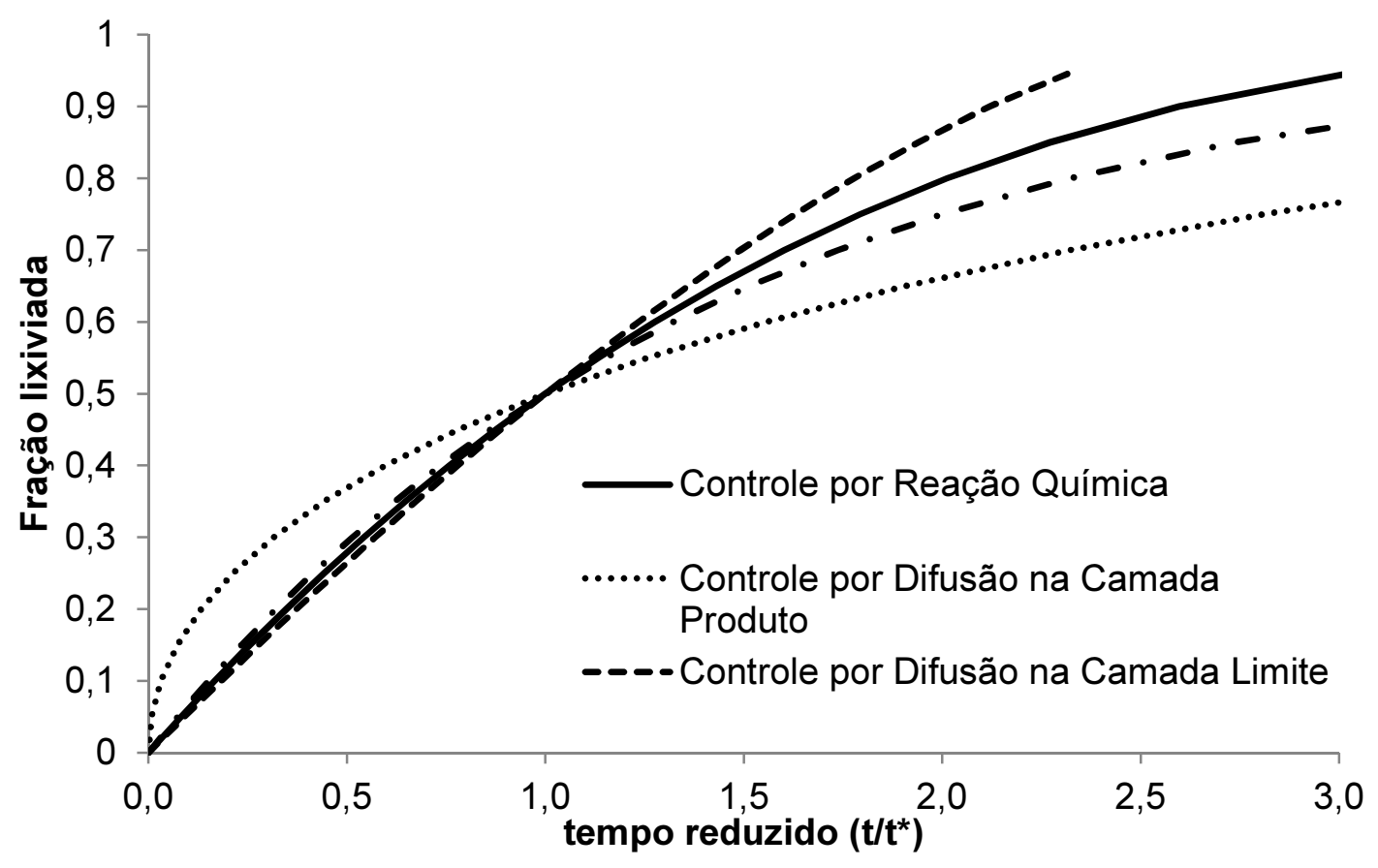

Figura 63. Aplicação do método do tempo reduzido adotando-se $X^{*}=0,5$.

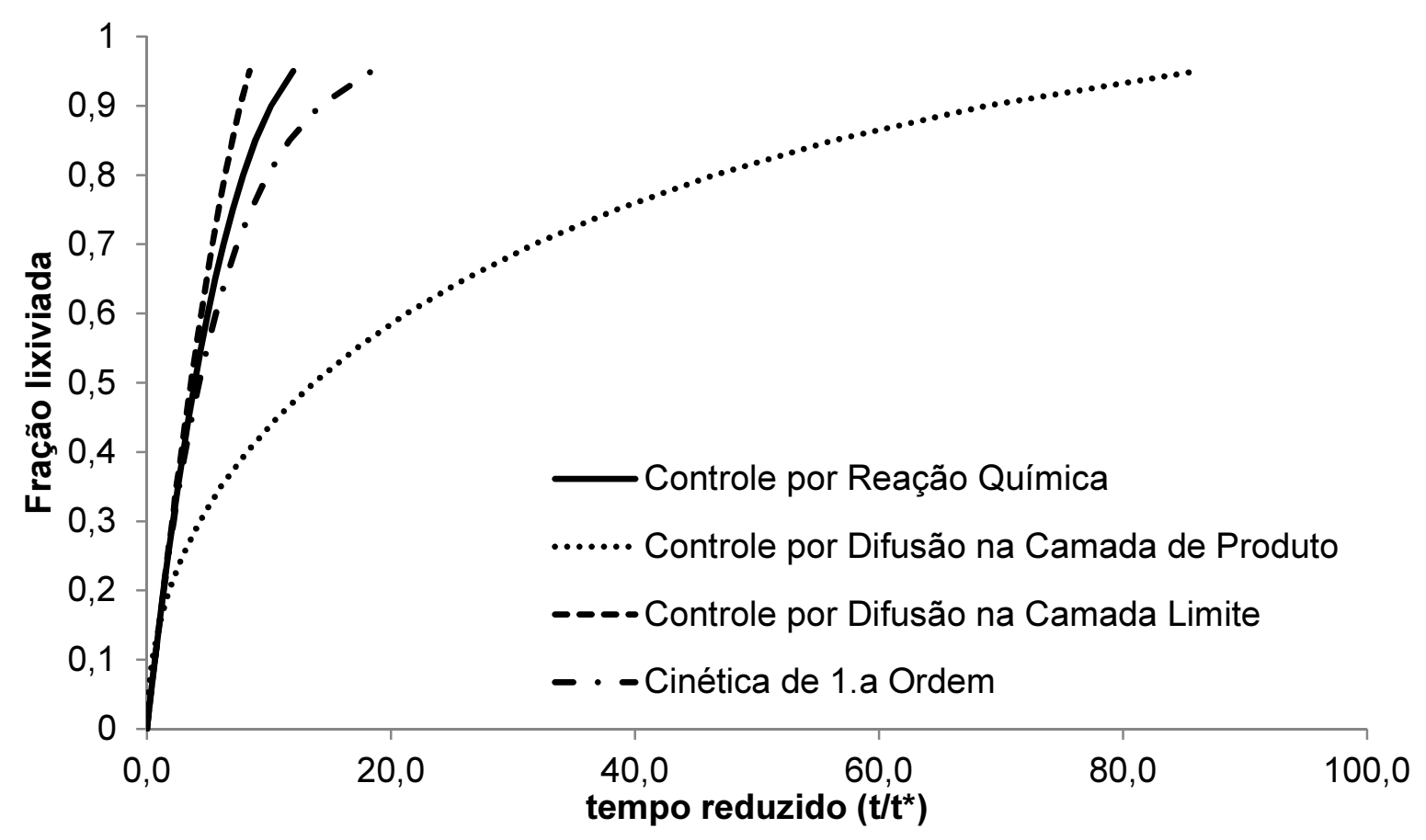

Figura 64. Aplicação do método do tempo reduzido adotando-se $X^{*}=0,15$.

Nas condições da Figura $64\left(X^{*}=0,15\right)$, a aproximação das curvas para frações lixiviadas inferiores a 0,5 impossibilita qualquer diferenciação entre 
elas. Este problema ocorreu nas análises para os metais alumínio, níquel e cobre, nas quais foi necessário adotar como referência os valores de 0,041, 0,084 e 0,008 , respectivamente. Os dois últimos casos foram apresentados nas Figura 61 e Figura 62. 


\section{CONCLUSÕES}

1. A placa DL contém $19,7 \% \mathrm{Cu}, 6,8 \% \mathrm{Al}, 5,0 \% \mathrm{Sn}, 2,2 \% \mathrm{Zn}, 0,6 \% \mathrm{Fe}$ e $0,2 \% \mathrm{Ni}$ em massa.

2. A moagem promovida pelo efeito do ultrassom mostrou que a placa multi-layer ML é cominuída mais facilmente do que a placa DL.

3. O aumento na potência causa uma maior cominuição das placas, devido ao aumento do número de eventos de cavitação.

4. O tamanho inicial de partícula influencia o resultado final da cominuição: partículas iniciais maiores sofrem maior cominuição relativa do que partículas iniciais menores. Quantitativamente, o melhor resultado de cominuição obtido foi a redução da partícula de placa ML, cominuída inicialmente em grelha de 6 $\mathrm{mm}$, de $25 \%$ em $4 \mathrm{~h}$ de exposição ao ultrassom com potência de $700 \mathrm{~W}$.

5. Os ensaios de lixiviação dos metais $\mathrm{Fe}, \mathrm{Al}$ e $\mathrm{Ni}$ com ácido sulfúrico revelaram que quando utilizada a razão $S / L$ de 1:40 obtém-se a melhor extração de metais, em detrimento as razões de 1:10 e 1:20.

6. A concentração de ácido que resultou a melhor extração foi a de 1 mol. $\mathrm{L}^{-1}$ para $\mathrm{Al}$ e Ni. Para o caso do $\mathrm{Fe}$, a melhor extração foi obtida pela menor concentração utilizada, de 0,01 mol. $\mathrm{L}^{-1}$.

7. O ultrassom não aumentou a extração de ferro, diferentemente do $\mathrm{Al} \mathrm{e}$ $\mathrm{Ni}$. Para o $\mathrm{Al}$, o aumento na lixiviação foi de $85 \%$ quando foi utilizado o ultrassom com potência de $700 \mathrm{~W}$. Para o caso do Ni, o aumento foi de $34 \%$ de aumento de extração quando comparados o ensaio silencioso e o ensaio sonicado a $700 \mathrm{~W}$.

8. Potências inferiores a $700 \mathrm{~W}$ não aumentaram a extração em relação ao ensaio silencioso.

9. O ensaio de lixiviação com meio oxidante aumentou a extração de $\mathrm{Fe}, \mathrm{Ni}$ e $\mathrm{Cu}$ em relação à lixiviação realizada somente com ácido sulfúrico. Neste caso, a extração do $\mathrm{Fe}$ foi aumentada em $85 \%$, a de $\mathrm{Ni}$ em $172 \%$ e a de Cu em $700 \%$.

10. A análise cinética foi inconclusiva no processo de determinação do controle cinético da lixiviação do ferro nos três tipos de ensaio realizados 
(silencioso sem oxidante, silencioso com oxidante e sonicado), não sendo possível identificar se o controle é químico ou por difusão na camada limite. 


\section{REFERÊNCIAS BIBLIOGRÁFICAS}

1. Cui, J. e Zhang, L. Metallurgical recovery of metals from electronic waste: A review. Journal of Hazardous Materials. 2008, Vol. 158, pp. 228-256.

2. Kasper, A.C., et al., et al. Printed wiring boards for mobile phones: Characterization and recycling of copper. Waste Management. 2011, Vol. 31, 12, pp. 2536-2545.

3. Luche, J.L. Effect of ultrasound on heterogeneous systems. Ultrasonics Sonochemistry. 1994, Vol. 1, 2, pp. S111-S118.

4. Super Interessante. Thomas Edison, o gênio da lâmpada. Super Interessante. 015, dezembro de 1988.

5. The Nobel Foundation. The Nobel Prize in Physics 1956. The Official Web Site of the Nobel Prize. [Online] [Citado em: 03 de janeiro de 2013.] http://www.nobelprize.org/nobel_prizes/physics/laureates/1956/.

6. Morimoto, C.E. O Transístor. Hardware, o Guia definitivo. [Online] 01 de 10 de 2007. [Citado em: 07 de 11 de 2012.] http://www.hardware.com.br/livros/hardware/transistor.html.

7. Yu, J., et al., et al. Forecasting global generation of obsolete personal computers. Environmental Science \& Technology. 2010, Vol. 44, 9, pp. 32323237.

8. Havlik, T., et al., et al. Leaching of cooper and tin from used printed circuit boards after thermal treatment. J. of Hazardous Materials. 2010, Vol. 183, 1-3, pp. 866-873.

9. ABINEE. Mercado de PCs deve crescer $9 \%$ em 2012. [Online] [Citado em: 13 de janeiro de 2013.] http://www.abinee.org.br/noticias/com48.htm.

10. - Comportamento da Indústria Elétrica e Eletrônica - Ano 2013. 2013. http://www.abinee.org.br/informac/arquivos/dados13.pdf.

11. Araújo, M.G., et al., et al. A model for estimation of potential generation of waste electrical and electronic equipment in Brazil. Waste Management. 2012, Vol. 32, pp. 335-342. 
12. Huang, K, Guo, J e Xu, Z. Recycling of waste printed circuit boards: A review of current technologies and treatment status in China. Journal of Hazardous Materials. 2009, Vol. 164, pp. 399-408.

13. Social, Assessoria de Comunicação. GOVERNO PRORROGA BENEFÍCIO FISCAL PARA O PROGRAMA DE INCLUSÃO DIGITAL. Ministério da Fazenda. [Online] [Citado em: 16 de 10 de 2014.] http://www.fazenda.gov.br/divulgacao/noticias/2014-1/agosto/governo-prorrogabeneficio-fiscal-para-o-programa-de-inclusaodigital/?searchterm=programa\%20de $\% 20$ inclus $\%$ C3\%A30\%20digital.

14. European Parlament, Council. Directiva 2002/95/CE. Jornal Oficial da União Européia. 13 de 02 de 2003, pp. 24-39.

15. Torreta, T., et al., et al. Management of waste electrical and electronic equipment in two EU countries: A comparison. Waste Management. 2012, p. No prelo. http://dx.doi.org/10.1016/j.wasman.2012.07.029.

16. BRASIL. Lei $n^{0} 12.305$, de 2 de agosto de 2010. Seção 1, p. 3. Institui a Política Nacional de Resíduos Sólidos; altera a Lei $n^{\circ}$ 9.605, de 12 de fevereiro de 1998; e dá outras providências.

17. Tsydenova, O. e Bengtsson, M. Chemical hazards associated with treatment of waste electrical and electronic equipment. Waste Management. 2011, Vol. 31, pp. 45-58.

18. Li, Y., et al., et al. Dynamic leaching test of personal computer components. J. Hazardous Materials. 2009, 171, pp. 1058-1065.

19. Chmielewski, AG, Urbánski, TS e Migdal, W. Separation technologies for metals recovery from industrial wastes. Hydrometallurgy. 1997, Vol. 45, pp. 333-344.

20. $\mathbf{W u}, \mathbf{J} ., \mathbf{L i}, \mathbf{J}$. e $\mathbf{X u}, \mathbf{Z}$. An improved model for computing the trajectories of conductive particles in roll-type electrostatic separator for recycling metals from WEEE. J. Hazardous Materials. 2009, Vol. 167, 1-3, pp. 489-493. 
21. Closed Loop WEEE Recycling? Challenges and opportunities for a global recycling society. Meskers, C. E. M. e Hagelüken, C. São Francisco : TMS Annual Meeting, 2009. EPD Congress 2009. pp. 1049-1054.

22. São Paulo (Estado). Decreto $n^{\circ} 57.817$, de 28 de fevereiro de 2012 de São Paulo. 2012. Institui, sob coordenação da Secretaria do Meio Ambiente, o Programa Estadual de Implementação de Projetos de Resíduos Sólidos e dá providências correlatas.

23. Coombs, C.F. Jr. Printed Circuits Handbook. 6a. s.I. : McGraw-Hill, 2008. $10.1036 / 0071467343$.

24. Ruan, J., Guo, Y. e Qiao, Q. Recovery of indium from scrap TFTLCDs by solvent extraction. Procedia Environmental Sciences. 2012, Vol. 16, pp. 545-551.

25. Marques, A.C., Cabrera, J.M. e Malfatti, C.F. Printed circuit boards: A review on the perspective of sustainability. Journal of Environmental Management. 2013, Vol. 131, 15, pp. 298-306.

26. Nakahara, H. Types of Printed Wiring Boards. [A. do livro] C. F. Jr. Coombs. [ed.] 6 ed. Printed Circuits Handbook. s.l. : McGraw-Hill, 2008, p. 5.1.

27. Point-to-point construction. Wikipedia, the free encyclopedia. [Online] [Citado em: 13 de 10 de 2014.$]$ http://en.wikipedia.org/wiki/File:Motorolagoldenviewchassis.jpg.

28. View topic - STARTERS GUIDE for Raspberry $\mathrm{Pi}, \mathrm{A}, \mathrm{B}$ and $\mathrm{B}+$. Raspberry Pi. [Online] [Citado em: 13 de 10 de 2014.] http://www.raspberrypi.org/forums/viewtopic. php?t=4751.

29. Kelley, E. J. Base Materials Components. [A. do livro] C. F. Jr. Coombs. Printed Circuit Handbook. s.I. : McGraw-Hill, 2008, p. 7.18.

30. Yang, X., et al., et al. Pyrolysis and dehalogenation of plastics from waste electrical and electronic equipment (WEEE): A review. Waste Management. 2013, Vol. 33, 2, pp. 462-473. 
31. Luda, M.P. Pyrolysis of WEEE plastics. [A. do livro] V. Gooship e A. Stevels. Waste of Electrical and Electronic Equipment (WEEE) handbook. $1^{\text {a }}$ Ed. Filadélfia : Woodhead Publishing, 2012, 11, p. 240.

32. Li, J., et al., et al. Characteristic of low-temperature pyrolysis of printed circuit boards subjected to various atmosphere. Resources, Conservation and Recycling. 2010, Vol. 54, 11, pp. 810-815.

33. Ritchey, L.W. Physical Characteristics of the PCB. [A. do livro] F.C. Jr Coombs. Printed Circuit Boards Handbook. 2008, p. 13.10.

34. Khandpur, R.S. Printed Circuit Boards: design, fabrication, assembly and testing. s.I. : The McGraw-Hill, 2006.

35. U1 Introduction to PCB Technology | AMI4809 Concepts of Printed Circuit Design. [Online] 2014. [Citado em: 01 de 10 de 2014.] http://www.ami.ac.uk/courses/ami4809_pcd/unit_01/.

36. Vianco, P.T. Assembly Processes. [A. do livro] C.F. Jr. Coombs. Printed Circuits Handbook. 2008, p. 40.3.

37. Johnson, S. K. e Oresjo, S. Assembly Inspection. [A. do livro] C. F. Jr. Coombs. Printe Circuit Handbook. 2008, 53.

38. Goosey, M. e Kellner, R. Recycling technologies for the treatment of end of life printed circuit boards (PCBs). Circuit World. 2003, Vol. 29, 3, pp. 3337.

39. Veit, H.M., et al., et al. Recovery of copper from printed circuit boards scraps by mechanical processing and electrometallurgy. Journal of Hazardous Materials. 2006, Vol. B137, pp. 1704-1709.

40. MetalPrices.com - Metal Index Listing. metalprices.com. [Online] [Citado em: 10 de 10 de 2014.] www.metalprices.com.

41. Ogunniyi, I. O., Vermaak, M. K. G. e Groot, D. R. Chemical composition and liberation characterization of printed circuit board comminution fines for beneficiation investigations. Waste Management. 2009, Vol. 29, pp. 2140-2146. 
42. Kariya, Y, Gagg, C e Plumbridge, W. Tin pest in lead-free solders. Soldering \& Surface Mount Technology. 2000, Vol. 13, 1, pp. 39-40.

43. Shuey, S. A., Vidal, E. E. e Taylor, P. R. Pyrometallurgical Processing of Electronic Waste. SME Annual Meeting. Março, 2006, pp. 27-29.

44. Zhao, Y., et al., et al. Recovery of Copper from pronted circuit boards. Minerals and Metal Processing. 2004, Vol. 2, 21, pp. 99-102.

45. Zhang, S. e Frossberg, E. Mechanical separation-oriented characterization of electronic scrap. Resource, Conservation and Recycling. 1997, Vol. 21, pp. 247-269.

46. Kim, B., et al., et al. A process for extracting precious metals from spent printed circuit boards and automobile catalysts. JOM. 2004, Vol. 56, 12 , pp. 55-58.

47. Iji, M. e Yokoyama, S. Recycling of printed wiring boards with mounted electronic components. Circuit World. 1997, Vol. 23, 3, pp. 10-15.

48. Kogan, V. Process for the recovery of precious metals scrap by means of hydrometallurgical technique. 6006/013568 A3 WO, 2006.

49. Behnamfard, A., Salarirad, M.M. e Veglio, F. Process development for recovery of copper and rpecious metals from waste printed circuit boards with enphasize on palladium and gold leaching and precipitation. Waste Management. 2013, Vol. 33, 11, pp. 2354-3463.

50. Yazici, E.Y. e Deveci, H. Extraction of metals from waste printed circuit boards (WPCBs) in $\mathrm{H} 2 \mathrm{SO} 4-\mathrm{CuSO} 4-\mathrm{NaCl}$ solutions. Hydrometallurgy. 2013, Vol. 139 , pp. 30-38.

51. Abtew, M. e Selvaduray, G. Lead-free solders in Microelectronics. Material Science And Engineering: R: Reports. 2000, Vol. 27, 5-6, pp. 95-141.

52. Freedman, G.M. Soldering Materials And Metallurgy. [A. do livro] C. F. Jr. Coombs. Printed Circuit Boards Handbook. 6'a . s.I. : The McGraw-Hill Companies, 2008,45 , p. 45.7. 
53. Townsend, T., et al., et al. Leachability of printed wire boards containing leaded and lead-free solder. Journal of Environmental Management. 2008, Vol. 88, pp. 926-931.

54. CEDIR USP CCE. CCE. [Online] [Citado em: 09 de 01 de 2013.] http://www.cce.usp.br/?q=node/266.

55. Departamento Nacional de Produção Mineral. Chumbo. Sumário Mineral. 2011, p. 1.

56. Espinosa, D.C.R. e Tenório, J.A.S. Reciclagem de Baterias: Análise da Situação Atual no Brasil. Revista Brasileira de Ciências Ambientais. 2004, Vol. 1, 2, pp. 14-20.

57. Schubert, G. e Bernotat, S. Comminution of non-brittle materials. International Journal of Mineral Processing. 2004, Vol. 74, Supplement, pp. S19-S30.

58. Shi, F., et al., et al. An energy-based model for swing hammer mills. International Journal of Mineral Processing. 2003, Vol. 71, 1-4, pp. 147-166.

59. Haith Group. Waste Shredding Machinery and Systems, Size / Waste Reduction Applications. Shredding Systems. [Online] Haith Group Recycling. [Citado em: 22 de 10 de 2014.] http://www.haithrecycling.com/waste_shredding_size_reduction_shredder.html.

60. Reuter, M.A. e van Schaik, A. Dynamic modelling of E-waste recycling system performance based on product design. Minerals Engineering. 2010, Vol. 23, pp. 192-210.

61. Tuncuk, A., et al., et al. Aqueous metal recovery techniques from escrap: Hydrometallurgy in recycling. Minerals Engineering. 2012, Vol. 25, 1, pp. 28-37.

62. Hagelügen, C. RECYCLING OF ELECTRONIC SCRAP AT UMICORE PRECIOUS METALS REFINING. Acta Metallurgica Slovaca. 2006, Vol. 12, pp. 11-120.

63. Zhang, S. e Forssberg, E. Inteligent liberation and classification of electronic scrap. Powder Technology. 1999, Vol. 105, pp. 295-301. 
64. Veit, HM, et al., et al. Utilization of magnetic and electrostatic separation in the recycling of printed circuit boards scrap. Waste Management. 2005, Vol. 25, pp. 67-74.

65. Das, A., Vidyadhar, A. e Mehrotra, S.P. A novel flowsheet for the recovery of metal values from waste printed circuit boards. Resources, Conservation and Recycling. 2009, Vol. 53, pp. 464-469.

66. Schlummer, M., et al., et al. Characterisation of polymer fractions from waste electrical and electronic equipment (WEEE) and implications for waste management. Chemosphere. 2007, Vol. 67, pp. 1866-1876.

67. Oleszek, S., et al., et al. Distribution of copper, silver and gold during thermal treatment with brominated flame retardants. Waste Management. 2013, Vol. 33, 9, pp. 1835-1842.

68. Xstrata Recycling. Xstrata Recycling: copper \& precious metals processing. [Online] [Citado em: 23 de 10 de 2012.] http://www.norandarecycling.com/commodity_pro.html.

69. Boliden AB. Inaguration of Boliden's billion kronor investment. Boliden AB. [Online] 1 de 07 de 2012. [Citado em: 23 de 10 de 2012.] http://www.boliden.com/Documents/Press/20120601_Inauguration\%20of\%20Bo Re_EN.pdf.

70. Hao, J., et al., et al. Pyrolysis characteristics of the mixture of printed circuit board scraps and coal powder. Waste Management. in press, 2013.

71. Quan, C., et al., et al. Characterization of products recycling from PCB waste pyrolysis. Journal of Analytical and Applied Pyrolysis. 2010, Vol. 89, 1, pp. 102-106.

72. Andrews, D., Raychaudhuri, A. e Frias, C. Environmentally sound technologies for recycling secondary lead. Journal of Power Sources. 2000, Vol. 88 , pp. $124-129$.

73. Öncel, M.S., Ince, M. e Bayramoglu, M. Leaching of silver from solid waste using ultrasound assisted thiourea method. Ultrasonics Sonochemistry. 2005, Vol. 12, pp. 237-242. 
74. Xie, F., et al., et al. The ultrasonically assisted metals recovery treatment of printed circuit board waste sludge by leaching separation. Journal of Hazardous Materials. 2009, Vol. 170, pp. 430-435.

75. Kim, E., et al., et al. Leaching kinetics of copper from waste printed circuit boards by electro-generated chlorine in $\mathrm{HCl}$ solution. Hydrometallurgy. 2011, Vol. 107, pp. 124-132.

76. Gurung, M., et al., et al. Recovery of gold and silver from spent mobile phones by means of acidothiourea leaching followed by adsorption using biosorbent prepared from persimmon tannin. Hydrimetallurgy. 133, 2013, pp. 84-93.

77. Lee, C.H., Tang, L.W e Popuri, S.R. A study on the recycling of scrap integrated circuits by leaching. Waste Management \& Research. 2011, Vol. 29, 7, pp. 677-685.

78. Koyama, K., Tanaka, M. e Lee, J. Copper Leaching Behavior from Waste Printed Circuit Board in Ammoniacal Alkaline Solution. Materials Transactions. 2006, Vol. 47, 7, pp. 1788-1792.

79. Abdel-Aal, E.A. e Rashad, M.M. Kinetic study on the leaching of spent nickel oxide catalyst with sulfuric acid. Hydrometallurgy. 2004, Vol. 74, pp. 189-194.

80. Kamberovic, Z., et al., et al. HYDROMETALLURGICAL PROCESS FOR EXTRACTION OF METALS FROM ELECTRONIC WASTE-PART I: MATERIALCHARACTERIZATION AND PROCESS OPTION SELECTION. Association of Metallurgical Engineers of Serbia. 4, 2009, pp. 231-243.

81. Wang, J., et al., et al. Bioleaching of metals from printed wire boards by Acidithiobacillus ferrooxidans and Acidithiobacillus thiooxidans and their mixture. Journal of Hazardous Materials. 2009, Vol. 172, pp. 1100-1105.

82. Brandl, H., Bosshard, R. e Wegmann, M. Computer-munching microbes: metal leaching from electronic scrap by bacteria and fungi. Hydrometallurgy. 2001, Vol. 59, pp. 319-326. 
83. Havlik, T. Kinetics of heterogeneous reactions of leaching processes. Hydrometallurgy Principles and Aplications. $1^{\mathrm{a}}$. Cambridge: Woodhead Publishing Limited, 2008, p. 186.

84. Han, K.N. Fundamentals of Aqueous Metallurgy. 1a. Littleton: Society for Mining, Metallurgy and Exploration (SME), 2002. p. 197.

85. Burkin, A.R. Chemical Hydrometallurgy: Theory and Principles. London : Imperial College Press, 2001.

86. Levenspiel, O. Chemical Reaction Engineering. $3^{\mathrm{a}}$. Nova lorque: John Wiley \& Sons, Inc., 1999. p. 566.

87. Atkins, P. e de Paula, J. The rates of Chemical Reactions. Atkins' Physical Chemistry. 8a . s.l. : Oxford University Press, 2006, 22, p. 797.

88. Li, J. e Miller, J.D. Reaction kinetics of gold dissolution in acid thiourea solution using ferric sulfate as oxidant. Hydrometallurgy. 2007, Vol. 89, 3-4, pp. 279-288.

89. Mason, T.J. e Lorimer, J.P. Applied Sonochemistry. Darmstadt, Alemanha : Wiley-VCH, 2002.

90. Thompson, L.H. e Doraiswamy, L.K. Sonochemistry: Science and Engineering. Industrial \& Engineering Chemistry Research. 1999, Vol. 38, pp. $1215-1249$.

91. Suslick, K.S. The Chemical Effects of Ultrasouns. Scientific American. 1989, Vol. 260, pp. 80-86.

92. Suslick, K. S. e Price, G. J. Applications of ultrasound to materials chemistry. Annual Reviews Materials Sience. 1999, Vol. 29, pp. 295-326.

93. Suslick, K. S. Sonochemistry. Science. 1990, Vol. 247, 4949, pp. $1439-1445$.

94. Raman, V. e Abbas, A. Experimental Investigation on Ultrasound Mediated Particle Breakage. Ultrasonics Sonochemistry. 2008, Vol. 15, 1, pp. 55-64.

95. Franco, F., Pérez-Maqueda, L.A. e Pérez-Rodríguez, J.L. Influence of the particle-size reduction by ultrasound treatment on the dehydroxylation 
process of kaolinites. J. Thermal Analysis and Calorimetry. 2008, Vol. 28, pp. 1043-1055.

96. Doktycz, S.J. e Suslick, K.S. Interparticle collisions driven by ultrasound. Science. 1990, Vol. 247, pp. 1067-1069.

97. Crevotto, G. e Cintas, P. Harnessing mechanochemical effects with ultrasound-induced reactions. Chemical Science. 3, 2012, pp. 295-307.

98. Yerkovic, C., Menacho, J. e Gaete, L. Exploring the ultrasonic comminution of copper ores. Minerals Engineering. 1993, Vol. 6, 6, pp. 607617.

99. Sarveswara Rao, K., et al., et al. Influence of Ultrasound Leaching of a Copper Oxide Ore. Metallurgical and Materials Transactions B. 1997, Vol. 28B, pp. 721-723.

100. Sayan, E. e Bayramoglu, M. Statistical modeling and optimization of ultrasound-assisted sulfuric acid leaching of $\mathrm{TiO} 2$ from red mud. Hydrometallurgy. 71, 2004, pp. 397-401.

101. Saterlay, A. J., Wilkins, S.J. e Compton, R.G. Towards disposal of waste cathode ray tubes via ultrasonically enhanced lead leaching. Green chemistry. 3, 2001, pp. 149-155.

102. Wang, X., et al., et al. Leaching kinetics of zinc residues augmented with ultrasound. Separation and Purification Technology. 2013, Vol. 115, pp. 66-72.

103. Reyes, M. I., et al., et al. Total Recovery of Gold Contained in Computer Printed Circuit Boards. Leaching Kinetics of $\mathrm{Cu}, \mathrm{Zn}$ and Ni. J. Mex. Chem. Soc. 56, 2012, Vol. 2, pp. 144-148.

104. Rieasz, P., Berdhal, D. e Christman, C.L. Free radical generation by ultrasound in aqueous and nonaqueous solutions. Environmental Health Perspectives. 1985, Vol. 64, pp. 233-252.

105. Mourão, M.B. Análise do processo de redução de minério de ferro por carbono na forma de pelotas auto-redutoras. Tese de Doutorado. São Paulo : s.n., 1988. 
106. Mookherjee, S., Ray, H.S. e Mukherjee, A. Isothermal reduction of iron ore finessurrounded by coal or char fines. Ironmanking and Steelmaking. 1986, Vol. 13, 5, pp. 229-235.

107. Platt, C. Encyclopedia of Electronic Components. 1. Sebastopol: O’Reilly, 2013. p. 18. Vol. 1.

108. - Encyclopedia of Electronic Components. 1. Sebastopol: O’Reilly, 2013. p. 103. Vol. 1.

109. Lee, J.C., Kim, Y. e Lee, J. Disassembly and physical separation of electric/electronic components layered in printed circuit boards (PCB). Journal of Hazardous Materials. 30, 2012, Vols. 241-242, pp. 387-394.

110. Epelboin, I., Morel, P. e Takenouti, H. Corrosion Inhibition and Hydrogem Adsorption in the Case of Iron in a Sulfuric Aqueous Medium. J. Electrochem. Society. 1971, Vol. 118, 8, pp. 1282-1287. 